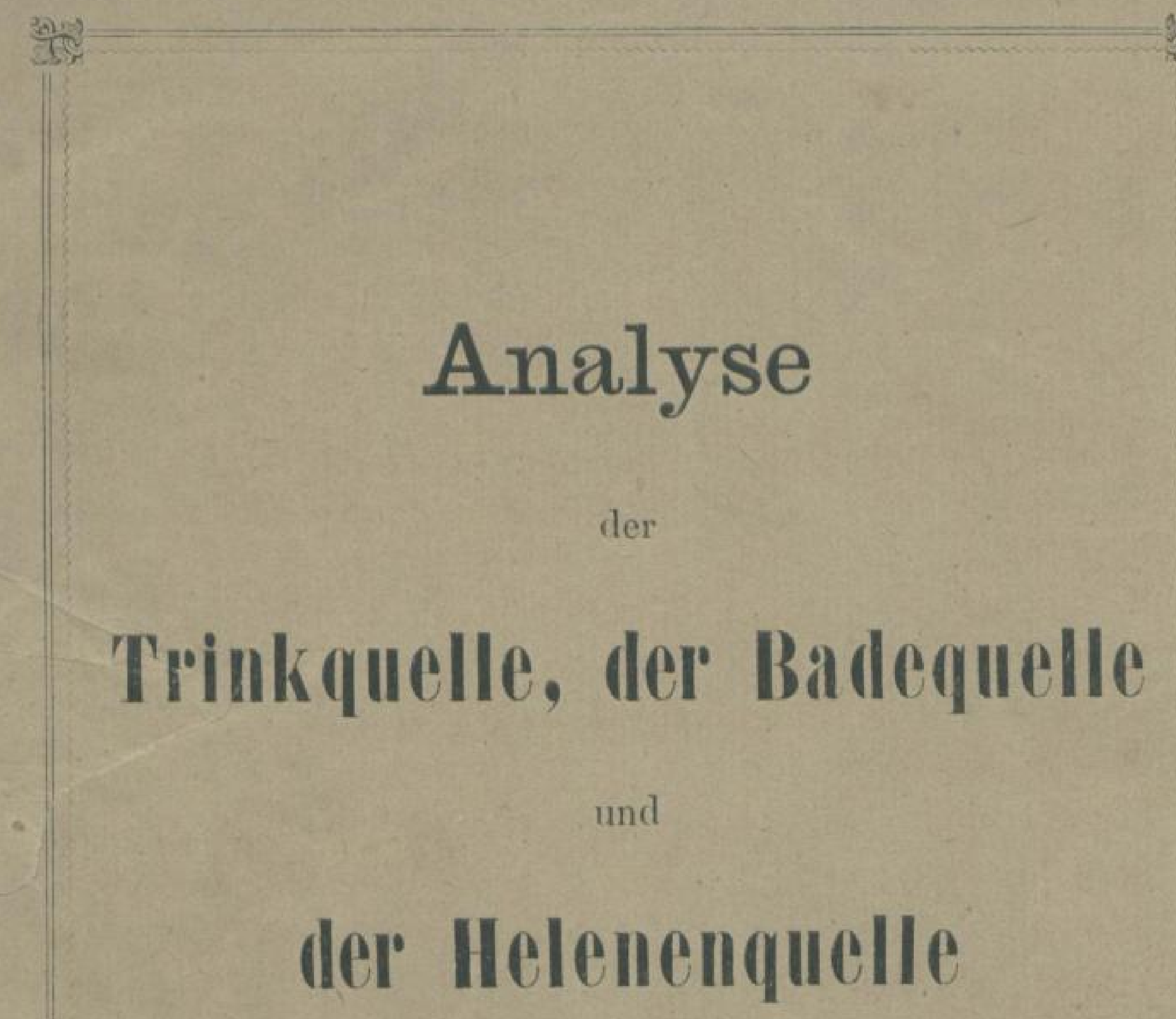

zu Pyrmont.

Von

Prof. Dr. It. Fresenius,

Herzoglich Nassanischem Geh. Hofrathe.

llist. urb. Germ.

$966,27 m$ 


\title{
Analyse
}

der

\section{Trinkquelle, der Badequelle}

und

\section{der Helenenquelle}

\author{
zu Pyrmont.
}

Von

\section{Prof. Dr. IR. Fresenius,}

Herzoglich Nassauischem Geh. Hofrathe.

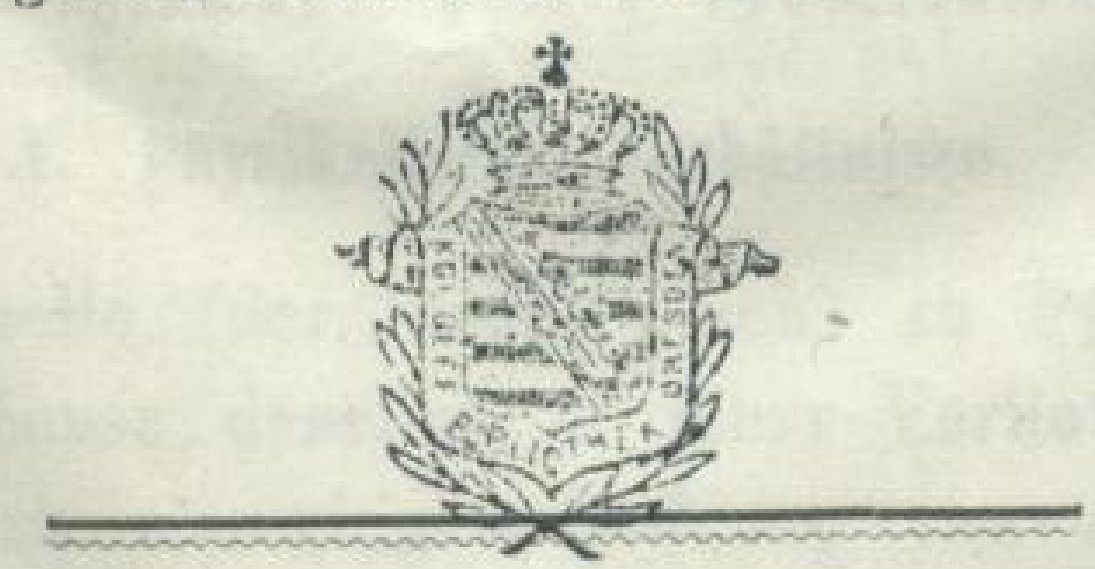

Arolsen.

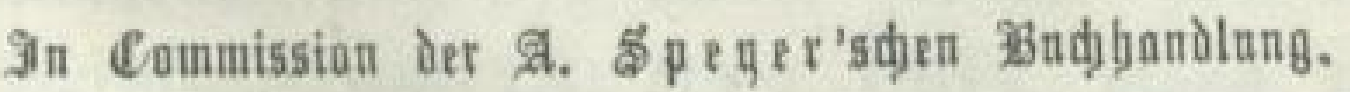
1865.

\section{$1885 * 2703$}




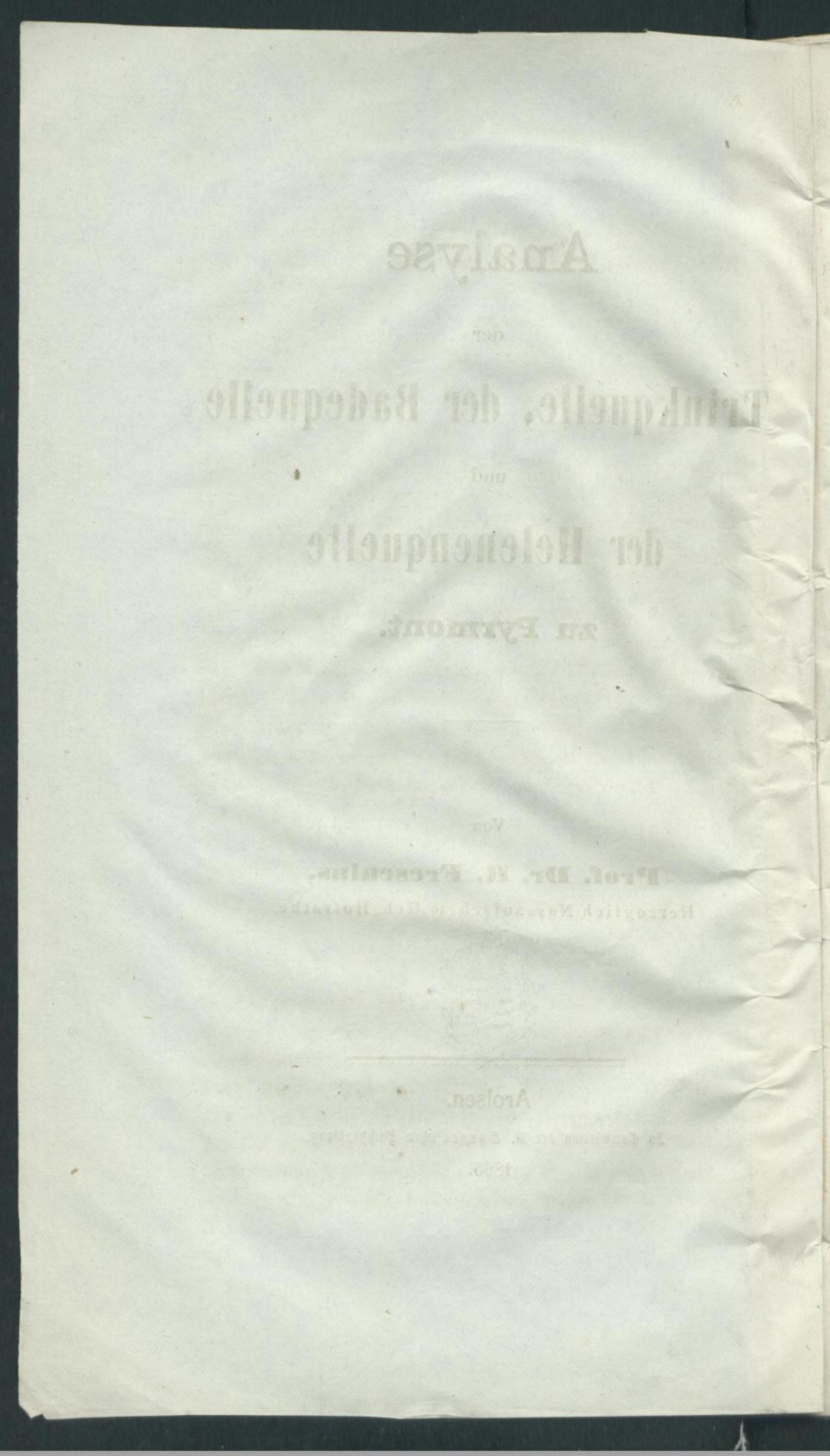

S.|| Sächsische Landesbibliothek - 
Die Trinkquelle (der Stahlbrunnen), die Badequelle (der Brodelbrunnen) und die Helenenquelle (die frühere Klosteralleequelle) zu Pyrmont sind im Laufe des Winters 1863 bis 1864 und des Frühjahrs 1864 neu gefasst worden. Die beiden ersten Quellen unter der speciellen Leitung des Herrn Director Ludwig zu Darmstadt, die letztere nach dessen Plan von Herrn Baumeister $\mathbf{G}$ ün the r zu Pyrmont. Nachdem die Fassungen sich bewährt hatten, und die Quellen längere Zeit hindurch klar abgelaufen waren, sind dieselben im Auftrage der fürstlich Waldeckischen Regierung von mir im Jahre 1864 einer neuen und umfassenden Analyse unterworfen worden. Die Resultate derselben theile ich nachstehend mit.

\section{I.}

\section{Die Trinkquelle (der Stahlbrunnem).}

A. Physikalische Verhältnisse.

Die Trinkquelle (der Stahlbrunnen) zu Pyrmont befindet sich im Brunnenhause daselbst in einer Vertiefung. Sie tritt aus einer länglich viereckigen 0effnung von etwa 0,6 Meter Länge und 0,3 Meter Breite aus in ein Holzfass von etwa 1 Meter Durchmesser und 0,6 Meter Höhe. Bei meiner Anwesenheit in Pyrmont, am 18. März 1864, stand das Wasser in dem genannten Fasse 0,494 Meter hoch. Auf dem Holzfasse liegt ein Marmorrand von etwa 0,3 Meter Höhe. 
Das Wasser in dem Quellenbassin erscheint nicht absolut klar, sondern ein wenig weisslich opalisirend; aber es lässt sich diess nur bei ganz aufmerksamer Beobachtung wahrnehmen. Sieht man von oben schief auf den Quellenspiegel, so bemerkt man, dass sich aus dem Wasser fortwährend kleine Gasbläschen entbinden. Es ist diess Kohlensäure, welche aus dem damit übersättigten Wasser zu entweichen beginnt, sobald dasselbe an die Oberfläche kommt und somit nur noch unter dem Druçke der atmosphärischen Luft sich befindet. Freies Gas in grösseren Blasen liefert die Quelle wenig. In $20 \mathrm{Mi}$ nuten konnte ich nur $725 \mathrm{Cub}$. Cent. sammeln; meist kommt dasselbe in Zwischenräumen von einigen Minuten in grösseren Blasen stossweise.

Füllt man das Wasser in grosse Flaschen von weissem Glase, so erscheint es beim ersten Anblick klar. Stellt man aber die Flaschen vor einem dunklen Hintergrund auf und vergleicht sie mit ähnlichen, destillirtes Wasser enthaltenden Flaschen, so erscheint das Mineralwasser etwas weisslich. Die Ursache dieses weisslichen Ansehens sind unendlich kleine, im Wasser suspendirte Flöckchen. Sie bestehen aus phosphorsaurem und kieselsaurem Eisenoxyd und treten auf in Folge der ersten Einwirkung des atmosphärischen Sauerstoffs auf das Wasser (siehe unten).

In einem Glase erscheint das der Trinkquelle entnommene Wasser klar; an den Wandungen setzen sich bald zahlreiche Gasperlen an.

Was die Menge des Wassers betrift, welches die Trinkquelle liefert, so betrug dieselbe nach den mir amtlich zugekommenen Mittheilungen vor der Neufassung 17-18 preussische Pfund in der Minute; nach der Neufassung hat sich in Folge der Abscheidung wilden Wassers die Quantität natürlieh vermindert und beträgt jetzt 11-12 Pfund in der Minute, also im Mittel 11,5 preuss. Pfund in der Minute, gleich 5378,6 Grm., oder abgerundet 5,4 Litre. Somit liefert die Quelle 
in einer Stunde 324 Litre.

in 24 Stunden 7776 Litre.

Der Geschmack des Wassers ist prickelnd säuerlich, eisenartig, nicht unangenehm, schwach nach Schwefelwasserstoff; der Geruch verrieth, namentlich beim Schütteln des Wassers in halbgefüllter Flasche, bei meiner Anwesenheit in Pyrmont einen geringen Schwefẻlwasserstoffgehalt deutlich. Ich bemerke hierzu, dass der schwache Geruch des Wassers nach Schwefelwasserstoff nicht ganz gleichbleibend ist. Während er, wie erwähnt, bei meiner Anwesenheit in Pyrmont am 18. März 1864 deutlich bemerkbar war, erhielt ich bald nachher (am 14. April 1864) die Nachricht, die Quelle liefere, seit man mit der Versendung des Wassers begonnen habe, und seit man die Quelle an jedem Abend ganz ausschöpfe, ein von Schwefelwasserstoffgeruch durchaus freies Wasser. Nach amtlichen Nachrichten, welche ich am 12. August 1864 erhielt, reigten sich ähnliche Schwankungen im Schwefelwasserstoffgehalte während des ganzen Sommers 1864. Bald trat der Geruch etwas stärker, bald schwächer hervor, bald erwies sich das Wasser geruchlos.

Die Temperatur des Wassers fand ich am 18. März bei $5^{\circ} \mathrm{C}$. Temperatur der Luft im Freien, gleich $12^{\circ} \mathrm{C}$. oder $9,6^{\circ} \mathrm{R}$.

Das specifische Gewicht des Wassers bestimmte ich nach der von mir kürzlich angegebenen, für gasreiche Wasser allein geeigneten Methode. $\left.{ }^{*}\right)$ Es ergab sich bei $19^{\circ}$ C. zu 1,00292.

\section{B. Chemische Verhältnisse.}

Das Wasser der Trinkquelle beginnt, sobald es zu Tage tritt und dem Einfluss der atmosphärischen Luft ausgesetzt ist, sich zu trüben; die ersten Antheile des durch Einwirkung des Sauerstoffs auf das doppelt kohlensaure Eisenoxydul gebildeten

*) Zeitschrift für analyt. Chemie I. S. 178 . 
Eisenoxyds scheiden sich in Verbindung mit Phosphorsäure und Kieselsäure etc. als äusserst feine, weissliche Flöckchen aus und verleihen dem an der Luft stehenden Wasser ein etwas weisslich opalisirendes Ansehen. Beim längeren Stehen an der Luft scheidet sich schliesslich alles Eisen aus. Der entstehende gelbrothe Niederschlag enthält dasselbe der Hauptsache nach als Oxydhydrat. Der erwähnte Process geht natürlich wie in luftenthaltenden Flaschen so auch in dem Quellenbassin von Statten, woher es kommt, dass in demselben und im Abflusscanale ziemlich starke 0 ckerabscheidung stattfindet.

Zu den wichtigsten Reagentien verhält sich das der Quelle frisch entnommene Wasser also:

A mmoniakflüssigkeit bewirkt einen weissen flockigen Niederschlag.

- Chlorwasserst of fsäure bringt eine mässige Kohlensäureentbindung hervor.

Bei Zusatz von Chlorbaryum zu dem mit Salzsäure angesäuerten Wasser bildet sich ein starker Niederschlag.

Oxalsaures A mmon bewirkt einen starken weissen Niederschlag.

Bei Zusatz von salpetersaurem Silberoxyd zu dem mit Salpetersäure angesäuertem Wasser scheidet sich ein nur mässiger Niederschlag aus,

Gerbsäure färbt bei Luftzutritt das Wasser tief rothviolett.

Gall ussä ure unter gleichen Umständen tief blau-violett,

Ferridcyankalium bewirkt in dem mit Salzsäure angesäuerten Wasser eine tief grün-blaue Färbung.

K upferchlorid zu einer grössern, in einer weissen Flasche befindlichen Wassermenge gesetzt, brachte eine schwach bräunliche Färbung hervor.

Beim Kochen des Wassers entsteht ein krystallinischer bräunlicher Niederschlag.

Die qualitative Analyse des Wassers, nach der in meiner "Anleitung zur qualitativen Analyse" 11. Auff. $\$ .211$ 
bis 214 angeführten Methode ausgeführt, liess folgende Bestandtheile erkennen:

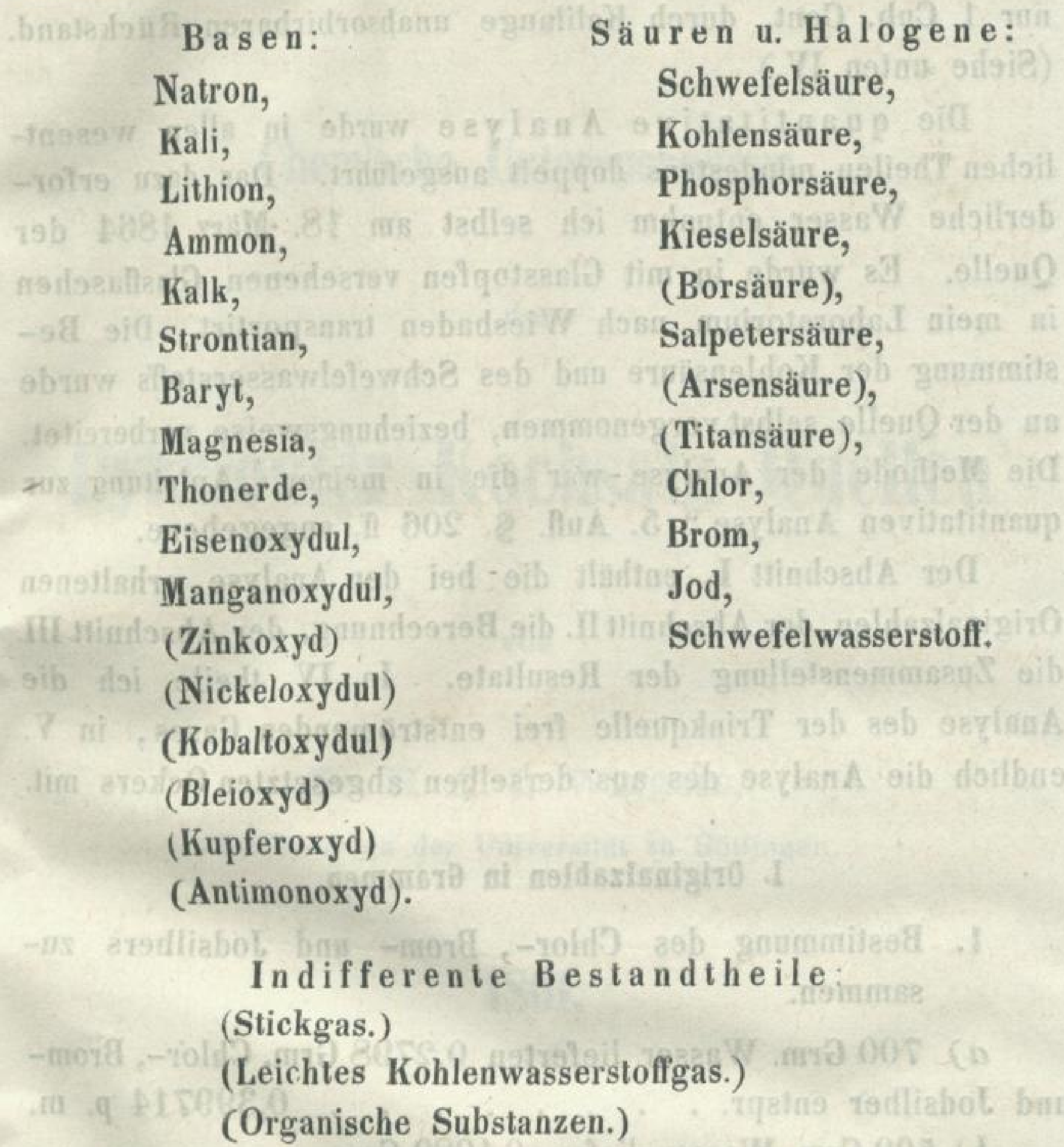

Die eingeklammerten Bestandtheile wurden ihrer geringen Menge wegen nicht quantitativ bestimmt. Zinkoxyd, Nickeloxydul, Kobaltoxydul, Antimonoxyd, Kupferoxyd, Bleioxyd, Arsensäure und Titansäure wies ich in dem aus dem Wasser abgesetzten 0cker nach. Prüfungen auf Fluor liessen dessen Anwesenheit weder in dem Abdampfungsrückstande einer grösseren Wassermenge (etwa von 50 Pfund) noch in dem aus dem Wasser abgesetzten 0cker mit Sicherheit erkennen. Caesium, Rubidium und Thallium fand ich bei Untersuchung des Abdampfungsrückstandes von 150 Pfund Wasser nicht. 
Das aus der Quelle frei ausströmende Gas ist fast reine Kohlensäure. 140 C. C. hinterliessen im Mittel von 4 Versuchen nur 1 Cub. Gent. durch Kalilauge unabsorbirbaren Rückstand. (Siehe unten IV.)

Die quantitative Analyse wurde in allen wesentlichen Theilen mindestens doppelt ausgeführt. Das dazu erforderliche Wasser entnahm ich selbst am 18. März 1864 der Quelle. Es wurde in mit Glasstopfen versehenen Glasflaschen in mein Laboratorium nach Wiesbaden transportirt. Die Bestimmung der Kohlensäure und des Schwefelwasserstoffs wurde an der Quelle selbst vorgenommen, beziehungsweise vorbereitet. Die Methode der Analyse war die in meiner, Anleitung zur quantitativen Analyse, “ 5. Aufl. \$. 206 ff. angegebene.

Der Abschnitt I. enthält die bei der Analyse erhaltenen Originalzahlen, der Abschnitt II. die Berechnung, der Abschnitt III. die Zusammenstellung der Resultate. In IV, theile ich die Analyse des der Trinkquelle frei entströmenden Gases, in V. endlich die Analyse des aus derselben abgesetzten Ockers mit.

\section{Originalzahlen in Grammen.}

1. Bestimmung des Chlor-, Brom- und Jodsilbers zusammen.

a) $700 \mathrm{Grm}$. Wasser lieferten $0,2798 \mathrm{Grm}$. Chlor-, Bromund Jodsilber entspr. . . . . . 0,399714 p. m.

b) $500 \mathrm{Grm}$. Wasser liefer. $0,1989 \mathrm{Grm}$.

Chlor-, Brom- und Jodsilber entspr. . . 0,397800 p. m. Mittel . 0,398757 p. m.

2. Bestimmung des Jods und Broms

a) $56725 \mathrm{Grm}$. Wasser wurden unter Zusatz von etwas vorwaltendem reinem kohlensaurem Natron in einem blanken gusseisernen Kessel eben zur Trockne verdampft, und die trockne Masse mit siedendem Weingeist von $96 \mathrm{pCt}$. erschöpft. Das Filtrat destillirte man unter Zusatz von 2 Tropfen reiner Kalilauge in einem Kolben ab, kochte den trocknen Rückstand mit 


\title{
Chemische Untersuchungen
}

$$
\text { der }
$$

\section{Pyrmonter Kochsalz-Quellen}

\author{
von \\ Dr. H. A. L. Wiggers, \\ Professor an der Universität zu Göttingen.
}

1861. 

 \\ 1. Die Trinkquelle.}

Das Wasser derselben ist farblos, krystallklar, perlt schwach in der Ruhe und ziemlich stark beim Schüsteln, ist geruchlos, schmeckt sehr rein und angenehm salzig, besitzt 1, 002377 specif. Gewicht, hat eine Temperatur von $+10^{\circ} \mathrm{C}$. und enthält in

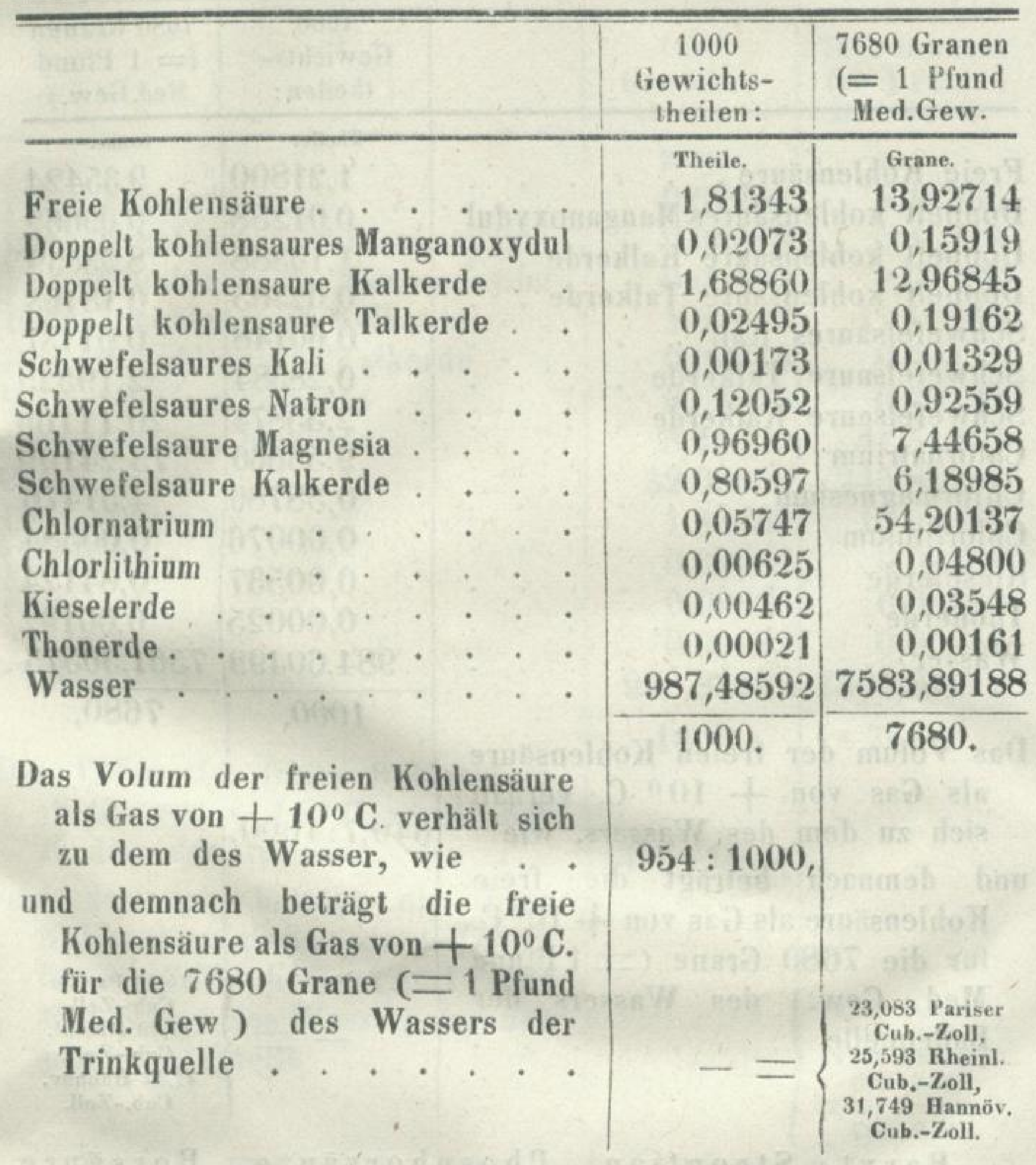

Baryt, Strontian, Eisen, Phosphorsäure, Borsäure und Schwefelwasserstoff habe ich in diesem Wasser gar nicht, und A mmoniack und Salpetersäure nur in unbestimmbaren Spuren auffinden können.

Ebenso war es mir auch nicht möglich, die Salzbilder, Fluor, Jod und Brom darin sicher zu erkennen. 


\section{Die Badequelle.}

Das Wasser ist farblos, völlig klar, geruchlos, schmeckt salzig und hintennach nur wenig bitter, perlt nur schwach beim Schütteln, besitzt 1,00617 specif. Gewicht, hat eine Temperatur von $+10^{\circ} \mathrm{C}$, , und enthält in

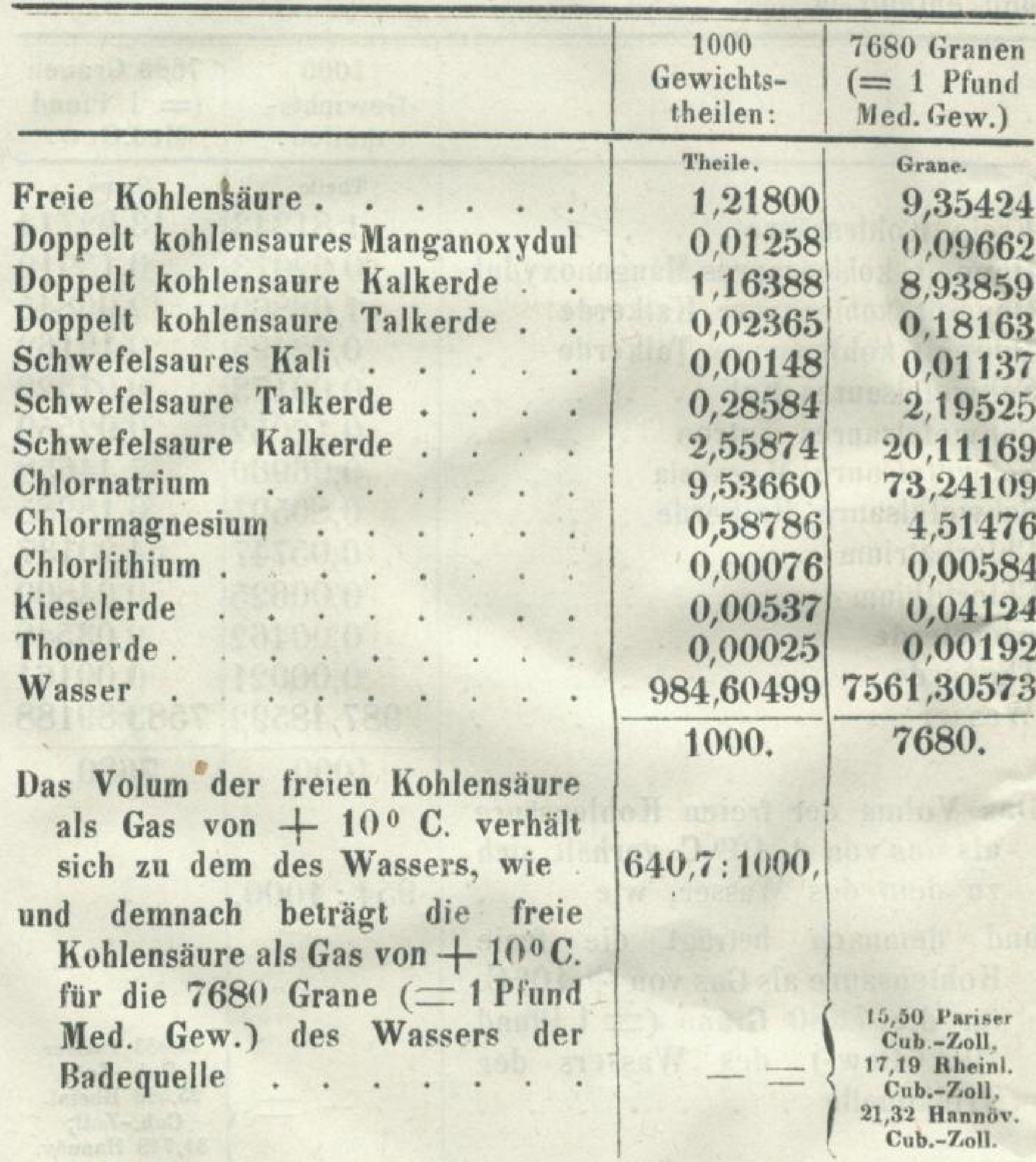

Baryt, Strontian, Phosphorsäure, Borsäure Jod und Schwefelwasserst of habe ich in diesem Wasser gar nicht, und $\mathbf{A} \mathrm{mmoniak}$, Salpetersäure, Fluor und B rom nur in unbestimmbaren Spuren auffinden können. 
 \\ 3. Die nenerbohrte Quelle.}

Das Wasser derselben ist farblos, völlig klar, geruchlos, schmeckt sehr salzig und hintennach etwas widerlich bitter, perlt nicht und beim Schütteln auch nur kaum merklich, besitzt 1,02819 specif. Gewicht, hat eine Temperatur von $+15^{\circ} \mathrm{C}$, und enthält in

\begin{tabular}{|c|c|c|}
\hline & $\begin{array}{l}1000 \\
\text { Gewichts- } \\
\text { theilen: }\end{array}$ & $\begin{array}{l}7680 \text { Granen } \\
(=1 \text { Pfund } \\
\text { Med. Gew.) }\end{array}$ \\
\hline & Theile. & Grane. \\
\hline Freie Kohlensäure $\cdot{ }^{*} \cdot \cdot \cdot \cdot \cdot$ & 0,67200 & 5,16096 \\
\hline Doppelt kohlensaures Eisenoxydul. & 0,06018 & 0,46218 \\
\hline Doppelt kohlensaures Manganoxydul & 0,00699 & 0,05368 \\
\hline Doppelt kohlensaure Kalkerde . . & 1,62876 & 12,50888 \\
\hline Doppelt kohlensaure Talkerde. . & 0,00446 & 0,03425 \\
\hline Schwefelsaure Talkerde . . . . & 0,03870 & 0,30722 \\
\hline Schwefelsaure Kalkérde . . . . & 5,40620 & 41,51962 \\
\hline Chlornatrium . . . . . . & 32,00550 & 245,81224 \\
\hline Chlormagnesium . . . . . & 1,33655 & 10,26471 \\
\hline Chlorlithium . . . & 0,00087 & 0,00668 \\
\hline Kieselerde . . . & 0,00625 & 0,00480 \\
\hline Thonerde . . . & 0,00032 & 0,00246 \\
\hline Wasser . . . . . . . . . . . & 958,83222 & 7363,81912 \\
\hline $\begin{array}{l}\text { Das Volum der freien Kohlensäure } \\
\text { als Gas von }+15^{\circ} \mathrm{C} \text {. verhält sich } \\
\text { zu dem des Wassers, wie } \\
\text { und demnach beträgt die freie } \\
\text { Kohlensäure als Gas von }+15^{\circ} \mathrm{C} \text {. } \\
\text { für die } 7680 \text { Grane }(=1 \text { Pfund } \\
\text { Med Gew.) des Wassers der neu } \\
\text { erbohrten Quelle }\end{array}$ & $373: 1000$ & $\begin{array}{c}\text { 9,009 Pariser } \\
\text { Cub.-Zoll, } \\
\text { 9,989 Rheinl. } \\
\text { Cub.-Zoll, } \\
\text { 12,391 Hannöv. } \\
\text { Cub.-Zoll. }\end{array}$ \\
\hline
\end{tabular}

Baryt, Strontian, Phosphorsäure, Borsäure, Jod und Schwefelwasserstoff habe ich in diesem Wasser gar nicht, und Ammoniak, Salpetersäure, Fluor und $\mathrm{K}$ ali nur in unbestimmbaren Spuren auffinden können.

Dagegen enthält dieses Wasser nicht unbedeutend Brom, für dessen quantitative Bestimmung, welche bekanntlich immer anch nur elwas unsicher bleibt, mir noch kein geeignetes Material vorlag. 1861 . 


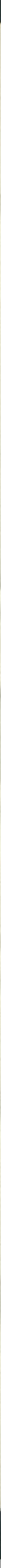

\begin{tabular}{l}
\hline S. Sächsische Landesbibliothek - \\
UB. Staats- und Universitätsbibliothek Dresden
\end{tabular} 
absolutem Alkohol mehrmals aus, brachte das Filtrat unter Zusatz eines Tropfens Kalilauge wiederum zur Trockne und erhitzte, zur Zerstörung organischer Substanzen, den Rückstand ganz gelinde. Derselbe wurde jetzt mit Wasser behandelt, die Lösung filtrirt, eingeengt, in einer kleinen weissen Stöpselflasche mit verdünnter Schwefelsäure angesäuert, mit reinem Schwefelkohlenstoff und einer geringen Menge einer Auflösung von Untersalpetersäure in Schwefelsäurehydrat zusammengebracht und geschüttelt. Der schön violett gefärbte Schwefelkohlenstoff wurde mittelst eines angefeuchteten Filters von der wässerigen Lösung getrennt und der Jodgehalt direkt mit einer Lösung von unterschwefligsaurem Natron titrirt, von der 2,11 Cub. Cent. 0,000382 Grm. Jod entsprachen. Verbraucht wurden 4,31 Cub. Cent Es berechnet sich somit der geringe Gehalt an Jod auf . . . 0,00001374 p m.

b) Die in a von dem jodhaltigen Schwefelkohlenstoff $a b-$ filtrirte wässerige Lösung, mit salpetersaurem Silberoxyd gefällt, lieferte 1,3509 Grm. eines alles Brom neben einer unbekannten Menge Chlor enthaltenden Niederschlages. 0,4303 Grm. dieses Niederschlages nahmen, in einer ganz kleinen Kugelröhre im Chlorstrom geglüht, ab um 0,0007 Grm. Hieraus berechnet sich der Gehalt an Brom zu . . . 0,0000698 p. m.

3. Bestimmung des Chlors.

Die Menge des Chlor-, Brom- und Jodsilbers betrug nach 1. . . . . . 0,398757 p. m.

Davon geht ab die dem Jod entsprechende Menge Jodsilber . • . . 0,000026, und die dem Brom entsprechende Menge Bromsilber ... . . 0,000164,

\begin{aligned} & \hline Summe * 0,000190 \\ & Rest: Chlorsilber 0,398567 p. m. \\ & entsprechend Chlor . 0,098537 p. m. \end{aligned}


19rin 4. Bestimmung der Schwefelsäure.

bain a) $500 \mathrm{Grm}$. Wasser liefer, $1,1677 \mathrm{Grm}$ sehwefels. Baryt, entspr. Schwefelsäure . . 0,801854 p. m.

b) $500 \mathrm{Grm}$. Wasser liefer. 1,1667 Grm.

schwefels. Baryt, entspr. Schwefelsäure . 0,801168 ,

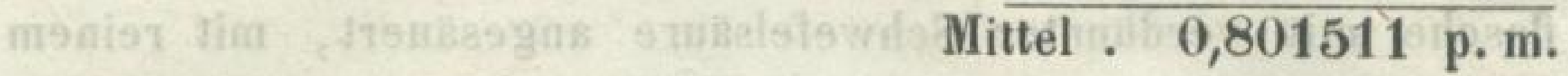

5. Bestimmung der Kohlensäure.

Das Wasser wurde mittelst eines Stechhebers der Quelle entnommerf und in sammt den dazu gehörigen Kautschukpfropfen gewogene Kochflaschen gebracht, welche eine zur Bindung der Kohlensäure mehr als genügende Menge reinen, kohlensäurefreien Kalkhydrates enthielten. Die Gewichtszunahme der Kochflaschen belehrte über die Menge des in dieselben gebrachten Wassers. Nach längerem Stehen wurden zwei Drittheile der über dem Niederschlag stehenden klaren Flüssigkeit durch ein kleines Filter abfiltrirt, das Filterchen in die betreffende Kochflasche geworfen, die Kohlensäure mit Salzsäure ausgetrieben, dem Gasstrom das Wasser vollständig entzogen, die Kohlensäure in einem Kaliapparat und einem Natronkalkrohr aufgefangen und aus der Gewichtszunahme dieser Apparate bestimmt. (Vergl. meine Abhandlung: Ueber die Bestimmung der Kohlensäure in Mineralwassern, Zeitschrift für analyt. Chemie 2, 49 u. 341.)

a) $221,978 \mathrm{Grm}$. Wasser lief. 0,6952 Grm. Kohlensäure, entspr. . • • . . . 3,131842 p. m. (17) $221,394 \mathrm{Grm}$. Wasser lief. 0,6965 Grm.

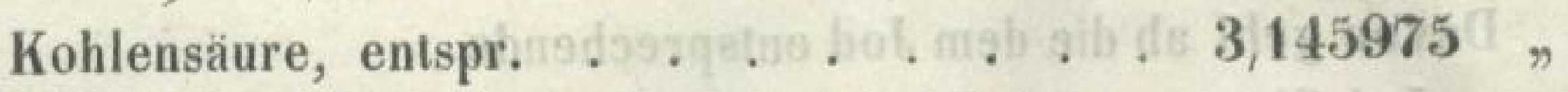

c) $222,164 \mathrm{Grm}$. Wasser lief. 0,6954 Grm.

Kohlensäure, entspr. . . $\quad$ Mittel $\frac{3130120}{3,135979 \mathrm{p} . \mathrm{m}}$

6. Bestimmung der Kieselsäure.

a) $2438,6 \mathrm{Grm}$. Wasser, der ganze Inhalt einer an der Quelle gefüllten Glasflasche mit Glasstopfen, wurde unter Zusatz von Salzsäure in einer Platinschale verdampft und die Kiesel- 
säure wie üblich und mit besonderer Berücksichtigung des Umstandes, dass aller ausgeschiedene schwefelsaure Kalk gelöst wurde, abgeschieden. Man erhielt $0,0769 \mathrm{Grm}$. Kieselsäure, entspr. * . . * * * + + 0,031534 p. m.

b) $1957,7 \mathrm{Grm}$. Wasser lieferten ferner

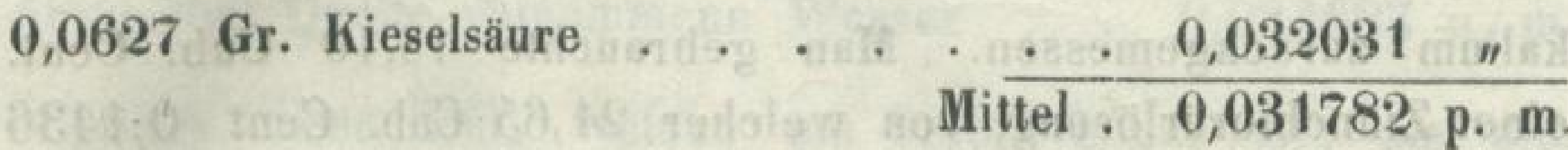

7. Bestimmung des Eisenoxyduls.

a) Das Filtrat von 6a (von $2438,6 \mathrm{Grm}$. Wasser) wurde, nachdem es unter Zusatz von etwas Salpetersäure gekocht worden, mit Ammon gefält, der Niederschlag in Salzsäure gelöst, die Lösung zur sicheren Abscheidung anfangs mitgefällten Kalkes nochmals mit Ammon gefällt. Der Nieủerschlag konnte jetzt noch Mangan, er musste Thonerde und Phosphorsäure enthalten. $\mathrm{Um}$ ihn von ersterem sicher zu befreien, wurde seine salzsaure Lösung mit essigsaurem Natron in Siedehitze gefältt, und um letztere abzuscheiden, fällte man die salzsaure Lösung des durch essigsaures Natron entstandenen Niederschlags nach Zusatz von etwas Weinsteinsäure mit Ammon und Schwefelammonium. Der so erhaltene Niederschlag hätte zwar durch Glühen im Wasserstoffstrom in wasserfreies Eisensulfür verwandelt und als solches gewogen werden können. Ich zog es aber, da diese Bestimmungsweise der Wägung als Oxyd an Genauigkeit nicht ganz gleich kommt, vor, den ausgewaschenen Niederschlag wieder in Salzsäure zu lösen und die mit Salpetersäure gekochte Lösung mit Ammon zu fällen. Alle diese Operationen wurden natürlich mit kleinen Mengen von Reagentien und der grössten Vorsicht ausgeführt. Erhalten wurden 0,0889 Grm. Eisenoxyd, entspr. Eisenoxydul 0,032810 p. m.

b) Das Filtrat von $6 \mathrm{~b}(1957,5 \mathrm{Grm}$. Wasser) lieferte, auf gleiche Weise behandelt, 0,0709 Grm. Eisenoxyd, entspr. Eisenoxydul. . . . . . . . 0,032598 p. m.

c) $2394,5 \mathrm{Grm}$. Wasser, der ganze Inhalt einer an der Quelle gefüllten Flasche, wurden in einem Glaskolben mit 
Salzsäure und etwas Chlorwasser bis auf einen kleinen Rest eingedampft, die so erhaltene, von freiem Chlor freie, alles Eisen als Eisenchlorid enthaltende Lösung mit einer titrirten Zinnchlorürlösung reducirt, und die Spur überschüssig zugesetzten Zinnchlorürs mit einer titrirten Lösung von Jod in Jodkalium zurückgemessen. "Man gebrauchte 13,10 Cub. Cent. einer Zinnchlorürlösung, von welcher 21,65 Cub. Cent 0,1436 Grm. Eisenoxyd entsprachen. Hiernach berechnet sich die Menge des Eisenoxyduls im Mineralwasser zu _. 0,032662 p. m.

Mittel . 0,032690 p. m.

Es ist diess die Zahl, welche als Ergebniss meiner Analyse bereits in öffentlichen Blättern mitgetheilt worden ist.

Wie bereits erwähnt, war zu der Zeit, als ich in Pyrmont das zur. Analyse bestimmte Wasser der Quelle entnahm, das Fülgeschäft und das damit im Zusammenhang stehende allabendliche gänzliche Ausschöpfen der Qüelle noch nicht im Gange. Die Vermuthung lag nahe, dass der Gehalt an Eisenoxydul in Folge der rascheren Erneuerung des Wassers im Quellenbassin sich etwas vermehrt haben könne, und es liess daher, um diese Frage zu entscheiden, Herr Kreisrath $\mathrm{Ne} \mathrm{u-}$ mann in Pyrmont am 14. April a.c. durch Herrn Brunnencommissär W ig a n d 8 Glasflaschen sorgfältig mit dem Wasser der Trinkquelle füllen und an mich abschicken.

aa) $1717,75 \mathrm{Grm}$. Wasser (der Inhalt zweier Flaschen), nach Abscheidung der Kieselsäure wie in a behandelt, lieferten $0,0659 \mathrm{Grm}$. Eisenoxyd entspr. Eisenoxydul 0,034528 p. m.

bb) $3266,5 \mathrm{Grm}$. Wasser (der Inhalt von 4 Flaschen) wurden mit Salzsäure unter Zusatz von etwas Chlorwasser stark eingeengt, die Lösung mit Ammon gefällt, der ausgewaschene Niederschlag wieder in Salzsäure gelöst, die Lösung mit Zinnchlorür in Siedehitze reducirt, und der geringe Ueberschuss von Zinnchlorïr mit Jodlösung bestimmt. Verbraucht wurden zur Reduction des Eisenchlorids 18,38 Cub. Cent. einer Zinn- 
chlorürlösung, von welcher $21,13 \mathrm{Cub}$. Cent. $0,1453 \mathrm{Grm}$. Eisenoxyd entsprachen. Daraus berechnet sich ein Gehalt des Mineralwassers an Eisenoxydul gleich . 0,034838 p. m.

Im Mittel enthält somit das am 14. April 1864 der Quelle entnommene Wasser . . 0,034683 p. m.

Da diese Zahl, welche um 0,002 höher ist, als die, welche das am 18. März von mir der Quelle entnommene Wasser enthielt, den Gehalt der in Gebrauch befindlichen Quelle ausdrückt, so halte ich es für entsprechend, dieselbe in die Zusammenstellung der Resultate aufzunehmen.

8. Bestimmung des Kalks und Strontians im Ganzen.

Das in $7 \mathrm{~b}$ erhaltene, von Eisen befreite Filtrat wurde mit oxalsaurem Ammon gefällt, der Niederschlag nach dem Absitzen abfiltrirt, ausgewaschen, wieder in Salzsäure gelöst, durch Ammon unter Zusatz von etwas oxalsaurem Ammon neuerdings gefältt, der Niederschlag abfiltrirt, ausgewaschen, getrocknet, durch gelindes Glühen in kohlensauren Kalk übergeführt und als solcher gewogen.

Das genannte Filtrat, herrührend von $1957,5 \mathrm{Grm}$. Wasser lieferte 2,5716 Grm. kohlensauren Kalk sammt etwas kohlensaurem Strontian entsp. . . . . . 1,313716 p. m.

$311,745 \mathrm{Grm}$. Wasser auf dieselbe Weise behandelt lieferten $0,4091 \mathrm{Grm}$. kohlensauren Kalk und k. Strontian entspr... . 1,312290 p. m.

9. Bestimmung der Magnesia.

Die von dem oxalsauren Kalk getrennten Filtrate wurden zur Trockne gebracht, der Salmiak durch vorsichtiges Glühen in einer Platinschale verjagt, der Rückstand mit Salzsäure und Wasser aufgenommen, und die Magnesia mit reinem phosphorsaurem Ammon gefällt.

a) $2438,6 \mathrm{Grm}$. Wasser liefer. 1,1931 Grm pyrophosphor- 
saure Magnesia, entspr. Magnesia . . . 0,176290 p. m, b) $1957,0 \mathrm{Grm}$. Wasser lieferten 0,9564 Grm. pyrophosphorsaure Magnesia, entspr. Magnesia . Mittel $\frac{\cdot 0,176041 \text { p. m. }}{0,176166 \text { p. m. }}$

10. Bestimmung des beim Kochen des Wassers gelöst bleibenden Kalks und Strontians.

a) $500 \mathrm{Grm}$. Wasser wurden mit mehr als der gleichen Menge destillirten Wassers vermischt und eine Stunde lang gekocht. (Vergl. Zeitschrift für analyt. Chemie 2, 337). Nach völligem Erkalten wog die Flüssigkeit sammt dem entstandenen Niederschlag 1036,2 Grm. Man filtrirte durch ein trocknes Filter. 1026,9 Grm. Filtrat lieferten mit oxalsaurem Ammon doppelt gefältt $\theta, 2923 \mathrm{Grm}$. kohlensauren Kalk sammt etwas kohlensaurem Strontian. Hieraus ergiebt sich, dass 1000 Theile Mineralwasser enthalten beim Kochen gelöst bleibenden Kalk und Strontian ausgedrückt im Gewicht der kohlensauren Salze

0,589936 Theile,

b) $500 \mathrm{Grm}$. Wasser, gleich behandelt, lieferten $971,8 \mathrm{Grm}$. nach dem Kochen und Erkalten, und $970 \mathrm{Grm}$. Filtrat 0,1628 Aetzkalk sammt etwas Aetzstrontian. $971,8 \mathrm{Grm}$. würden demnach 0,1631 Grm. geliefert haben, oder ausgedrückt im Gewicht kohlensaurer Salze... . . . . 0,582000 p. m. Mittel 0,585968 p. m.

\footnotetext{
8 
Da der Strontian an Sehwefelsäure gebunden ist und beim Kochen des Wassers gelöst bleibt, so ist die erwähnte Zahl nur kohlensaurer Kalk, sie entspricht Kalk $.0,407140$ p. m.

12. Bestimmung des beim Kochen gelöst bleibenden Kalks.

Die beim Kochen, gelöst bleibende Menge Kalk und Strontian befrägt, ausgedrückt im Gewichte der einfach kohlensauren Salze, nach 10 . . . . . . 0,585968 p. m.

Hiervon geht ab die Menge des Strontians (13 f.) ausgedrückt als kohlensaurer Strontian . . . . . . . . . . 0,002930 p. m. entspr, Kalk . . . . . 0, 0,326501 p. m.

13. Bestimmung des Lithions, des Baryts, Strontians, der Thonerde, des Mangans und der Phosphorsäure.

20218 Grm Wasser wurden in einer Silberschale eingedampft und zur Bestimmung der angegebenen Bestandtheile der Behandlung unterworfen, welche ich in meiner „Anleitung zur quantitativen Analyse", 5. Auflage, $\$$. 209, 7 ausführlich beschrieben habe. Erhalten wurden

a) $0,0183 \mathrm{Grm}$, reines basisch phosphorsaures Lithion, entspr. Lithion . . . . . . . . 0,000351 p. m.

oder Chlorlithium ...... . 0,000994 p. m.

b) $0,0686 \mathrm{Grm}$. reines im Wasserstoffstrom geglühtes Mangansulfür, entsprechend Mlanganoxydul . . . . 0, 002769 p. m.

c) $0,0017 \mathrm{Grm}$ phosphorsaure Thonerde $\left(\mathrm{Al}_{2} \mathbf{0}_{3}, \mathrm{P} \mathbf{O}_{5}\right)$, entsprechend Thonerde . . . . . . 0,000035 p. m. entsprechend Phosphorsäure . . . . . 0,000049 p. m.

d) Aus dem Filtrate von der phosphorsauren Thonerde wurde durch schwefelsaure Magnesia noch eine Spur phosphorsaurer Ammonmagnesia gefällt, welche geglüht $0,0008 \mathrm{Grm}$. pyrophosphorsaure Magnesia lieferte, entspr.

Phosphorsäure . . . . . . . . 0,000025 p. m.

Hierzu die in $13 \mathrm{c}$ gefundene mit . 0,000049 p. m. liefert Gesammtphosphorsäure . . . 
e) 0,0060 schwefelsaurer Baryt, entspr. Baryt . . . . . . . . 0,000195 p. m f) 0,0737 schwefelsaurer Strontian, entsprechend Strontian . . . . . 0,002050 p. m oder kohlensaurem Strontian . . . 0,002930 p. m

14. Bestimmung des Kalis, Natrons und Lithions zusammen.

a) Aus den in $6 \mathrm{~b}$ erwähnten $1957,7 \mathrm{Grm}$. Wasser wurd wie sich aus 6, 7, 8 und 9 ergibt, Kieselsäure, Eisenoxyd Kalk nebst Strontian und Magnesia entfernt. Die von der phosphorsauren Ammonmagnesia abfiltrirte Flüssigkeit diente zur Bestimmung der fixen Alkalien. Sie wurde zu dem Endt zur Fällung der Schwefelsäure, Oxalsäure und Phosphorsäure mit reinem essigsaurem Bleioxyd in geringem Ueberschuss versetzt. Aus dem Filtrat entfernte man das überschüssige Bleioxyd durch Schwefelwasserstoff, dampfte die vom Schwefelble getrennte Flüssigkeit in einer Platinschale mit Salzsäure zuI Trockne ein, entfernte das Chlorammonium durch Glühen, nahn den Rückstand mit Wasser auf, versetzte mit etwas Ammon und kohlensaurem Ammon, filtrirte, verdampfte in einer kleiner Platinschale zur Trockne und wog die reinen Chlormetalle de: Natriums, Kaliums und Lithiums. Erhalten * 0,209195 p. m.

b) Die in 13 genannten 20218 Grm. Wasser hatten, nach der daselbst angegebenen Methode behandelt, geliefert 4,2084 Grm. reine, gelinde geglühte Chloralkalimetalle entsprechend . . . . . . . $\frac{0,208151 \mathrm{p.} \mathrm{m}}{0,208673 \mathrm{p.} \mathrm{m}}$

15. Bestimmung des Kalis.

a) Die in 14 a genannten Chloralkalimetalle lieferten nact üblicher Art mit Platinchlorid behandelt, 0,0914 Grm. Kaliumplatinchlorid, entspr. Kali . . . . . . 0,008999 p. m

b) Die in $14 \mathrm{~b}$ erhaltenen Chlormetalle lieferten 0,9265 Gr. Kaliumplatinchlorid entspr. Kali . • $\cdot 0,008831$ p. m Mittel 0,008915 p. m entspr. Chlorkalium . . . 0,014111 p. m 
16. Bestimmung des Natrons.

Die Gesammtmenge der fixen Chloralkalimetalle beträgt nach 14 . . . . . . . . . . 0 0,208673 p. m.

Davon geht $\mathrm{ab}$ :

Chlorkalium (15) . . 0,014111 p. m.

Chlorlithium (13 a). . 0,000994 p. m.

Zusammen 0,015105 p. m.

bleibt Chlornatrium. . . 0, 0,193568 p. m.

entsprechend Natron . . . . . . 0,102645 p. m.

17. Bestimmung des Ammons.

4291 Grm Wasser wurden unter Zusatz von Salzsäure in einer Retorte eingedampft, dann mit Kalkhydrat destillirt. Das Destillat, in Salzsäure aufgefangen, mit Platinchlorid verdampft, lieferte Platin aus Ammoniumplatinchlorid 0,0167 Grm., entsprechend Ammoniumoxyd . . . . . 0,001023 p. m.

18. Bestimmung der Salpetersäure.

$4585 \mathrm{Grm}$. Wasser wurden in einer Retorte bis auf einen kleinen Rest abgedampft, die von dem Niederschlag getrennte Flüssigkeit sammt Waschwassern neuerdings eingeengt, der dabei entstandene Niederschlag abfiltrirt, die Lösung concentrirt, und in der kleinen Menge Flüssigkeit die Salpetersäure nach der in meiner "Anleitung zur quantitativen Analyse" 5. Aufl., Seite $426 \beta$ angeführten Methode bestimmt. Die Salpetersäure erzeugte, mit Eisenchlorür und Salzsäure erhitzt, so viel Eisenchlorid, dass zu dessen Reduction 0,33 Cub. Cent. einer Zinnchlorürlösung erforderlich waren, von welcher $23,15 \mathrm{Cub}$. Cent. 0,1003 Grm. Eisen aus dem Zustande des Chlorids in den des Chlorürs überzuführen vermochten. Hieraus berechnet sich die Menge der Salpetersäure zu . . . 0,0001002 p. m.

19. Bestimmung des Schwefelwasserstoffs.

660 Cub Cent. frisch der Quelle entnommenes Wasser wurden unter den üblichen Vorsichtsmassregeln (meine Anleitung zur quantitativen Analyse, 5. Aufl., S. 411) mit Stärke- 
kleister und titrirter Jodlösung versetzt bis zur beginnenden Bläuung. Man verbrauchte 18,6 und 18,9 Cub. Cent., im Mittel 18,75. - 10 Cub. Cent. der Jodlösung enthielten $0,003735 \mathrm{Grm}$. Jod, entsprechend 0,0005 Schwefelwasserstoff. Daraus berechnet sich der Gehalt an Schwefelwasserstoff $\mathrm{zu}$. . . . . . . . . $0,001420 \mathrm{p,} \mathrm{m}$.

Dass dieser Gehalt nicht constant ist, habe ich bereits oben, wo von dem Geruche des Wassers die Rede ist, bemerkt Ich führe nun für diesen Ausspruch auch einen Zahlenbeleg an. Bei meiner Anwesenheit in Pyrmont am 20. November 1864 bestimmte ich nämlich den Schwefelwasserstoffgehalt nochmals. 500 Cub. Cent. erforderten, unter den üblichen Vorsichtsmassregeln, bis zur beginnenden Bläuung zugesetzten Stärkekleisters 2,3 Cub. Cent. Jodlösung; - 1 Cub. Cent. der Jodlösung entsprach 0,00137 Grm. Jod. Hieraus berechnet sich der Gehalt an Schwefelwasserstoff zu 0,000844 p. m.

20. Bestimmung der Gesammtmenge der fixen Bestandtheile.

$322,426 \mathrm{Grm}$. Wasser lieferten schwach geglühten Rückstand $0,7319 \mathrm{Grm}$. entspr. . . . . . 2,269978 p. m.

\section{Berechnung der Analyse.}

a) Schwefelsaurer Baryt.

Baryt ist vorhanden nach $13 \mathrm{e}$. . . . $0,000195 \mathrm{p} . \mathrm{m}$ zu schwefelsaurem Baryt . . . 0,000297 p. m.

b) Schwefelsaurer Strontian.

Strontian ist vorhanden nach $13 \mathrm{f} . . .0,002056 \mathrm{p} . \mathrm{m}$. bindend Schwefelsäure . . . . . . . 0,001589, zu schwefelsaurem Strontian . . 0,003645 p. m.

c) Schwefelsaurer Kalk.

Beim Kochen gelöst bleibender Kalk ist vorhanden nach 12 . . . . . . 0,326501 p.m.

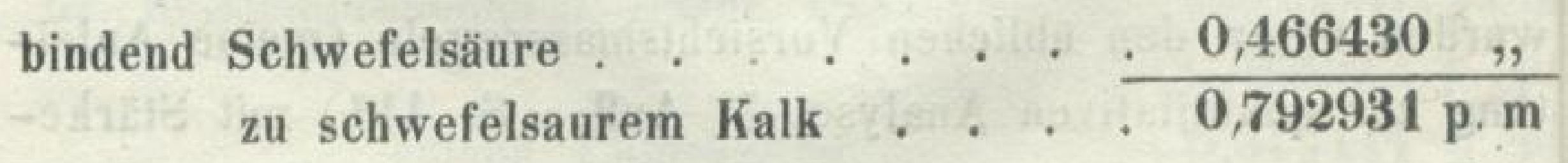


d) Schwefelsaures Kali.

Kali ist vorhanden nach $15 .+.+0,008915$ p. m.

bindend Schwefelsäure . . . . . . $\frac{0,007570,}{0,016485 \mathrm{pm}}$

e) Jodnatrium.

Jod ist vorhanden nach $2 \mathrm{a}$. . . . 0,00001374 p. m.

bindend Natrium . . . . . . . . . . 0,00000249 ",

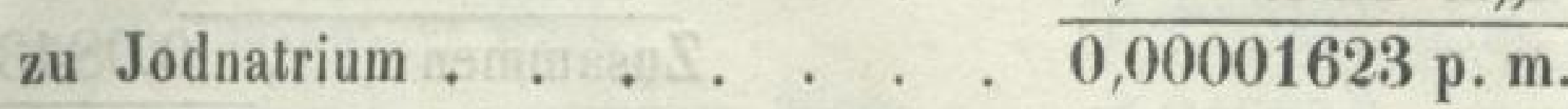

f) Bromnatrium.

Brom ist vorhanden nach $2 \mathrm{~b}$. . . $0,0000698 \mathrm{p} . \mathrm{m}$.

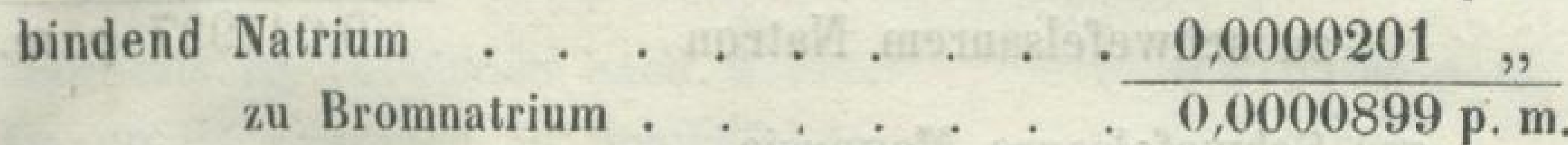

g) Salpetersaures Natron.

Salpetersäure ist vorhanden nach 18 ? 0,0001002 p. m. bindend Natron . . . . . . . . 0,0000575, zu salpetersaurem Natron. . . 0,0001577 p. m.

h) Chlorlithium.

Lithion ist vorhanden nach 13 a 0,000351 , entsprechend Lithium . . . . . . . . . . 0,000165 p. m. bindend Chlor

$$
\text { zu Chlorlithium . . . . . . } 0,000995 \text { p. m. }
$$

i) Chlorammonium.

Ammoniumoxyd ist vorhanden nach 170,001023 , entsprechend Ammonium . . . . . . 0,000708 p. m. bindend Chlor . . . . . . . . . 0,001395 zu Chlorammonium ... . . 0,002103 p.m.

k) Chlornatrium.

Chlor ist vorhanden nach $3 \ldots$. 0,098597 p. m.

Davon ist gebunden:

an Lithium . . . . . 0,000830 p. m.

an Ammonium . .. . . . 0,001395 ,

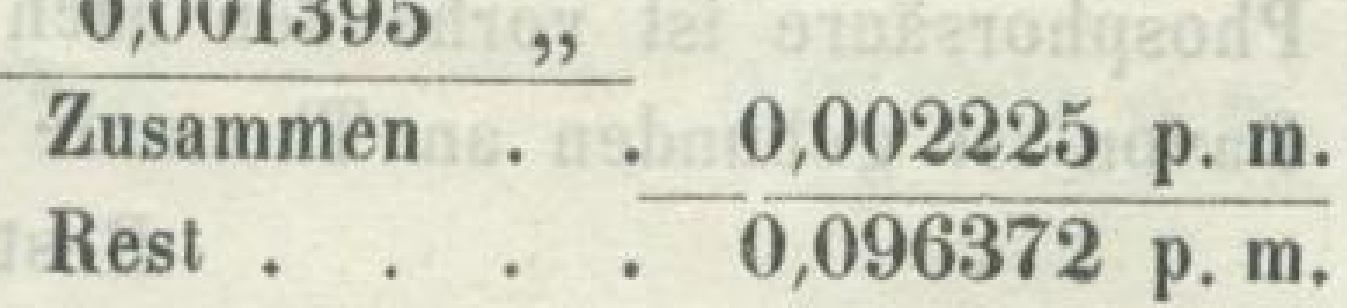

bindend Natrium. . . . . . . . 0,062509

zu Chlornatrium . . . . . . $0,158881 \mathrm{p.} \mathrm{m}$. 
l) Schwefelsaures Natron.

Natron ist vorhanden nach 16 . . . . 0,102645 p.m.

Davon entspricht: dem Jod

0,00000336

dem Brom . . . . . . 0,00002709

der Salpetersäure . . . 0,00005750

dem Chlor . . . . . . . 0,08425100

Rest . . . 0,018306 p. m. Zusammen $\cdot \frac{0,084339,,}{0,018306 \text { p. m. }}$
Rest . . $.0,023621$.

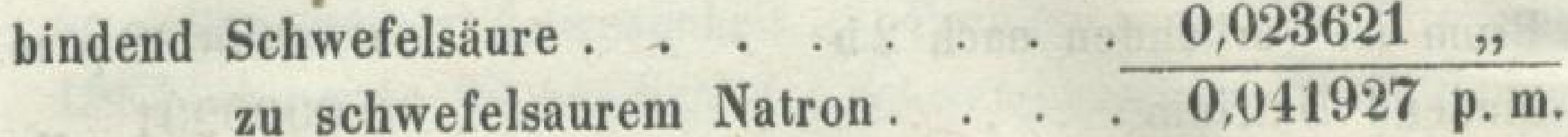

m) Schwefelsaure Magnesia.

Schwefelsäure ist vorhanden nach 4

0,801511 p. m.

Davon ist gebunden :

an Baryt

. 0,000102

an Strontian . . . . . . . 0,001589

an Kalk . . . . . . . . 0,466430

an Kali . . . . . . . . 0,007570

an Natron . . . . . . . 0,023621

Zusammen $\cdot \frac{0,499312}{\text { p. m. }}$.
Rest . .

bindend Magnesia

zu schwefelsaurer Magnesia . . 0,453298 p. m.

n) Phosphorsaure Thonerde.

Thonerde ist vorhanden nach $13 \mathrm{c} . .0,000035 \mathrm{p.}$.

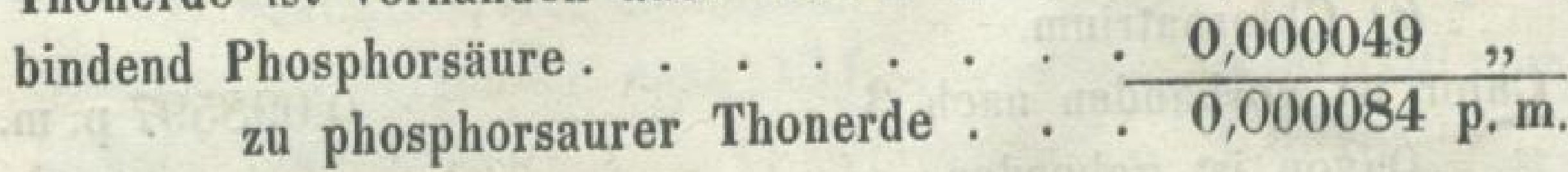

o) Phosphorsaurer Kalk.

Phosphorsäure ist vorhanden nach $13 \mathrm{~d}$. 0,000074 p. m. Davon ist gebunden an Thonerde . . . 0,000049, Rest . . 0,000025 p.m.

bindend Kalk.

0,000030 zu phosphorsaurem Kalk (3 C a 0, P $\left.0_{5}\right) \longdiv { 0 , 0 0 0 0 5 5 \text { p. m. } }$ 
p) Kohlensaurer Kalk.

Beim Kochen niederfallender Kalk ist vorhanden nach 11 . . . . . . 0,407140 p. m.

Davon ist gebunden an Phosphorsäure. . . 0,000030 \#

Rest . . . 0,407110 p. m.

bindend Kohlensäure . . . . . . . 0,319872,

zu kohlensaurem Kalk . . . . . 0,726982 p. m.

entsprechend doppelt kohlensaurem Kalk . 1,046854 "

q) Kohlensaure Magnesia.

Magnesia ist vorhanden nach 9 . . . . 0,176166 p. m.

Davon ist gebunden an Schwefelsäure. $\frac{0,151099 ~}{\text { Rest . . }}$

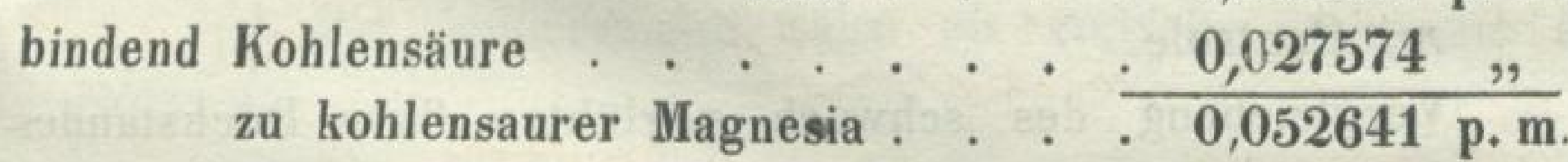
entsprechend doppelt kohlensaurer Magnesia 0,080215 p. m.

$r$ ) Kohlensaures Eisenoxydul.

Eisenoxydul ist vorhanden nach 7 aa. $\mathbf{u}$. bb.

im Mittel . . . . . . . . . 0,034683 p. m.

bindend Kohlensäure . . . . . . . . 0,021195 ,

zu einfach kohlensaurem Eisenoxydul 0,055878 p. m. entsprechend doppelt kohlensaur. Eisenoxydul 0,077073 p. m.

s) Kohlensaures Manganoxydul.

Manganoxydul ist vorhanden nach $13 \mathrm{~b} . \quad 0,002769 \mathrm{p} . \mathrm{m}$. bindend Kohlensäure . . . . . . . 0,001716 ", zu einfach kohlensaur. Manganoxydul 0,004485 p. m. entsprech, doppelt kohlensaurem Manganoxydul 0,006201 p. m.

t) Kieselsäure.

Kieselsäure ist vorhanden nach 6 . . . 0,031782 p. m.

u) Freie Kohlensäure.

Die Gesammtmenge der Kohlensäure beträgt nach $5.2 . \quad . \quad . \quad . \quad . \quad . \quad 3,135979$ p. m. 
Transport . $3,135979 \mathrm{p.} \mathrm{m}$.

Davon ist gebunden:

an Kalk . . . . . . . . 0,319872

an Magnesia . . . . . . . 0,027574

an Eisenoxydul . . . . . 0,021195

an Manganoxydul. . . . . 0,001716

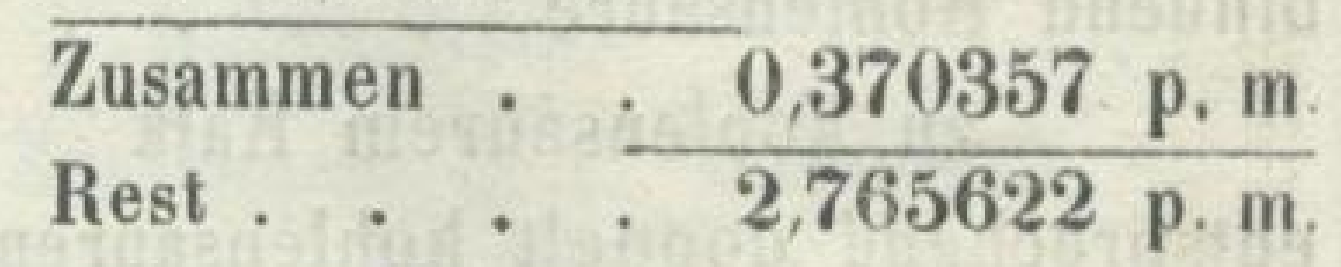

Davon ist mịt einfachen Carbonaten zu Bicar-

bonaten verbunden

Rest, völlig freie Kohlensäure

v) Freier Schwefelwasserstoff.

Menge schwankend, daher unten als „starke Spur" aufgeführt w) Controle.

Vergleichung des schwach geglühten fixen Rückstandes mit der Summe der einzeln erhaltenen Bestandtheile in den Zuständen, welche sie bei schwachem Glühen annehmen.

Schwefelsaurer Baryt

$0,000297 p+m$.

Strontian ... 0,003645

(57) $\#$ Kalk . . . . . . . 0,792931

Schwefelsaures Kali . . . . . . . 0,016485 ,

Jodnatrium . . . . . . . . . 0 0,00016

Bromnatrium . . . . . . . 0,000090

Salpetersaures Natron . . . . . . 0,000158

Chlorlithium . . . . . . . . . 0,000994

Chlornatrium . . . . . . . . 0,158881

Schwefelsaures Natron . . . . 0,041927

Schwefelsaure Magnesiå . . . . . . 0,453298

Phosphorsaure Thonerde . . . . 0,000084 "

Bas. phosphorsaurer Kalk . . . . . 0,000055 "

Kohlensaurer Kalk . . . . . . . 0,726982 "

Magnesia . . . . . . . . . 0,025067 "

Eisenoxyd . . . . . . . . . 0,036322 ,

Manganoxyd . . . . . $\frac{0,003081 \%}{2,260313 \%}$ 


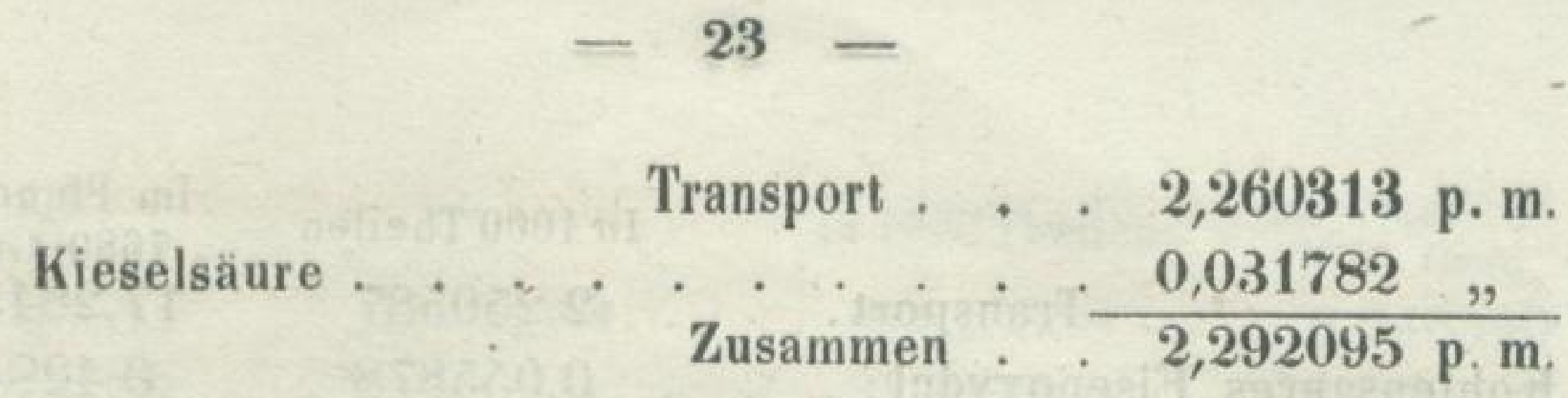

Davon geht ab die durch Kieselsäure

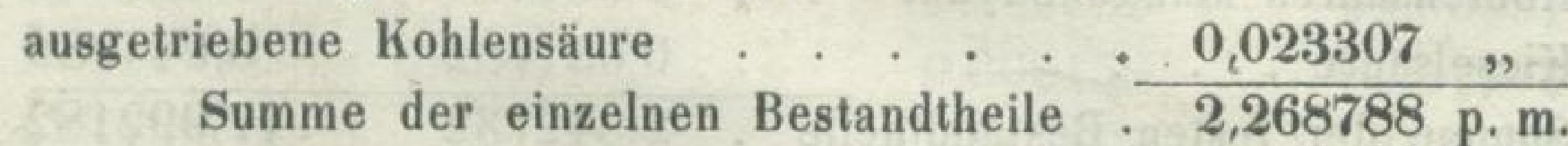

Durch Abdampfen und schwaches Glühen

wurde direct erhalten nach $20 \ldots .+2,269978$ p. m.

III. Zusammenstellung der Resultate.

In der Pyrmonter Trinkquelle sind folgende Bestandtheile enthalten.

a) Die kohlensauren Salze als einfache Carbonate berechnet:

๔) In wägbarer Menge vorhandene Bestandtheile:

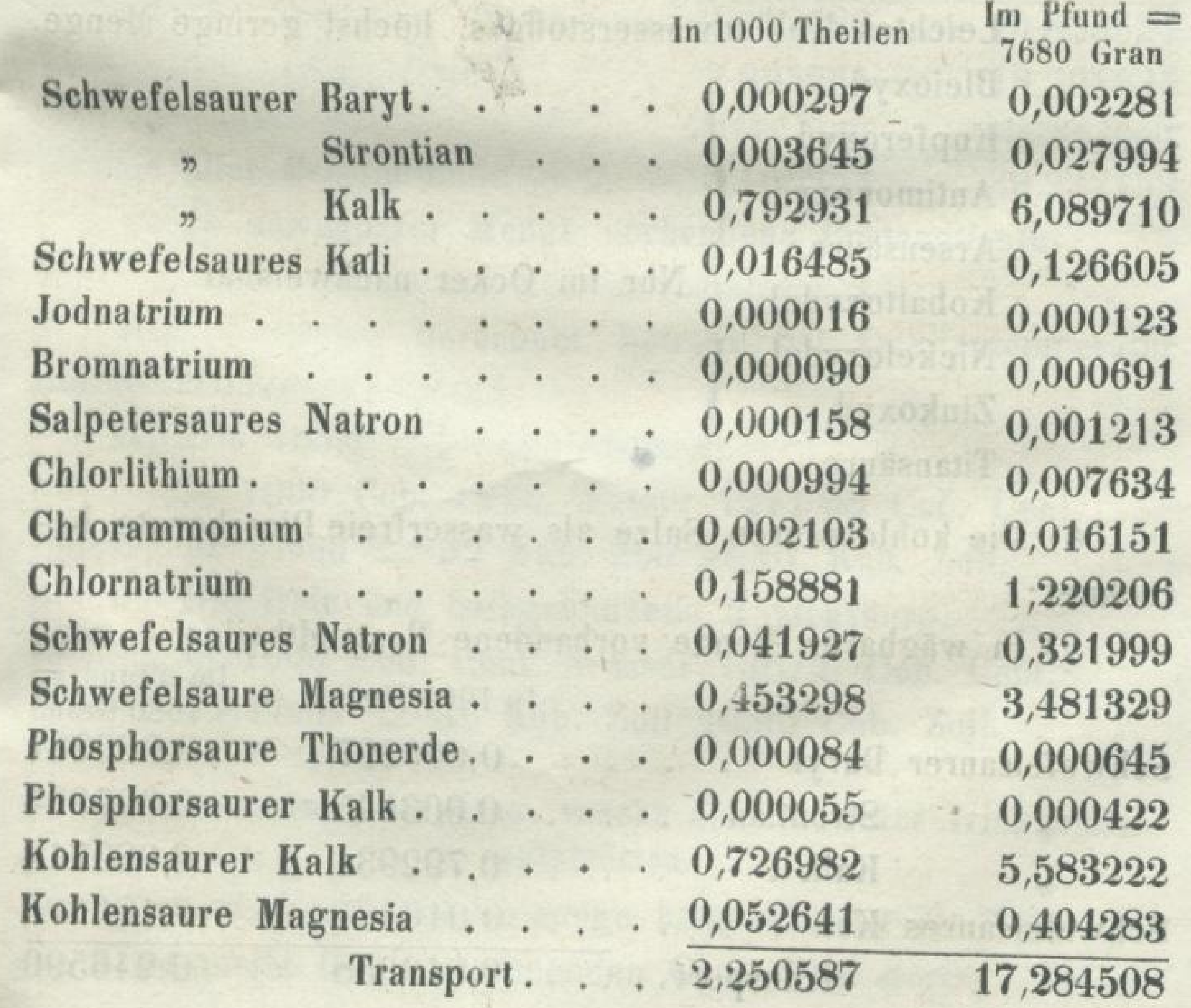




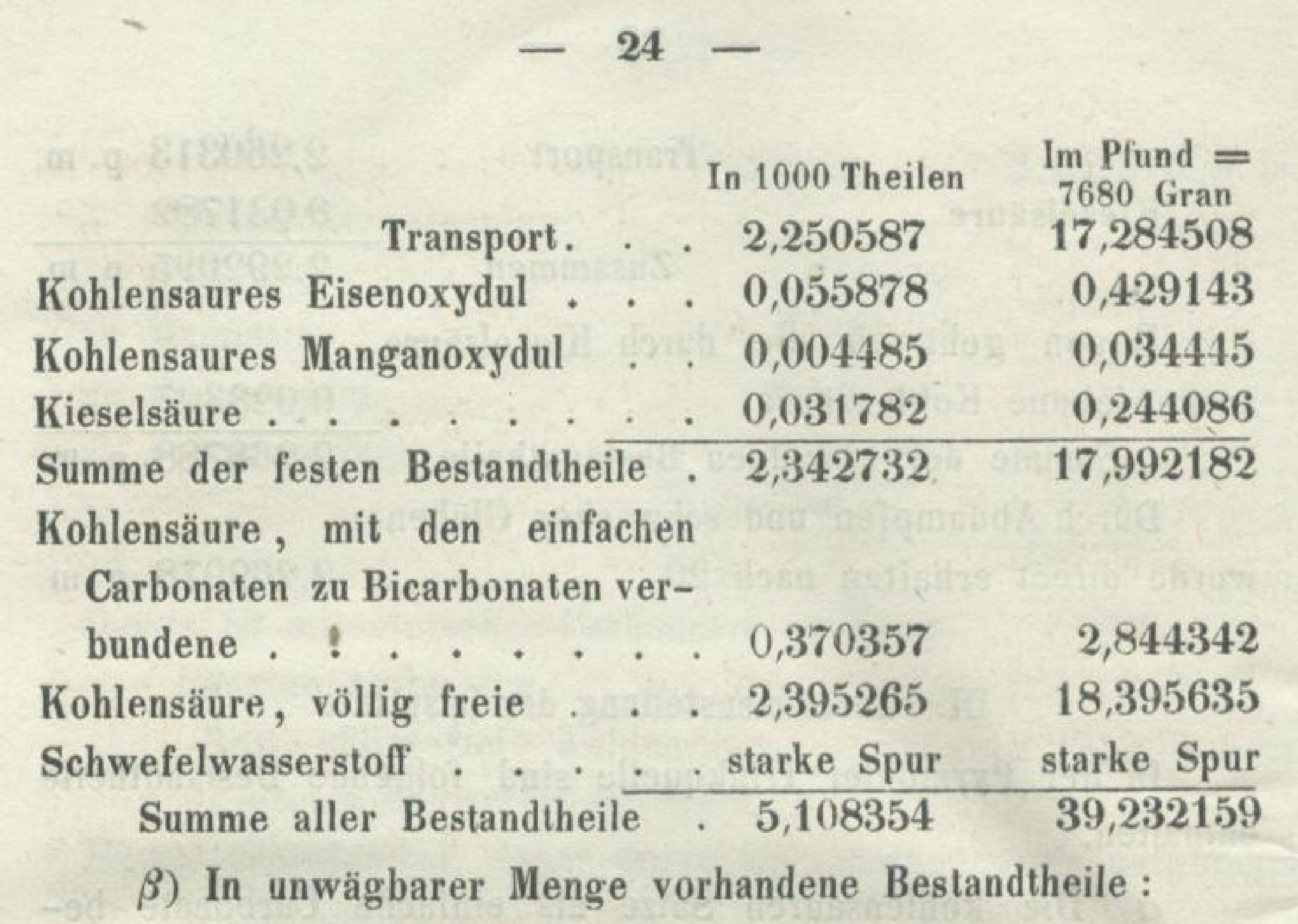

Borsäure, Spur.

Organische Substanzen, geringe Spuren.

Stickgas, geringe Menge.

Leichtes Kohlenwasserstoffgas, höchst geringe Menge.

Bleioxyd, Kupferoxyd

Antimonoxyd,

Arsensäure,

Kobaltoxydul,

Nur im Ocker nachweisbar

Nickeloxydul,

Zinkoxyd,

Titansäure

b) Die kohlensauren Salze als wasserfreie Bicarbonate berechnet:

$\alpha)$ In wägbarer Menge vorhandene Bestandtheile: In 1000 Theilen Im Pfund $=$

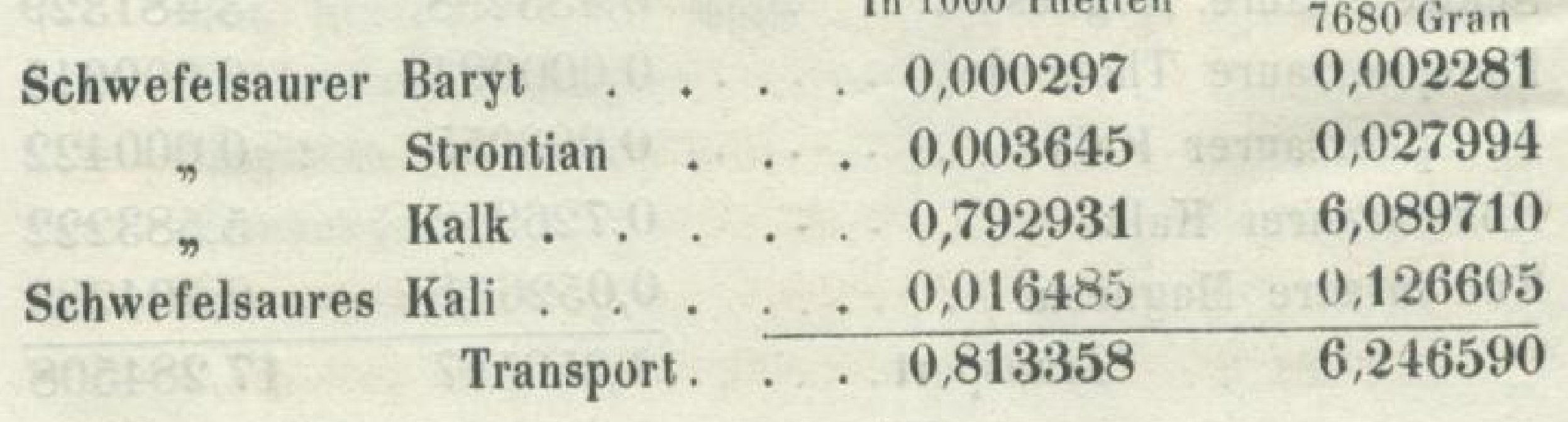




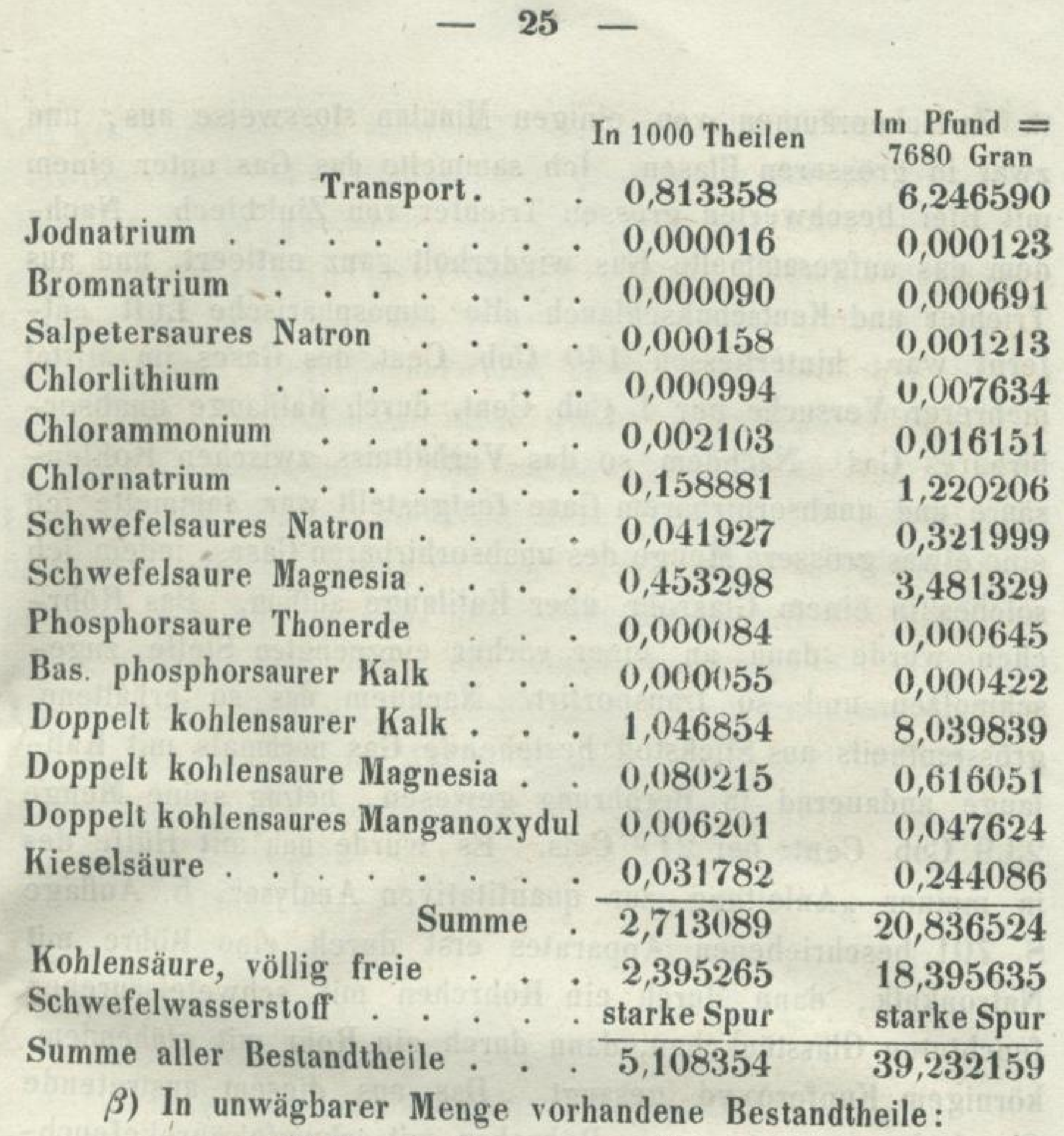

(Siehe die Zusammenstellung a.)

Auf Volumina berechnet beträgt bei Quellentemperatur und Normalbarometerstand:

a) Die völlig freie Kohlensäure :

In 1000 Cub. Cent. Wasser 1271,05 Cub. Cent.

Im Pfund $=32 \mathrm{Kub}$. Zoll 40,67 Kub. Zoll.

b) Die freie und halbgebundene Kohlensäure:

In 1000 Cub. Cent. Wasser 1467,6 Cub. Cent.

Im Pfund $=32$ Kub. Zoll 46,96 Cub. Zoll.

IV. Untersuchung der Gase, welche der Pyrmonter Trinkquelle entströmen.

Wie ich bereits im Eingange bemerkte, ist die Menge des der Trinkquelle frei entströmenden Gases sehr gering; es tritt 
in Zwischenräumen von einigen Minuten stossweise aus, und zwar in grösseren Blasen. Ich sammelte das Gas unter einem mit Blei beschwerten grossen Trichter von Zinkblech. Nachdem das aufgesammelte Gas wiederholt ganz entleert, und aus Trichter und Kautschukschlauch alle atmosphärische Luft entfernt war, hinterliessen 140 Cub. Cent. des Gases im Miftel mehrerer Versuche nur 1 Cub. Cent. durch Kalilauge unabsorbirbares Gas Nachdem so das Verhältniss zwischen Kohlensäure und unabsorbirbarem Gase festgestellt war, sammelte ich eine etwas grössere Menge des unabsorbirbaren Gases, indem ich solches in einem Glasrohr über Kalilauge auffing. Das Röhrchen wurde dann an einer vorher eingeengten Stelle zugeschmolzen und so transportirt. Nachdem das so erhaltene, grösstentheils aus Stickstoff bestehende Gas nochmals mit Kalilauge andauernd in Berührung gewesen, betrug seine Menge 23,9 Cub. Cent. bei $21^{\circ}$ Cels. Es wurde nun mit Hülfe des in meiner "Anleitung zur quantitativen Analyse“, 5. Auflage S. 701 beschriebenen Apparates erst durch eine Röhre mit Natronkalk, dann durch ein Röhrchen mit schwefelsäurebefeuchteten Glasstückchen, dann durch ein Rohr mit glühendem, körnigem Kupferoxyd gesaugt. Das aus diesem austretende Gas gelangte erst in ein Röhrchen mit schwefelsäurebefeuchteten Glasstückchen, dann in ein Natronkalk enthaltendes Röhrchen. Das letztere war leicht und sehr genau gewogen. Es nahm zu um 0,0006 Grm., entsprechend der durch Verbrennung leichten Kohlenwasserstoffs erzeugten Kohlensäure. Aus diesen Daten ergibt sich, dass 1000 Volumina des der Quelle frei entströmenden Gases bestehen aus:

992,86 Vol. Kohlensäure

7,04 Vol. Stickgas.

0,10 Vol, leichten Kohlenwasserstoffs.

1000,00 .

v. Untersuchung des aus der Trinkquelle abgesetzten Ockers. Da es bei der Benutzung der Quelle und der Beschaffen- 
heit des Abflusskanals schwierig war einen 0cker, wie er sich freiwillig unter dem Einfluss der Atmosphäre auf das Wasser ausscheidet, zu gewinnen, so übersandte mir Herr Brunnenkommissär Wigand einen 0cker, welcher dadurch erhalten worden war, dass man das Wasser in 2 Bütten der Luft ausgesetzt hatte. Begreiflicherweise kann dieser mit dem freiwillig sich abscheidenden nicht gleich zusammengesetzt sein; er muss vielmehr ärmer sein an den beim ersten Angriff der Luft auf das Wasser niederfallenden Stoffen und reicher an den sich erst bei längerer Einwirkung abscheidenden. Ich erwähne dies ausdrücklich, um zu begründen, weshalb die $\mathrm{Zu-}$ sammensetzung des Ockers der Trinkquelle wesentlich abweicht von der des (freiwillig abgeschiedenen) Brodelbrunnen-0ckers Der nach angegebener Art erhaltene Ocker der Trinkquelle ergab bei der Analyse folgende Bestandtheile:

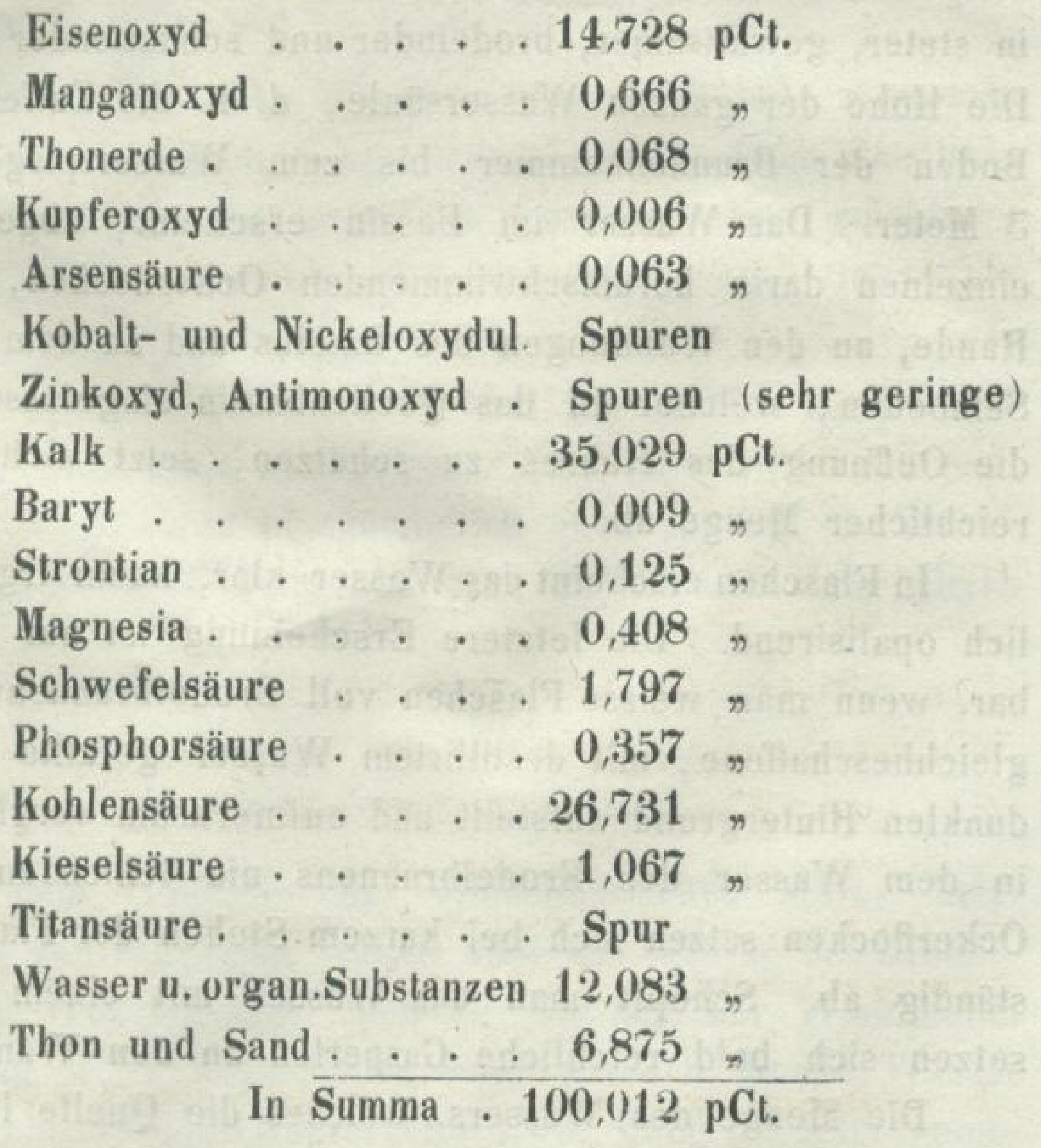


II.

\section{Die Tadequelle (der Mrodelbrumnem).}

A. Physikalische Verhältnisse.

Die Badequelle (der Brodelbrunnen) liegt auf dem freien Platze vor dem Brunnenhause. Das Wasser und die sehr grosse Mange des der Quelle frei entströmenden Gases sammeln sich in einer Brunnenkammer und steigen dann durch ein verzinntes Kupferrohr von 0,2 Meter Weite, welches oben in ein rundes Holzbassin mündet. Das letztere hat 1,5 Meter Durchmesser und 1,2 Meter Höhe. Auf seinem oberen Rande liegt ein Kranz von Marmor. Die Wassersäule in dem Fasse ist etwa 0,9 Meter hoch; sie ist durch das ausströmende Gas in steter, gewaltsamer, brodelnder und schäumender Bewegung. Die Höhe der ganzen Wassersäule, d. h. die Entfernung vom Boden der Brunnenkammer bis zum Wasserspiegel ist fast 3 Meter. Das Wasser im Bassin erscheint, abgesehen von einzelnen darin herumschwimmenden Ockerflocken, klar; am Rande, an den Wandungen des Bassins und an dem kupfernen Seihboden, welcher in das Quellenbassin eingelassen ist, um die Oeffnung des Rohres zu schützen, setzt sich Ocker in reichlicher Menge ab.

In Flaschen erscheint das Wasser klar, kaum irgend weisslich opalisirend. Die letztere Erscheinung ist nur wahrnehmbar, wenn man weisse Flaschen voll Brodelbrunnenwasser und gleichbeschaffene, mit destillirtem Wasser gefülte vor einem dunklen Hintergrund aufstellt und aufinerksam vergleicht. Die in dem Wasser des Brodelbrunnens nie fehlenden grösseren Ockerflocken setzen sich bei kurzem Stehen der Flaschen vollständig ab. Schöpft man das Wasser mit einem Glase, so setzen sich bald reichliche Gasperlen an den Wandungen ab.

Die Menge des Wassers, welches die Quelle liefert, betrug nach amtlichen Mittheilungen vor der Neufassung in der 
Minute 238-242 preussische Pfunde, nach der Neufassung aber 276 Pfund oder 129 Litre. Somit liefert die Quelle:

$$
\begin{aligned}
& \text { in einer Stunde } \\
& \text { in } 24 \text { Stunden . . . } \\
& \hline
\end{aligned}
$$

Die Menge des freien Gases ist so bedeutend, dass sich nach meinen Versuchen ein 1 hannover'schen Kubikfuss fassendes Gefäss in 6-7 Secunden, im Mittel in 6,5 Secunden füllt. Da ein hannover'scher Kubikfuss gleich 0,02489 Kubikmeter ist, so liefert die Quelle in einer Minute 0,2297 Kubikmeter, in einer Stunde 13,782 Kubikmeter oder 13782 Litre, in 24 Stunden 331 Kubikmeter oder 331000 Litre und in einem Jahre 120815 Kubikmeter oder 120815000 Litre.

Das Verhältniss zwischen dem gelieferten Wasser und dem zugleich ausströmenden Gase wird demnach ausgedrückt durch die Zahlen 7740:13782 und entspricht abgerundet dem Verhältnisse 1 Vol. : 1,78 Vol.

Der Geschmack des Wassers ist prickelnd säuerlich, eisenartig, schwach nach Schwefelwasserstoff, Beim Schütteln in halbgefüllter Flasche entbindet dasselbe eine reichliche Menge Gas, welches deutlich, aber nicht stark, nach Schwefelwasserstoff riecht.

Die Temperatur des Wassers fand ich am 19. März 1864 bei $9^{\circ}$ Cels. Luftwärme gleich $12,7^{\circ}$ Cels. oder $10,16^{\circ}$ Reaum. Das specifische Gewicht bestimmte ich nach der bei der Trinkquelle angeführten Methode und fand es bei $19^{\circ}$ Cels. gleich 1,00347 .

\section{B. Chemische Verhältnisse.}

Unter dem Einflusse der atmosphärischen Luft, beim Kochen und zu Reagentien yerhält sich das Wasser des Brodelbrunnens im Wesentlichen eben so wie das der Trinkquelle. Die Bräunung beim Vermischen einer grossen Menge Wasser mit einer kleinen Menge Kupferchlorid war beim Brodelbrunnen- 
wasser nur dann wahrnehmbar, wenn man die grosse Flasche auf eine weisse Unterlage stellte und von oben durch das Wasser sah.

Die qualitative Analyse des Wassers ergab dieselben Bestandtheile, welche bei der Trinkquelle aufgeführt worden sind. Das aus der Quelle frei ausströmende Gas ist fast reine Kohlensäure (vergl, unten IV).

Die quantitative Analyse wurde in allen wesentlichen Theilen mindestens doppelt ausgeführt. Die Untersuchungsmethode war die beim Trinkbrunnen beschriebene. Das zur Untersuchung verwandte Wasser entnahm ich am 19. März 1864 mit Hülfe 7 Liter haltender Glasflaschen, welche unter dem Wasserspiegel gefültt wurden. Ich liess die Flaschen kurze Zeit im Dunkeln stehen, bis sich die anfangs im Wasser schwimmenden Ockerflocken abgesetzt hatten, entleerte das davon freie Wasser in andere Glasflaschen und transportirte diese in mein Laboratorium nach Wiesbaden. Zur Bestimmung der Kohlensäure, zur Feststellung des specifischen Gewichtes des Wassers und zur Ermittelung des Schwefelwasserstoffs wurde-natürlicherweise kein in angegebener Art abgesetztes, sondern der Quelle unmittelbar entnommenes Wasser verwandt.

Die folgenden, die quantitative Analyse und deren Resultate darlegenden Abschnitte sind in derselben Art geordnet, welche bei der Trinkquelle eingehalten wurde.

\section{Originalzahlen in Grammen.}

1. Bestimmung des Chlor-, Brom- und Jodsilbers.

a) $700 \mathrm{Grm}$. Wasser lieferten $0,3172 \mathrm{Grm}$.

Chlor-Brom- und Jodsilber, entsprechend . 0 0,453143 p. m.

b) $500 \mathrm{Grm}$. Wasser lieferten $0,2263 \mathrm{Grm}$.

Chlor-Brom- und Jodsilber, entsprechend . 0,452600 ",

Mittel . 0,452872 p. m.

2. Bestimmung des Broms und Jods.

Wassermenge $59255 \mathrm{Grm}$ 
a) Brom: Die Menge des Chlor- und Bromsilbers betrug 1,2989 Grm. 0,2633 Grm. desselben nahmen im Chlorstrom $0,0004 \mathrm{Grm}$. an Gewicht ab. Die Menge des Broms berechnet sich hiernach zu. . . . . . . 0,000060 p. m.

b) Jod : In der concentrirten wässerigen Lösung der ChlorBrom- und Jodalkalimetalle wurde das Jod durch eine Auflösung von Untersalpetersäure in Schwefelsäure ausgetrieben und mit Schwefelkohlenstoff aufgenommen. Der Schwefelkohlenstoff wurde direct mit einer Lösung von unterschwefligsaurem Natron titrirt, von der 2,11 Cub. Cent. 0,000382 Gr. Jod entsprachen. Verbraucht wurden 0,34 Cub. Cent. unterschwefligsauren Natrons, entsprechend Jod 0,00000104 p. m.

3. Bestimmung des Chlors.

Die Gesammtmenge des Chlor-, Brom- und Jodsilbers betrug

Davon geht $a b$ :

Bromsilber 0,452872 p. m Jodsilber .

5. Bestimmung der Kohlensäure.

$\begin{aligned} \begin{array}{l}0,000140 \\ 0,000002\end{array} & \frac{0,000142}{\text { Zusammen }}, \\ \text { Rest: Chlorsilber. } & 0,452730 \text { p. m. } \\ \text { entsprechend Chlor } & 0,111921 \text { p. m. }\end{aligned}$

4. Bestimmung der Schwefelsäure.

a) $500 \mathrm{Grm}$. Wasser lieferten 1,3800 schwefelsauren Baryt, entsprechend Schwefelsäure . . . . . 0,947638 p. m.

b) $667,9 \mathrm{Grm}$. Wasser lieferten 1,8452

Grm. schwefels. Baryt, entspr. Schwefelsäure. 0,948563 Mittel $\frac{0,948563 \%}{0,948101 \text { p. m. }}$

a) Wasser aus dem obern Bassin des Brodelbrunnens, mittelst eines Stechhebers entnommen.

$220,669 \mathrm{Grm}$. Wasser lieferten 0,6571 Grm. Kohlensäure, entspr . + . . . . . . . . 2,977763 p. m. $220,453 \mathrm{Grm}$. Wasser lieferten $0,6571 \mathrm{Grm}$. Kohlensäure, entspr. . . . . $\frac{2,980925 \text { p. m. }}{\text { Mittel . }}$ 
b) Wasser aus der unteren Brunnenkammer, mittelst des von mir angegebenen Apparates (Zeitschr. f. analyt. Chemie
I. 175) entnommen.

215,437 Grm. Wasser lieferten 0,7158 Grm Kohlensäure, entspr. . • . . . . . . . . . . 3,322549 p. m. $242,713 \mathrm{Grm}$. Wasser lieferten 0,8035 Grm. Kohlensäure entspr. . . . . . . . 3,310494 p. m. 215,499 Grm. Wasser lieferten 0,7046 Grm. Kohlensäure, entspr. . .

6. Bestimmung der Kieselsäure. Mittel $\frac{3,269621 \text { p. m. }}{3,300888 \text { p. m. }}$

a) 1658,7 Grm. Wasser lieferten 0,0604 Grm. Kieselsäure, entspr. . . . . . . . . . . 0,036414 p.m.

b) $2392 \mathrm{Grm}$. Wasser lieferten 0,0841 Grm. Kieselsäure, entspr. . . . . . .

7. Bestimmung des Eisenoxyduls.

a) $1658,7 \mathrm{Grm}$. Wasser lieferten $0,0618^{\mathrm{Grm}}$. Eisenoxyd, entsp. Eisenoxydul . . . . . . . . . 0,033532 p. m.

b) 2392 Grm. Wasser lieferten 0,0888 Grm. Eisenoxyd, entspr. Eisenoxydul . . . 0,033411 p. m. Mittel 0,033471 p. m.

8. Bestimmung des Kalks und Strontians im Ganzen.

a) $1658,7 \mathrm{Grm}$ Wasser lieferten $2,5045 \mathrm{Grm}$ kohlensauren Kalk mit etwas kohlensaurem Strontian, entspr. 1,509918 p. m.

b) $2392 \mathrm{Grm}$. Wasser lieferten 3,6126

Grm kohlensauren Kalk mit etwas kohlensaurem Strontian

9. Bestimmung der Magnesia. Mittel $\frac{1,510284 \text { p. m. }}{1,510101 \text { p. m. }}$

a) $1658,7 \mathrm{Grm}$. Wasser lieferten $0,9457 \mathrm{Grm}$. pyrophosphorsaure Magnesia, entspr. Magnesia . . 0,205458 p. m.

b) $2392 \mathrm{Grm}$. Wasser lieferten 1,3620 Grm.

pyrophosphorsaure Magnesia, entspr. Magnesia 0,205188 p. m. Mittel $\overline{0,205323 \text { p. m. }}$ 
10. Bestimmung des beim Kochen des Wassers gelöst hleibenden Kalks und Strontians.

a) 35: Grm. Mineralwasser, mit etwa dem gleichen Volum destillirten Wassers versetzt, wogen nach dem Kochen und Erkalten $692,1 \mathrm{Grm}$; $686,7 \mathrm{Grm}$. davon lieferten $0,1274 \mathrm{Grm}$. Kalk und Strontian; $692,1 \mathrm{Grm}$. würden demnach geliefert haben 0,1284 Grm Dabei sind nach (16) 0,0017 Grm. Strontian, wonach für Kalk $0,1267 \mathrm{Grm}$. bleibt.

$0,1267 \mathrm{Grm}$. Kalk entsprechen . 0,2263 Grm. kohlensaurem Kalk. 0,0017 Grm. Strontian entspr. 0,0024 Grm. kohlens. Strontian.

Zusammen . 0,2287 Grm. oder auf $1000 \mathrm{Grm}$.

Mineralwasser berechnet, gleich .

0,640616 p. m.

b) $544,4 \mathrm{Grm}$ Mineralwasser, mit destillirtem Wasser versetzt, wogen nach dem Kochen und Erkalten 1094,9 Grm.; $1087,5 \mathrm{Grm}$. davon lieferten $(, 3498 \mathrm{Grm}$. kohlensauren Kalk und kohlensauren Strontian, entsprechend . . . 0,646951 p.m.

$$
\text { Mittel . } \overline{0,643784 \text { p. m. }}
$$

11. Bestimmung des beim Kochen des Wassers niederfallenden Kalks.

Die Gesammtmenge des Kalks und Strontians, ausgedrückt im Gewicht der kohlensauren Salze, beträgt nach (8) . . . . . . . . . 1,510101 p m.

Hiervon geht ab die beim Kochen gelöst bleibende Menge Kalk u. Strontian, ausgedrückt im Gewicht der kohlensauren Salze, nach (10) 0,643784 p. m. Rest . . . 0,866317 p. m. entsprech. Kalk 0,485138 p. m.

12. Bestimmung des beim Kochen gelöst bleibenden Kalks.

Die beim Kochen gelöst bleibende Menge Kalk und Strontian, ausgedrückt als kohlensaure Salze, beträgt nach $(10)$. . . . . . . . . 0,643784 p. m.

Hiervon geht ab die dem vorhandenen Strontian entspr. Menge kohlens. Strontians . 0,006402 , Rest . . 0,637382 p. m. entsprechend Kalk . . . . . . . . 0,356934 p. m. 
13. Bestimmung des Lithions, der Thonerde, des Mangans, der Phosphorsäure, des Baryts und Strontians.

Wassermenge: $20272 \mathrm{Grm}$.

a) Lithion: Erhalten 0,0050 Grm. basisch phosphorsaures Lithion, entsprechend Lithion. . . . . 0,000095 p. m. entsprechend Chlorlithium. . . . . . 0,000269 p. m.

b) Manganoxydul: Erhalten 0,0828 Mangansulfür, entsprechend Manganoxydul . . . . . 0,003333 p. m.

c) Thônerde: Erhalten 0,0060 Grm. phosphorsaure Thonerde, entsprechend Thonerde . . . . 0,000124 p. m. entsprechend Phosphorsäure . . . . . 0,000171 p. m.

d) Phosphorsäure: Als phosphorsaure Thonerde wurde erhalten Phosphorsäure

Pyrophosphorsaure

e) Baryt: Schwefelsaurer Baryt wurde erhalten 0,0064 Grm. entsprechend Baryt . . . . . . . 0,000207 p. m.

f) Strontian: Schwefelsaurer Strontian wurde erhalten 0,1614 Grm., entsprechend Strontian . . . 0,004491 p. m.

14. Bestimmung des Kalis, Natrons und Lithions zusammen.

a) $1658,7 \mathrm{Grm}$. Wasser lieferten $0,3826 \mathrm{Grm}$. Chloralkalien, entsprechend

b) 2392 Grm. Wasser lieferten 0,5542

Grm. Chloralkalien, entsprechend . . $\frac{0,231689,}{0,231176 \text { p. m. }}$

15. Bestimmung des Kalis.

a) $1658,7 \mathrm{Grm}$. Wasser lieferten 0,0781

Grm. Kaliumplatinchlorid, entspr. Kali . . . 0,009074 p. m.

b) $2392 \mathrm{Grm}$ Wasser lieferten 0,1022

Grm. Kaliumplatinchlorid, entspr. Kali . . . 0,008235 ,

entsprechend

Mittel . . $0,008655 \mathrm{p.} \mathrm{m}$. 
16. Bestimmung des Natrons.

Gesammtmenge der Chloralkalien nach(13) 0,231176 p. m.

Davon geht ab die dem Kali entsprechende

Menge Chlorkalium mit . . 0,013700

ferner Chlorlithium . . . . 0,000269

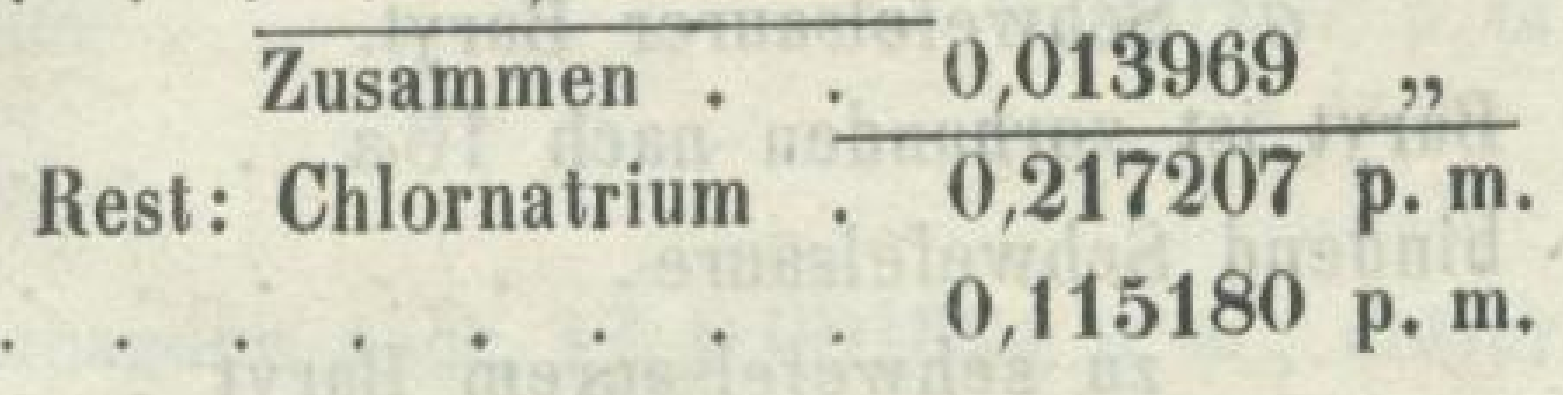

entsprechend Natron

17. Bestimmung des Ammons.

3544 Grm. Wasser lieferten 0,0188 Grm. Platin aus Ammoniumplatinchlorid, entspr. Ammoniumoxyd . . 0,001394 p. m.

18. Bestimmung der Salpetersäure.

Die aus $4405 \mathrm{Grm}$. Wasser erhaltene Menge Salpetersäure erforderte zur Reduction 0,75 Cub. Cent. einer Zinnchlorürlösung, von der 23,15 Cub. Cent. 0,1003 Grm. Eisen entsprachen. Hiernach berechnet sich Salpetersäure . . 0,000237 p.m.

19. Bestimmung des Schwefelwasserstoffs.

$660 \mathrm{Grm}$. frisch der Quelle entnommenen, mit Stärkekleister gemischten Wassers erforderten von der bei der Trinkquelle näher bezeichneten Jodlösung im Mittel mehrerer Versuche 5,7 Cub. Cent. bis zur Bläuung. Hieraus berechnet sich ein Gehalt an Schwefelwasserstoff von . . . 0,000431 p m.

Ich betrachte diese Zahl nur als eine annähernde, da sich bei so grosser Verdünnung die Endreaction nicht mit genügender Genauigkeit treffen lässt, auch in Betreff des Abzugs, den man für die gleiche Bläuung eines von Schwefelwasserstoff freien Wassers von sonst gleicher Beschaffenheit zu machen hat, eine gewisse Unsicherheit bleibt. Wenn es sich aber im Laufe der Zeit darum handelt festzustellen, ob sich der Gehalt an Schwefelwasserstoff vermindert oder vermehrt hat, wird die gemachte Angabe immerhin werthvoller sein, als wenn ich den Schwefelwasserstoff hier als nur in Spuren vorhanden angegeben hätte.

20. Bestimmung des fixen Rückstandes $296,4 \mathrm{Grm}$. Wasser 3 * 


\section{$-36-$}

hinterliessen 0,7845 Grm. gelinde geglühten fixen Rückstand, entsprechend 2,646761 p. m.

II. Berechnung der Analyse.

a) Schwefelsaurer Baryt.

Baryt ist vorhanden nach $16 \mathrm{a}$. . . . 0,000207 p. m. bindend Schwefelsäure. • • • • • 0,000108 ,

b) Schwefelsaurer Strontian

Strontian ist vorhanden nach $16 \mathrm{~b}$. . . $0,004491 \mathrm{p} . \mathrm{n}$ bindend Schwefelsäure . . . . . 0,003471 zu schwefelsaurem Strontian . . 0,007962 p. n

c) Schwefelsaurer Kalk.

Beim Kochen gelöst bleibender Kalk ist vor-

handen nach 12 . . . . . . . . 0,356934 p. m. bindend Schwefelsäure . . . . • • 0,509906 zu schwefelsaurem Kalk . . . 0,866840 p. m.

d) Schwefelsaures Kali.

Kali ist vorhanden nach $14 \ldots .+\ldots, 008655$ p. m. bindend Schwefelsäure . . . . . . . . 0,007349 zu schwefelsaurem Kali . . . $\frac{0,016004 \text { p. m. }}{0.00}$

e) Jodnatrium.

Jod ist vorhanden nach 2b . . . 0,00000104 p m. bindend Natrium . . . . . . . . 0,00000019 ,

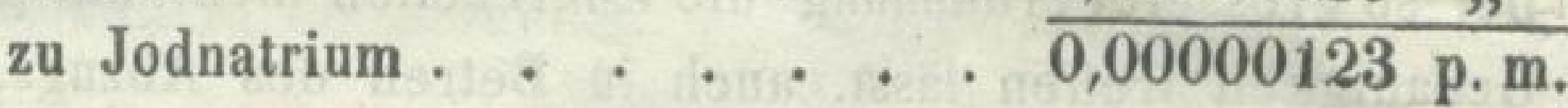

f) Bromnatrium.

Brom ist vorhanden nach $2 \mathrm{a}$. . . . 0,000060 p. m bindend Natrium. zu Bromnatrium . . . . . $0,000077 \mathrm{p} \mathrm{m}$.

g) Salpetersaures Natron.

Salpetersäure ist vorhanden nach 18 . . 0,000237 p. m. bindend Natron ...... . . . . 0,000136 zu salpetersaurem Natron:. . $\frac{0,000373 \text { p. m. }}{0,000}$ 
h) Chlorlithium.

Lithion ist vorhanden nach 12 a 0,000095 p. m. entsprechend Lithium . . . . . . . . . 0,000044 p. m. bindend Chlor zu Chlorlithium . . . . . . 0,000267 p. m.

i) Chlorammonium

Ammoniumoxyd ist vorhanden nach 170,001394 p. m, entspr. Ammonium . . . . . . . . . . 0,000965 p. m.

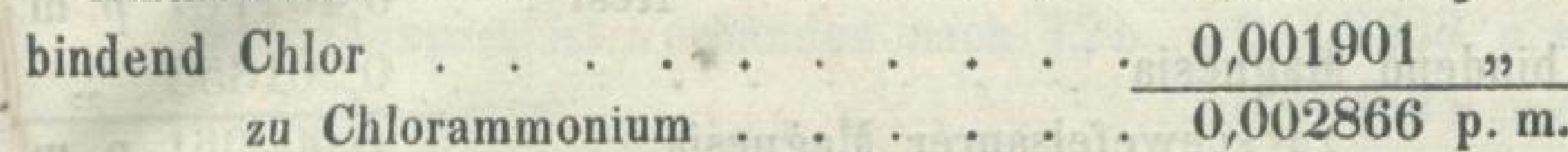

k) Chlornatrium.

Chlor ist vorhanden nach $3 . .+0,111921$ p. m. Davon ist gebunden:

an Lithium.

an Ammonium

. . 0,000223

anmonium

Zusammen
Rest .
. . .

bindend Natrium . zu Chlornatrium. $\frac{0,071216 \%}{0,181013 \text { p. m. }}$

l) Schwefelsaures Natron.

Natron ist vorhanden nach $15 . . \quad 0,115180$ p. m.

Davon ist gebunden an:

Jod. . . . . . 0,00000026

Brom . . . . . 0,00002300

Salpetersäure . . . 0,00013600

Chlor . . . . . 0,09598700

$$
\text { Zusammen } \cdot \text { Rest . } \frac{0,096146,0}{0,019034 \text { p. m. }}
$$

bindend Schwefelsäure.

zu schwefelsaurem Natron. * $\frac{0,024560 \%}{0,043594 \text { p. m. }}$

m) Schwefelsaure Magnesia.

Schwefelsäure ist vorhanden nach 4 . 0,948101 p. m. 
0,948101 p. m.

Davon ist gebunden an:

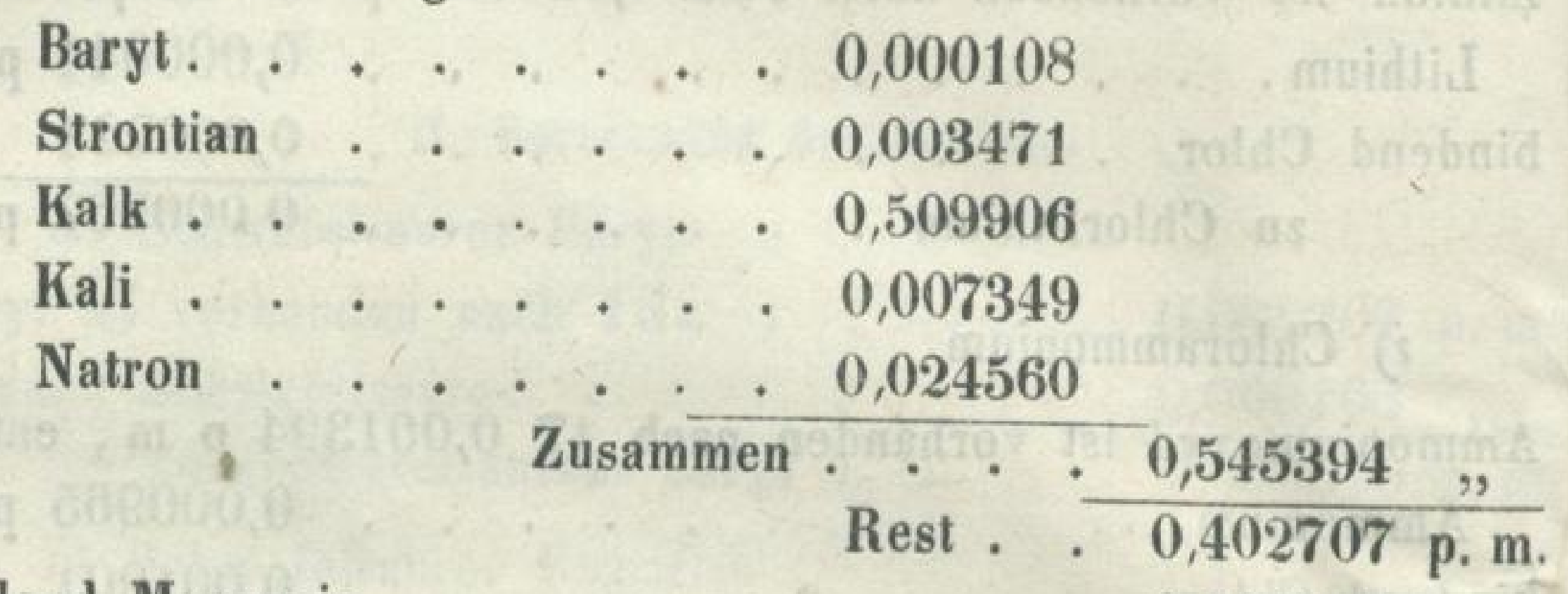

bindend Magnesia

zu schwefelsaurer Magnesia $\cdot \frac{0,604061 \text { p. m. }}{0,0,604}$

n) Phosphorsaure Thonerde.

Thonerde ist vorhanden nach $12 \mathrm{c} . .0,000124$ p. $\mathrm{m}$. bindend Phosphorsäure. . . . . . . 0,000171,

zu phosphorsaurer Thonerde . . 0,000295 p. m.

o) Basisch phosphorsaurer Kalk.

Phosphorsäure ist vorhanden nach $13 \mathrm{~d} .0,000345$ p. m. (ai) Davon ist gebunden an Thonerde . . 0,000171 ,

bindend Kalk . Rest . 0,000174 p.m.

zu basisch-phosphorsaurem Kalk. 0,000380 p. m.

p) Kohlensaurer Kalk.

Beim Kochen niederfallender Kalk ist vor-

handen nach 11 . . . . . . 0,485138 p. m.

Davon ist gebunden an Phosphorsäure . 0,000206 ,,

bindend Kohlensäure Rest . 0,484932 p. m.

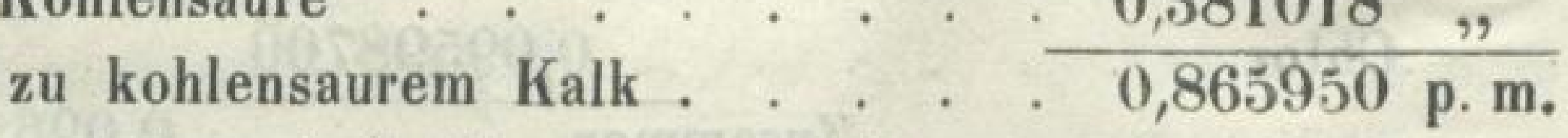
entsprechend doppelt kohlensaurem Kalk . 1,246968 p m.

q) Kohlensaure Magnesia.

Magnesia ist vorhanden naeh $9.0,205323$ p. m.

Davon ist gebunden an Schwefelsäure $\quad 0,201353$ p. m

$$
\text { bindend Kohlensäure } \cdot \frac{0,003970 \text { p. m. }}{0,004367 \text { p. m. }}
$$




\section{$-39-$}

zu kohlensaurer Magnesia. . . . . . 0,008337 p. m. entspr. doppelt kohlensaurer Magnesia. . . 0,012704 p. m.

$r$ ) Kohlensaures Eisenoxydul.

Eisenoxydul ist vorhanden nach 7 , 0,033471 p. m. bindend Kohlensäure . . . . . . . 0,020455 p. m. zu kohlensaurem Eisenoxydul . . . 0,053926 p. m. entspr. doppelt kohlensaurem Eisenoxydul - 0,074381 p. m.

$s$ ) Kohlensaures Manganoxydul.

Manganoxydul ist vorhanden nach $12 \mathrm{~b} .0,003333$ p. m. bindend Kohlensäure . . . . . . . 0,002065 p. m. zu kohlensaurem Manganoxydul . . . . 0,005398 p. m. entspr. doppelt kohlensaurem Manganoxydul . 0,007463 p. m.

t) Kieselsäure.

Kieselsäure ist vorhanden nach 6 . 0,035787 p. m.

u) Freie Kohlensäure.

Die Gesammtmenge der Kohlensäure beträgt nach $5 \mathrm{~b}$

3,300888 p. m.

Davon ist gebunden zu neutralen Salzen an:

$$
\begin{aligned}
& \text { Kalk . . . . . 0,381018 } \\
& \text { Magnesia . . . } 0,004367 \\
& \text { Eisenoxydul . . } 0,020455 \\
& \text { Manganoxydul } \quad \text {. } 0,002065 \\
& \begin{array}{r}
\text { Zusammen } \\
\text { Rest }
\end{array} \cdot \frac{0,407905 \text { p. m. }}{2,892983 \text { p. m. }}
\end{aligned}
$$

Davon ist mit einfach kohlensauren Salzen zu Bicarbonaten verbunden $\cdot \cdot \cdot \cdot \cdot \frac{0,407905 \text { p. m. }}{2,485078 ~ p . ~ m}$.
Rest, völlig freie Kohlensäure

v) Vergleichung des fixen Rückstandes mit der Gesammtmenge der einzelnen Bestandtheile, aufgeführt in den Zuständen, in welche sie beim gelinden Glühen übergehen.

Schwefelsaurer Baryt . 0,000315 p. m.

Schwefelsaurer Strontian $\frac{0,007962,}{0,008277 \text { p. m. }}$ 


\section{$-40-$}

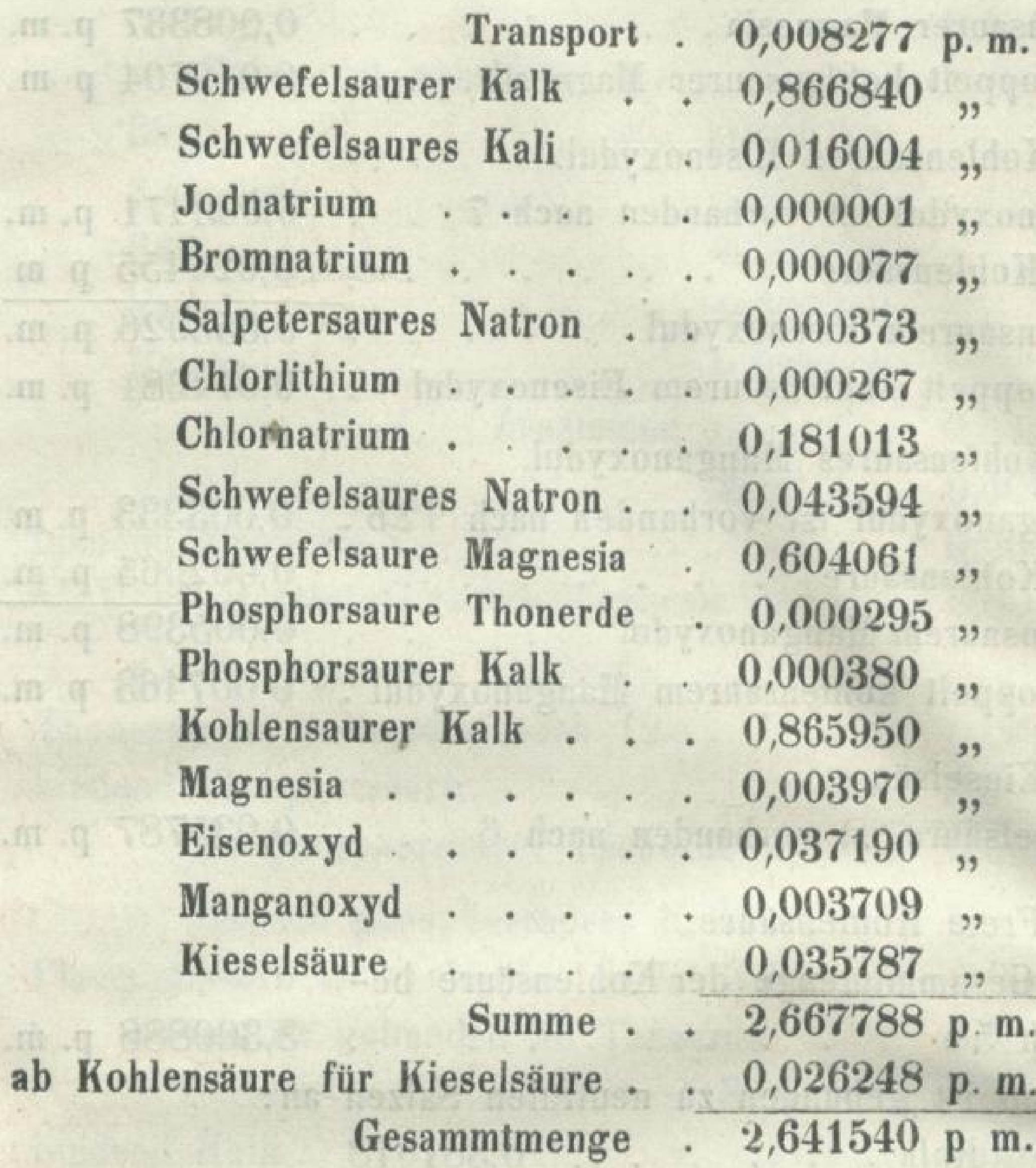

Gewogener, schwach geglühter Rückstand . . . . . . . . . 2,646761 p. m.

\section{Zusammenstellung der Resultate.}

In der Pyrmonter Badequelle sind folgende Bestandtheile enthalten :

a) Die kohlensauren Salze auf einfache Carbonate berechnet:

a) In wägbarer Menge vorhandene Bestandtheile:

$$
\text { In } 1000 \text { Theilen }
$$

Im Pfund $=$ 7680 Gran

Schwefelsaurer Baryt. 0,002419

,

Strontian 0,007962 0,061148 


\section{In 1000 Theilen Im Pfund =}

Transport • $0,008277 \quad 0,063567$

Schwefelsaurer Kalk . . . . $0,866840 \quad 6,657331$

Schwefelsaures Kali . . . . . $0,016004 \quad 0,122911$

Jodnatrium . . . . . . . 0,000001 0,000008

Bromnatrium . . . . . . $0,000077 \quad 0,000591$

Salpetersaures Natron . . . 0,000373 0,002865

Chlorlithium . . . . . . 0,000267 0,002051

Chlorammonium . . . . . $0,002866 \quad 0,022011$

Chlornatrium . . . . . . . 0,181013 1,390180

Schwefelsaures Natron . . . . $0,043594 \quad 0,334802$

Schwefelsaure Magnesia . . . . 0,604061 4,639188

Phosphorsaure Thonerde. . . . 0,000295 0,002266

Phosphorsaurer Kalk . . . . 0,000380 0,002918

Kohlensaurer Kalk . . . . . $0,865950 \quad \mathbf{6 , 6 5 0 4 9 6}$

Kohlensaure Magnesia _ . . . $0,008337 \quad 0,064028$

Kohlensaures Eisenoxydul . . $0,053926 \quad 0,414152$

Kohlensaures Manganoxydul . . 0,005398 0,041457

Kieselsäure . . . • • . . 0,035787 0,274844

$$
\text { Summe } \quad 2,693446 \quad 20,685666
$$

Kohlensäure, mit einfach kohlensauren Salzen zu Bicarbonaten ver-

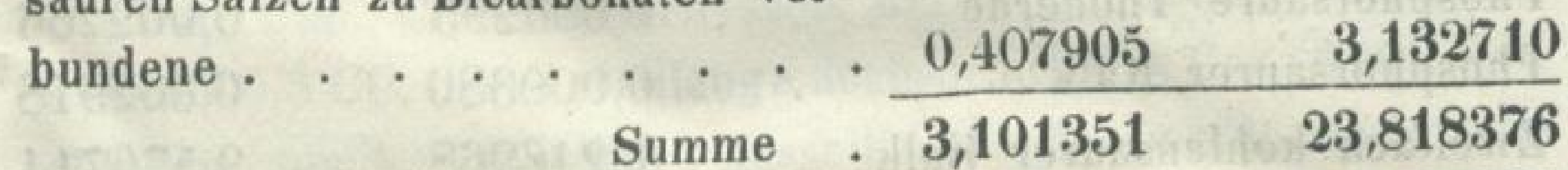

Kohlensäure, völlig freie • • $2,485078 \quad 19,085399$

Freier Schwefelwasserstoff ... . Spur Spur

Summe aller Bestandtheile $.5,586429 \quad 42,903775$

$\beta)$ In unwägbarer Menge vorhandene Bestandtheile:

Borsäure, Spur.

Organische Substanzen, geringe Spuren

Stickgas, geringe Menge.

Leichtes Kohlenwasserstoffgas, höchst geringe Menge.

Bleioxyd, \& Nur im Ocker nachweisbar. 
Antimonoxyd, Arsensäure, Kobaltoxydul, Nickeloxydul, Nur im Ocker nachweisbar.

Zinkoxyd, Titansäure,

b) Die kohlensauren Salze als Bicarbonate berechnet.

$\alpha)$ In wägbarer Menge vorhandene Bestandtheile:

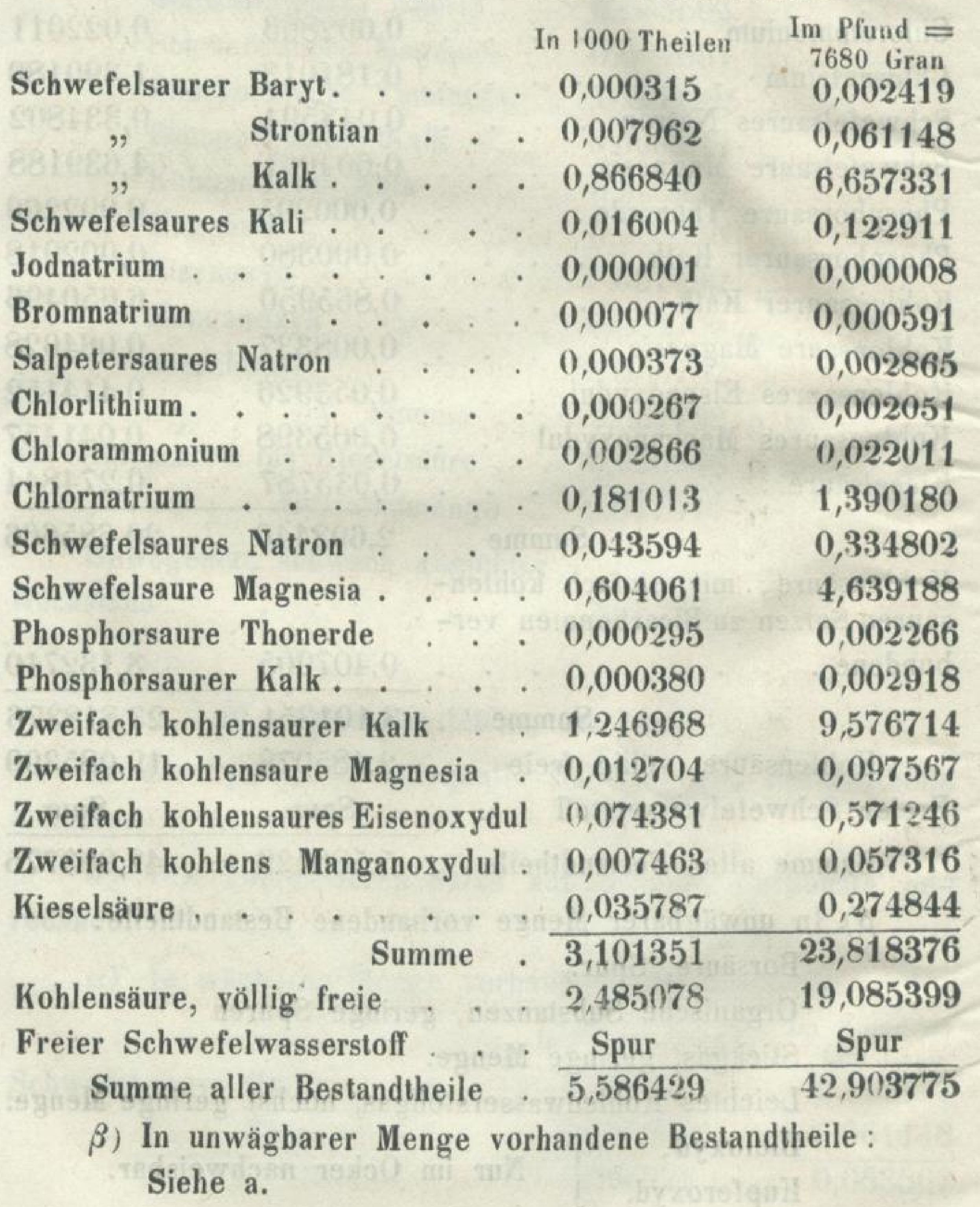


Auf Volumina berechnet beträgt bei Quellentemperatur und Normalbarometerstand:

a) Die völlig freie Kohlensäure :

In 1000 Cub. Cent. Wasser 1323,72 Cub. Cent. Im Pfund $=32$ Cub. Zoll 42,36 Cub. Zoll.

b) Díe freie und halbgebundene Kohlensäure :

In 1000 Cub. Cent. Wasser 1541,00 Cub. Cent. Im Pfund $=32$ Cub. Zoll 49,31 Cub. Zoll.

IV. Analyse des Gases, welches aus der Pyrmonter Badequelle frei ausströmt.

Das der Pyrmonter Badequelle in so ungeheurer Menge frei entströmende Gas ist - wie schon oben erwähnt - fast reine Kohlensäure. Um es gut untersuchen zu können, befestigte ich einen mit Blei stark beschwerten Zinktrichter in dem Quellenbassin über der oberen Oeffnung des aus der Brunnenkammer kommenden Rohres, und leitete das sich unter dem Trichter ansammelnde Gas längere Zeit durch einen Kautschukschlauch, an dessen Ende eine gekrümmte, unter Wasser tauchende Glassöhre befestigt war. Nachdem alle atmosphärische Luft ausgetrieben war, konnte man das aus der Glasröhre austretende Gas beliebig auffangen und verwenden.

$140 \mathrm{Cub}$. Cent. hinterliessen bei wiederholten Versuchen im Mittel 0,5 CC. durch Kalilauge unabsorbirbares Gas, 1000 Vol. enthalten somit $3,55 \mathrm{Vol}$ desselben. Es wurde nun eine grössere Menge dieses Gases durch langsames Auffangen über Kalilauge gesammelt. Nachdem das in zugeschmolzenen Glasröhren nach Wiesbaden transportirte Gas nochmals mit starker Kalilauge andauernd in Berührung gewesen war, betrug seine Menge 24,62 Cub Cent. bei 210. Cels. Als dieses Gas nach der bei der Trinkquelle beschriebenen Methode analysirt wurde, wurden unter Anwendung aller nöthigen Vorsicht 0,0004 Grm. Kohlensäure erhalten, entsprechend 0,2197 Cub. Cent. leichten Kohlenwasserstoffs bei $21^{\circ}$ Cels, Somit besteht das der Quelle frei entströmende Gas in 1000 Raumtheilen aus: 
996,430 Vol. Kohlensäure,

3,538 Vol. Stickgas,

0,032 Vol. leichten Kohlenwasserstoffs.

V. Analyse des Ockers, der sich aus der Pyrmonter Badequelle bei Lufteinwirkung abscheidet.

Bei meiner Anwesenheit in Pyrmont am 19. März 1864 liess ich das kupferne Sieb herausnehmen, welches in das Quellenbassin eingehängt ist; dasselbe schützt wie erwähnt die Mündung des Rohres durch welches Wasser und Gas aus der Brunnenkammer aufsteigen. Es war mit einer grossen Menge schlammigen braunrothen 0ckkers bedeckt. Derselbe wurde vorsichtig abgeschabt, mit destillirtem Wasser zur Entfernung des anhaftenden Mineralwassers ausgewaschen, bei $100^{\circ}$ Cels. getrocknet und das gleichmässig gemengte Pulver der Analyse unterworfen.

Es stellte sich dabei heraus, dass der untersuchte Ocker nur zu etwa $1 / 5$ wirklich aus dem Mineralwasser abgeschiedener Ocker war, die übrigen $4 / 5$ waren Thon und Sand, welche von aussen (als Staub etc.) in das Quellenbassin gelangt waren und sich dem Ocker beigemengt hatten.

Die Analyse ergab in 1000 Theilen des bei $100^{\circ}$ Cels. getrockneten Ockers:

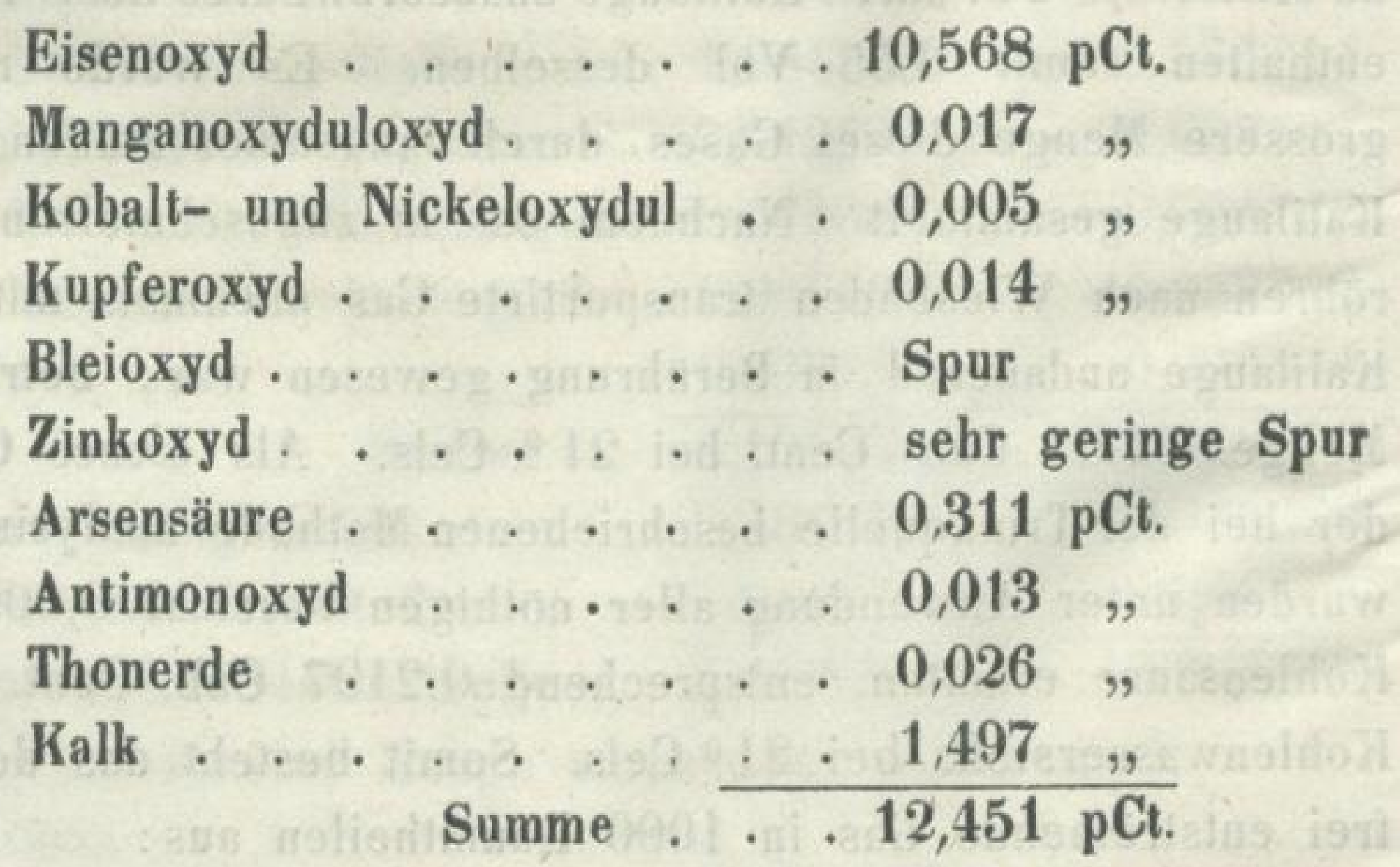




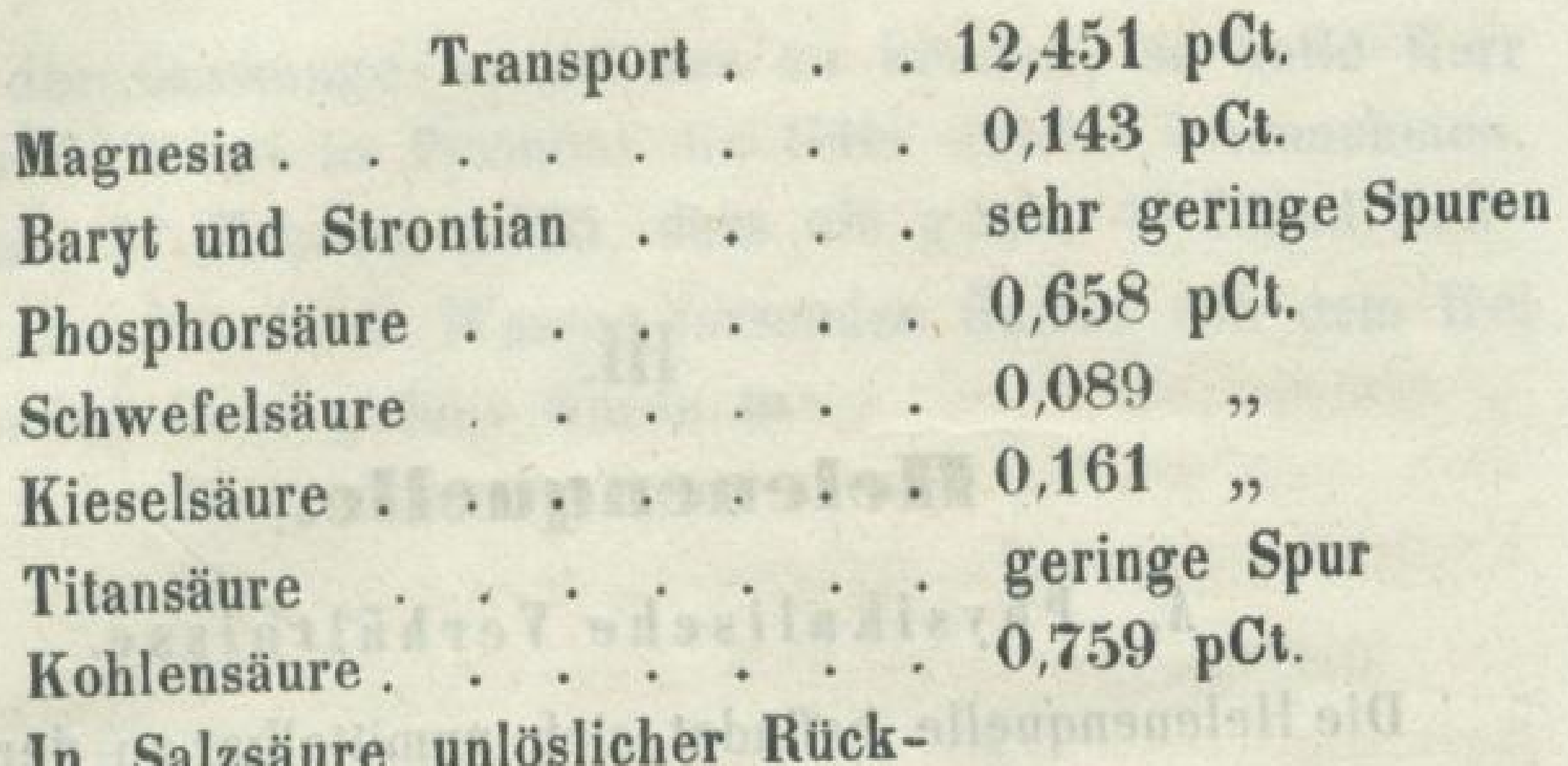

stand (Thon und Sand) wasserfrei 81,150 ,"

Wasser, nebst geringen Mengen

organischer Materien . . $\frac{4,637, "}{100,048 \mathrm{pCt} \text {. }}$

Bei dem Umstande, dass der analysirte Ocker sich auf einem kupfernen Siebe abgesetzt hatte, bleibt es unentschieden, ob das gefundene Kupferoxyd, oder ein wie grosser Theil desselben, aus dem Wasser der Quelle stammt. 
III.

\section{Telemenquelle.}

\section{A. Physikalische Verhältuisse.}

Die Hêlenenquelle befindet sich unmittelbar an der Klosterallee, 175 Meter westlich vom Brodelbrunnen. Sie kommt in einem runden, konisch vertieften Sandsteinbecken aus einer runden Oeffnung von etwa 44 Centimeter Durchmesser zu Tage. Das Sandsteinbecken hat am Wasserspiegel einen Durchmesser von 1,02 Meter.

Das Wasser in dem Quellenbassin erscheint vollkommen klar; wo es die Beckenwandung berührt, bildet sich allmählich ein starker Ockerrand. Unter dem Ockerrande fand ich einen weisslichen, fest an der Wandung anhaftenden Absatz von Thon, der sich wohl - da er zu den im Wasser der Quelle gelösten Bestandtheilen in keiner Beziehung steht - später nicht mehr erneuern wird Das Wasser im Quellenbassin ist in sehr starker wallender Bewegung durch reichliche grosse Gasblasen, welche der Quelle unausgesetzt entströmen.

Auch im Glase und in grossen Flaschen erscheint das Wasser, wenn man mit einiger Vorsicht füllt, vollkommen klar, an den Wänden setzen sich reichliche Gasperlen an.

Aus den Messungen des Herrn Baumeister Günthe r zu Pyrmont ergibt sich, dass die Helenenquelle in einer Minute 3 hannoversche Kubikfuss, das ist fast 75 Litre Wasser, liefert, somit:

in einer Stunde . 4500 Litre,

in 24 Stunden . 108000 Litre.

Die Menge des der Quelle frei entströmenden Gases ist bedeutend. Da bei meiner Anwesenheit in Pyrmont die Vorbereitungen noch nicht getroffen waren, um eine genaue 
Messung der Gasmenge vornehmen zu können, so hatte Herr Medicinalrath Hugi in Pyrmont die Güte solche vorzunehmen. Er fand am 27. Februar 1865, dass ein genau 17 Pfund Zollgewicht, also 8,5 Liter Wasser fassendes Gefäss von dem frei ausströmenden Gase gefüllt wurde in

30

in 28

in 32

in 32

in 33

und in 32 ,

demnach im Mittel in 31,17 Secunden.

Somit liefert die Quelle in einer Minute 16,36 Litre, also

981,60 Litre in einer Stunde, $23558,40, \quad$ in 24 Stunden.

Das Verhältniss zwischen dem in gleichen Zeiten von der Quelle gelieferten Wasser und freien Gase ist somit wie:

4500 Wasser zu 982 Gas, oder wie

100, zu 21,8 Gas.

Der Geschmack des Wassers ist sehr angenehm, prickelnd säuerlich, mässig eisenartig, nicht nach Schwefelwasserstoff. Einen Geruch zeigt das Wasser, wenn man es im Glase prüft, kaum. Beim Schütteln des Wassers in halbgefülter Flasche wird viel Gas entbunden. Dasselbe riecht kaum merklich nach Schwefelwasserstoff.

Die Temperatur der Quelle fand ich am 22. Novbr. 1864 bei $6^{\circ} \mathrm{C}$ oder $4,8^{\circ} \mathrm{R}$. der Luft gleich $12,7^{\circ} \mathrm{C}$. oder $10,16^{\circ} \mathrm{R}$. Das specifische Gewicht ergab sich, nach der bei der Trinkquelle angeführten Methode bestimmt, gleich 1,00374 bei $18^{\circ} \mathrm{C}$.

\section{B. Chemische Verhältnisse.}

Beim Stehen an der Luft zeigt das Wasser der Helenenquelle im Wesentlichen dieselben Erscheinungen, welehe bei dem Wasser der Trinkquelle beschrieben worden sind. Bleibt das 
Wasser längere Zeit in etwas Luft enthaltenden Flaschen stehen, so setzt sich auf deren Boden ein ockergelber Niederschlag ab. Beim Kochen und zu den wichtigsten Reagentien verhält sich das Wasser der Helenenquelle wie das der Trinkquelle und des Brodelbrunnens, mit Ausnahme des Umstandes, dass sich in der Helenenquelle Schwefelwasserstoff mittelst Kupferchlorids nicht nachweisen lässt.

Die qualitative Analyse des Wassers der Helenenquelle liess die Anwesenheit derselben Bestandtheile erkennen, welche auch in der Trinkquelle und dem Brodelbrunnen vorhanden sind. Das aus der Quelle frei ausströmende Gas erwies sich als aus Kohlensäure, Stickgas und etwas leichtem Kohlenwasserstoff bestehend.

Die quantitative Analyse wurde nach den bei der Trinkquelle angeführten Methoden in allen wesentlichen Theilen doppelt ausgeführt. Das zu derselben erforderliche Wasser entnahm ich am 22. November 1864 mit eigner Hand der Quelle und liess es in mit Glasstöpseln verschlossenen Flaschen nach Wiesbaden transportiren.

In den folgenden Abschnitten finden sich unter I. die Originalzahlen ir: Grammen, unter II. die Berechnung, unter III die Zusammenstellung der Resultate; in IV. wird die Zusammensetzung des der Quelle frei entströmenden Gases und in V. die Analyse des Ockers, welchen die Quelle im Bassin absetzt, mitgetheilt.

\section{Originalzahlen in Grammen.}

1. Bestimmung des Chlor-, Brom- und Jodsilbers zusammen.

a) $500 \mathrm{Grm}$ Wasser lieferten 0,2198 Grm. Chlor-, Bromund Jodsilber, entsprechend . . . . . 0,439600 p.m.

b) $500 \mathrm{Grm}$. Wasser lieferten 0,2195

Grm Chlor-, Brom- und Jodsilber, entspr. + 0,439000 "

Mittel. 0,439300 p. m. 
2. Bestimmung des Broms.

$54319 \mathrm{Grm}$. Wasser lieferten 1,2793 Grm. eines alles Brom enthaltenden Chlorsilbers. 0,7252 Grm. hiervon nahmen im Chlorstrom um 0,0006 Grm. ab. Hieraus berechnet sich der Gehalt des Wassers an Brom zu . . 0,000035 p. m.

3. Bestimmung des Chlors.

Die Menge des Chlor-, Brom- und Jodsilbers beträgt nach 1 . . . . . . 0,439300 p. m.

Davon geht ab die dem Brom entsprech. Menge Bromsilber mit . . . . . . . . 0,000082 p. m.

Rest: Chlorsilber 0,439218 p. m. entsprechend Chlor . 0,108587 p. m.

Ein Gehalt an Jod liess sich im Rückstand der 54319 Grm. Wasser zwar eben noch nachweisen aber nicht quantitativ bestimmen.

4. Bestimmung der Schwefelsäure.

a) $500 \mathrm{Grm}$. Wasser lieferten $1,3603 \mathrm{Grm}$. schwefelsauren Baryt, entspr. Schwefelsäure. . . . . 0,934112 p. m.

b) $500 \mathrm{Grm}$. Wasser liefert. 1,3598 Grm.

schwefelsauren Baryt, entsp. Schwefelsäure . 0,933768 p. m. Mittel . 0 0,933940 p. m.

5. Bestimmung der Kohlensäure.

a) 220,770 Grm. Wasser lieferten 0,6914 Grm. Kohlensäure, entsprechend . . . . . . $3,131966 \mathrm{p.} \mathrm{m}$.

b) $221,547 \mathrm{Grm}$. Wasser liefert. ferner 0,6950 Grm. Kohlensäure, entspr. . , . 3,137032 p. m. Mittel 3,134399 p. m

6. Bestimmung der Kieselsäure.

a) 2403,7 Grm. Wasser lieferten 0,0747 Grm. Kieselsäure, entsprechend . . . . . . 0,031077 p. m.

b) $2381,8 \mathrm{Grm}$. Wasser lieferten ferner 0,0738 Grm Kieselsäure, entspr. . . . . 0,030985 p. m. Mittel . 0,031031 p. m. 


\section{$-50-$}

7. Bestimmung des Eisenoxyduls.

a) $2403,7 \mathrm{Grm}$. Wasser lieferten 0,0441 Grm. Eisenoxyd, entsprechend Eisenoxydul . . . . . . 0,016512 p. m.

b) $2381,8 \mathrm{Grm}$. Wasser lieferten 0,0436

Grm. Eisenoxyd, entspr. Eisenoxydul . . . 0,016475 p. m. Mittel 0,016494 p. m.

8. Bestimmung des Kalks und Strontians im Ganzen.

a) 2403,7 Grm. Wasser lieferten 3,4173 Grm. kohlensauren Kalk mit etwas kohlensaurem Strontian, entsprechend . . . . . . . . . 1,421683 p. m.

b) $2381,8 \mathrm{Grm}$. Wasser lieferten ferner 3,3850 Grm. kohlensauren Kalk mit etwas kohlensaurem Strontian, entsprechend . . 1,421194 p. m. Mittel . 1,421439 p. m.

9. Bestimmung der Magnesia.

a) 2403,7 Grm. Wasser lieferten 1,2510 Grm. pyrophosphorsaure Magnesia, entspr. Magnesia - 0,187544 p. m.

b) $2381,8 \mathrm{Grm}$. Wasser liefert. 1,2425 Grm. pyrophosphorsaure Maguesia, entsprech.

Magnesia . . . . . . . . . . 0,187988 p. m. Mittel . 0,187766 p. m.

10. Bestimmung des beim Kochen des Wassers gelöst bleibenden Kalks und Strontians.

a) 501,274 Grm. Mineralwasser, mit etwa dem gleichen Volum destillirten Wassers versetzt, wogen nach dem Kochen und Erkalten 886,0 Grm. - 879,6 Grm. hiervon lieferten 0,3589 Grm. kohlensauren Kalk nebst etwas kohlensaurem Strontian, entsprechend . . . . . . 0,721181 p. m.

b) $504,400 \mathrm{Grm}$. Mineralwasser wie in a behandelt wogen nach dem Kochen und Erkalten 851,9 Grm. - 844,0 Grm. hiervon lieferten 0,3634 Grm. kohlensauren Kalk nebst etwas hohlensaurem Strontian, entspr. . 0,727201 p. m. Mittel 0,724191 p. m. 
11. Bestimmung des beim Kochen des verdünnten Wassers niederfallenden Kalks:

Die Gesammtmenge des Kalks und Strontians beträgt, ausgedrückt im Gewichte der einfach kohlensauren Salze, nach 8 . . . . . . . 1,421439 p m.

Hiervon geht ab die beim Kochen gelöst bleibende Menge Kalk und Strontian, welche in gleicher Art ausgedrïckt nach 10 beträgt 0,724191 p. m.

$$
\begin{aligned}
& \text { Rest . 0,697248 p. m. } \\
& \text { entsprechend Kalk . . . . 0,390459 p. m. }
\end{aligned}
$$

12. Bestimmung des beim Kochen gelöst bleibenden Kalks.

Die beim Kochen des verdünnten Wassers gelöst bleibende Menge Kalk und Strontian beträgt, ausgedrückt im Gewichte der einfach kohlensauren Salze, nach 10. 0,724191 p.m.

Hiervon geht ab die Menge des Strontians, ausgedrückt als kohlensaurer Strontian, nach (13e).

$$
\begin{array}{llll} 
& \text { Rest . } & 0,720705 \text { p m. } \\
\text { entsprechend Kalk } \quad . \quad . \quad & 0,403595 \text { p. m. }
\end{array}
$$

13. Bestimmung des Strontians, des Lithions, der Thonerde, des Mangans und der Phosphorsäure.

Von $19667 \mathrm{Grm}$. Wasser wurden nach der bei, der Trinkquelle angegebenen Methode erhalten :

a) 0,0128 Grm. basisch phosphorsaures Lithion, entspr. Lithion.

$$
0,000252 \text { p. m. }
$$

b) $0,0372 \mathrm{Grm}$. Mangansulfür $\mathrm{r}$, entspr. Manganoxydul 0,001544 p. m.

c) $0,0018 \mathrm{Grm}$. phorphorsaure Thonerde, entspr. Thonerde . . . . . . 0,000038 p.m. entsprechend Phosphorsäure . . . . . $0,000053 \mathrm{p} \mathrm{m}$.

d) 0,0030 Grm pyrophosphorsaure Magnesia, entsprechend Phosphorsäure . . . 0,000097 p. m. liefert Gesammtphosphorsäure $\quad 0,000150$ p.m. 
e) 0,0853 Grm. schwefelsaurer Strontian, entsprechend Strontian. . . * 0,002446 p. m. oder kohlensaurem Strontian . 0,003486 p. m.

14. Bestimmung des Kalis, Natrons und Lithions zusammen.

a) $2403,7 \mathrm{Grm}$. Wasser lieferten 0,5262 Grm. Chlorkalium, -Natrium und -Lithium, entsp. . 0,218912 p. m. b) $2381,8 \mathrm{Grm}$. Wasser lieferten 0,5194 Grm. Chlorkalium, -Natrium und -Lithium, entsprechend . . . . . . . . . . 0,218070 p. m. Mittel 0,218491 p. m.

15. Bestimmung des Kalis.

a) 2403,7 Grm. Wasser lieferten 0,1041 Grm. Kaliumplatinchlorid, entsprechend Kali . . . . 0,008362 p. m.

b) $2381,8 \mathrm{Grm}$. Wasser lieferten 0,1008

Grm. Kaliumplatinchlorid, entspr. Kali . . 0,008187 p. m.

Mittel $\overline{0,008275 \text { p. m. }}$

16. Bestimmung des Natrons.

Die Gesammtmenge der Chloralkalimetalle beträgt nach 14 . . . . . . . 0,218491 p. m. Davon geht ab die dem Kali entsprech. Menge Chlorkalium mit . . 0,013098

- Ferner das dem Lithion entsprechende Chlorlithium mit $\cdot 0,000713$

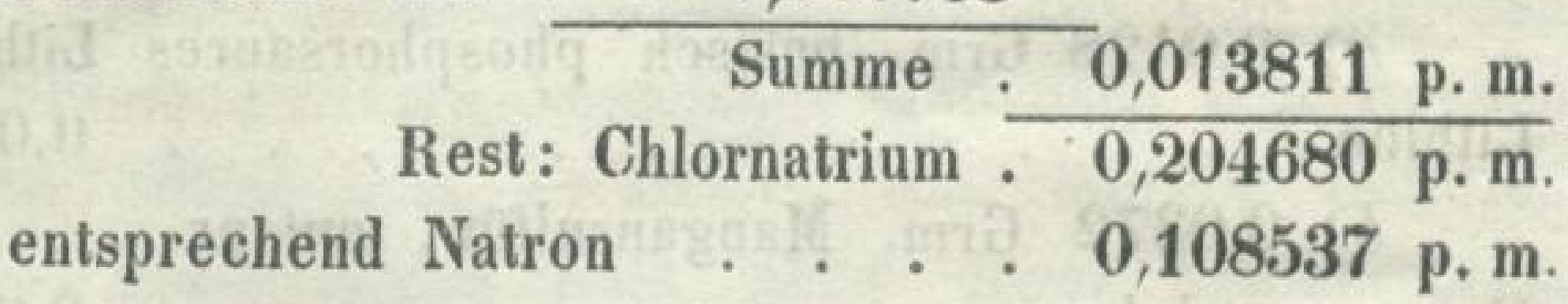

17. Bestimmung des Ammons.

$3000 \mathrm{Grm}$. Wasser lieferten $0,0187 \mathrm{Grm}$. Platin aus Ammoniumplatinchlorid, entsprech. Ammoniumoxyd . . . . . . . . 0,001633 p. m.

18. Bestimmung der Salpetersäure.

Die aus $3000 \mathrm{Grm}$. Wasser erhaltene Menge Salpetersäure erforderte zur Reduction 9,04 CC. einer Zinnchlorür- 
lösung, von der 10,89 CC. 0,00137 Grm. Salpetersäure entsprachen. Hiernach berechnet sich die Menge der Salpetersäure $\mathrm{zu}$. . . . . . . . . . . 0,000380 p. m.

19. Bestimmung des fixen Rückstandes.

258,45 Grm. Wasser lieferten 0,6339

Grm. schwach geglühten fixen Rückstand, entsprechend . . . . . . . . 2 2452738 p. m.

\section{Berechnung der Analyse.}

a) Schwefelsaurer Strontian.

Strontian ist vorhanden nach $13 \mathrm{e}$. . . $0,002446 \mathrm{p} . \mathrm{m}$. bindend Schwefelsäure. . . . . . 0,001891 p. m. zu schwefelsaurem Strontian . 0,004337 p. m.

b) Schwefelsaurer Kalk.

Beim Kochen des verdünnten Wassers gelöst bleibender Kalk ist vorhanden nach $12 \ldots . . .40,403595$ p. m. bindend Schwefelsäure. . . . . . . 0,576564 p. m. zu schwefelsaurem Kalk . . 0,980159 p. m.

c) Schwefelsaures Kali.

Kali ist vorhanden nach $15 \ldots . . .00,008275$ p. m. bindend Schwefelsäure... . . . . 0,007026 p. m. zu schwefelsaurem Kali . . 0,015301 p. m.

d) Bromnatrium.

Brom ist vorhanden nach 2. . . . 0,000035 p. m. bindend Natrium. . . . . . . . 0,000014 p. m. zu Bromnatrium ... . . . 0,000049 p.m.

e) Salpetersaures Natron.

Salpetersäure ist vorhanden nach 18 . . 0,000380 p. m. bindend Natron . . . . . . . . 0,000218 p. m. zu salpetersaurem Natron . . 0,000598 p. m.

f) Chlorlithium.

Lithion ist vorhanden nach 13 a $0,000252 \mathrm{p} . \mathrm{m}$, entspr. Lithium .

bindend Chlor ...... . . 0,000595 p. m. zu Chlorlithium . . . 0,000713 p. m. 
g) Chlorammoniun.

Ammoniumoxyd ist vorhanden nach 170,001633 p. m. entsprechend Ammonium . . . . . . 0,001131 p m bindend Chlor . . . . . . . 0,002228 p. m h) Chlornatriưm. zu Chloramnoniuin . . . . 0,003359 p. m Chlor is vorhanden nach 3

Davon ist gebunden: an Lithium an Ammoniứm

0,108587 p. m

$$
\begin{aligned}
& 0,000595 \\
& \text {. } 0,002228 \\
& \text { Summe : 0,002823 p. m. } \\
& \text { Rest . 0,105764 p.m. } \\
& \text { bindend Natrium . . . . . 0,068600 p.m }
\end{aligned}
$$$$
\text { zu Chlornatrium . . . . 0,174364 p. m }
$$

i) Schwefelsaures Natron.

Natron ist vorhanden nach 16

Davon entspricht dem:

Bromnatrium . . . . . . . 0,000014

salpetersauren Natron . . . 0,000218

0,108537 p. m.
Chlornatrium .
4a94. Summe 0,092694 p. $m$.
Rest . 0,015843 p. m

bindend Schwefelsäure . . . 0,020443 p. m

zu schwefelsaurem Natron: . $\frac{0,036286 \mathrm{p} \text { m. }}{0.00}$

k) Schwefelsaure Magnesia.

Schwefelsäure ist vorhanden nach 4 . 0,933940 p. m

Davon ist gebunden an:

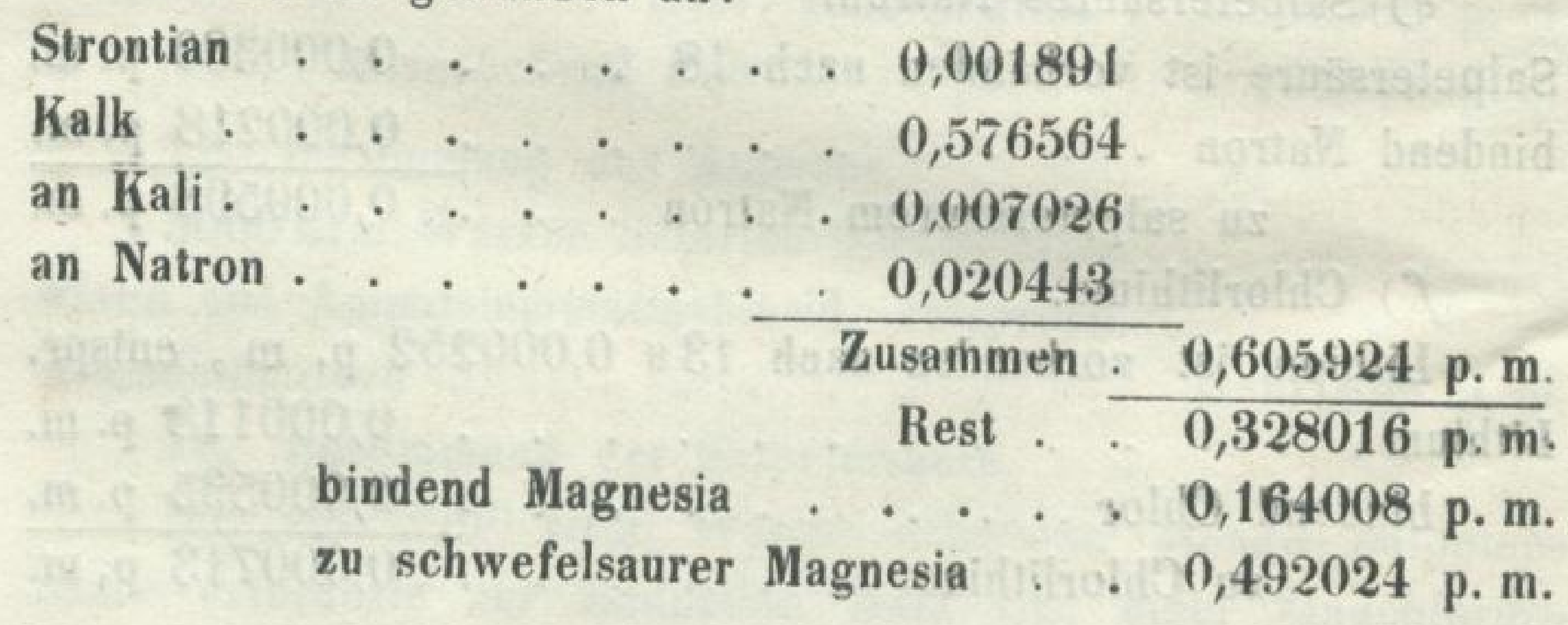


l) Phosphorsaure Thonerde.

Thonerde ist vorhanden nach $13 \mathrm{c}$. . . $0,000038 \mathrm{p} . \mathrm{m}$. bindend Phosphorsäure . . . . . 0,000053 p. m.

Zu phosphorsaurer Thonerde . 0,000091 p. m.

$m$ ) Phosphorsaurer Kalk

Phosphorsäure ist vorhanden nach $13 \mathrm{~d} . \cdot 0,000150 \mathrm{p.m}$.

Davon ist gebunden an Thonerde . . . $\frac{0,000053 \mathrm{p} . \mathrm{m}}{0,000097}$

bindend Kalk . . . . . . 0,000115 p. m.

zu 3 basisch phosphorsaurem Kalk . . . 0,000212 p. m.

n) Kohlensaurer Kalk.

Beim Kochen niederfallender Kalk ist vor-

handen nach 11 . . . . . . . . . . 0,390459 p. m.

Davon ist gebunden an Phosphorsäure . 0,000115 p. m.

Rest . 0,390344 p. m.

bindend Kohlensäure * • • 0,306699 p. m.

zu einfach kohlensaurem Kalk . . . . 0,697043 p. m. entsprechend doppelt kohlensaurem Kalk . 1,003742 p. m.

o) Kohlensaure Magnesia.

Magnesia ist vorhanden nach 9 . . . . 0,187766 p. m. Davon ist gebunden an Schwefelsäure . . 0,164008 p. m. Rest . $0,023758 \mathrm{p.} \mathrm{m}$. bindend Kohlensäure . . . 0,026133 p. m. zu einfach kohlensaurer Magnesia .. 0,049891 p. m. entsprechend doppelt kohlensaurer Magnesia . 0,076024 p. m.

p) Kohlensaures Eisenoxydul.

Eisenoxydul ist vorhanden nach 7 . . . 0,016494 p. m. bindend Kohlensäure . . . 0,010080 p. m. zu einfach kohlensaurem Eisenoxydul . . 0,026574 p. m. entspr. doppelt kohlensaurem Eisenoxydul - 0,036654 p. m.

q) Kohlensaures Manganoxydul.

Manganoxydul ist vorhanden nach $13 \mathrm{~b} .0,001544$ p. m. zu einfach kohlensaurem Manganoxydul * * * $\frac{0,000957 \text { p. m. }}{0,002501 \text { p. m. }}$ entspr doppelt kohlensaurem Manganoxydul . 0,003458 p. m. 
$r$ ) Kieselsäure.

Kieselsäure ist vorhanden nach $6 \quad . \quad 0,031031$ p. m

s) Freie Kohlensäure.

Die Gesammtmenge der Kohlensäure beträgt nach 5

3,134399 p. m.

Davon ist gebunden:

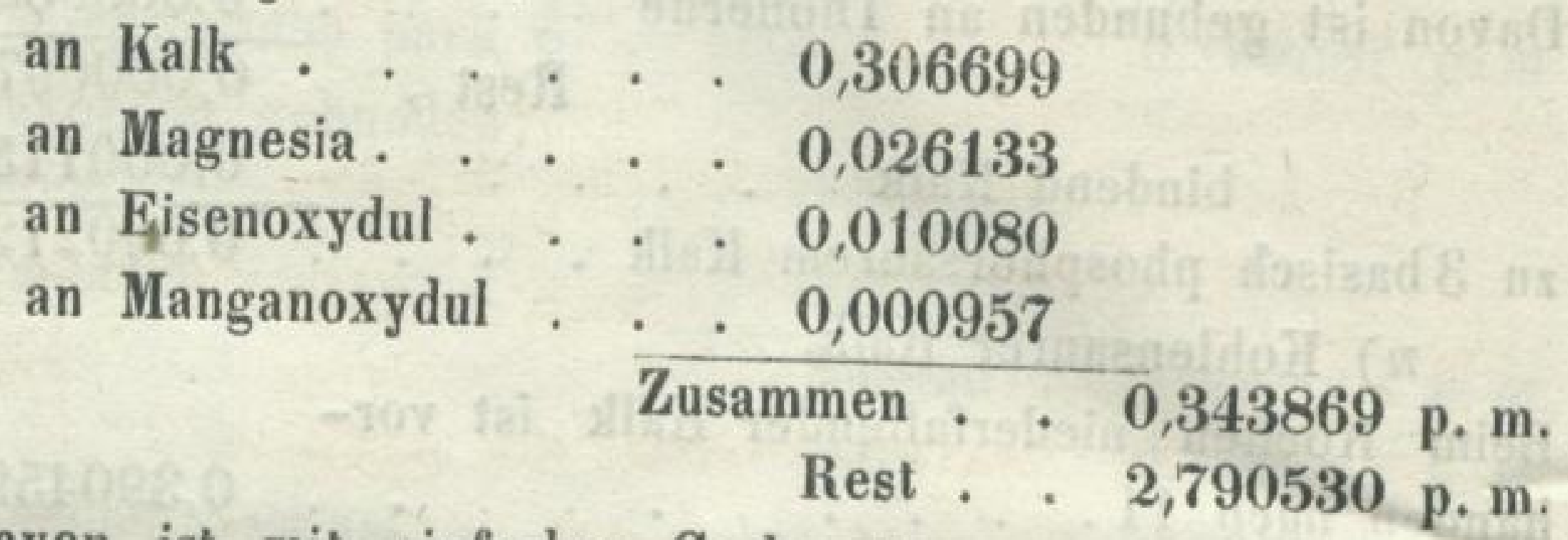

Davon ist mit einfachen Carbonaten zu

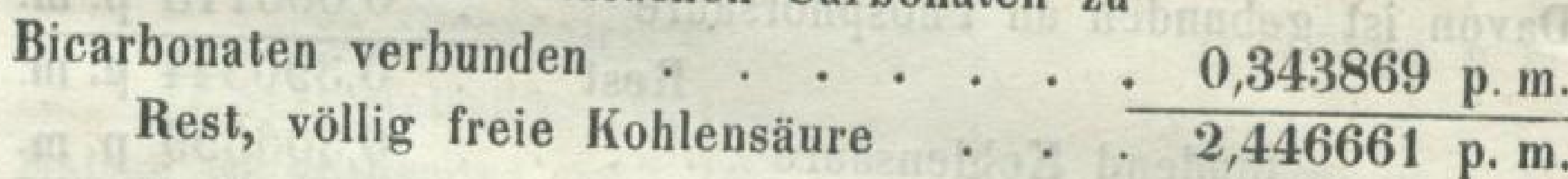

t) Controle.

Vergleichung des schwach geglühten fixen Rückstandes mit der Summe der einzeln erhaltenen Bestandtheile in dem Zustande, den sie beim schwachen Glühen annehmen :

Schwefelsaurer Strontian . . . 0,004337 p. m.

Schwefelsaurer Kalk . . . . 0, 080159 p. m.

Schwefelsaures Kali . . . . 0,015301 p. m.

Bromnatrium . . . . . 0,000049 p. m.

Salpetersaures Natron . . . 0,000598 p. m.

Chlorlithium . . . . . . 0,000713 p. m.

Chlornatrium . . . . . $0,174364 \mathrm{p} \mathrm{m}$.

Schwefelsaures Natron . . . 0,036286 p. m.

Schwefelsaure Magnesia. . . . 0,492024 p. m.

Phosphorsaure Thonerde . . . 0,000091 p. m.

3 bas. phosphorsaurer Kalk . 0,000212 p. m.

Kohlensaurer Kalk. . . . . . 0,697043 p. m.

Magnesia . . . . . . 0,023758 p. m.

Transport 2,424935 p. m. 
Transport 2,424935 p. m.

Eisenoxyd . . . . . . . 0,018327 p. m.

Manganoxyd . . . . . . 0,001718 p. m.

Kieselsäure . * . $\underset{\text { Summe }}{\cdot} \cdot \frac{0,031031 \text { p. m. }}{2,476011 \text { p. m. }}$

Davon geht ab die durch Kieselsäure ausgetriebene Kohlensäure . . . . . 0,022756 p. m. Rest . $\overline{2,453255 \text { p. m. }}$

Durch Abdampfen und schwaches Glühen wurde direct erhalten nach $19 . . .2,452738 \mathrm{p}$. m.

\section{Zusammenstellung der Resultate.}

In der Pyrmonter Helenenquelle sind folgende Bestandtheile enthalten.

a) Die kohlensauren Salze als einfache Carbonate berechnet:

a) In wägbarer Menge vorhandene Bestandtheile:

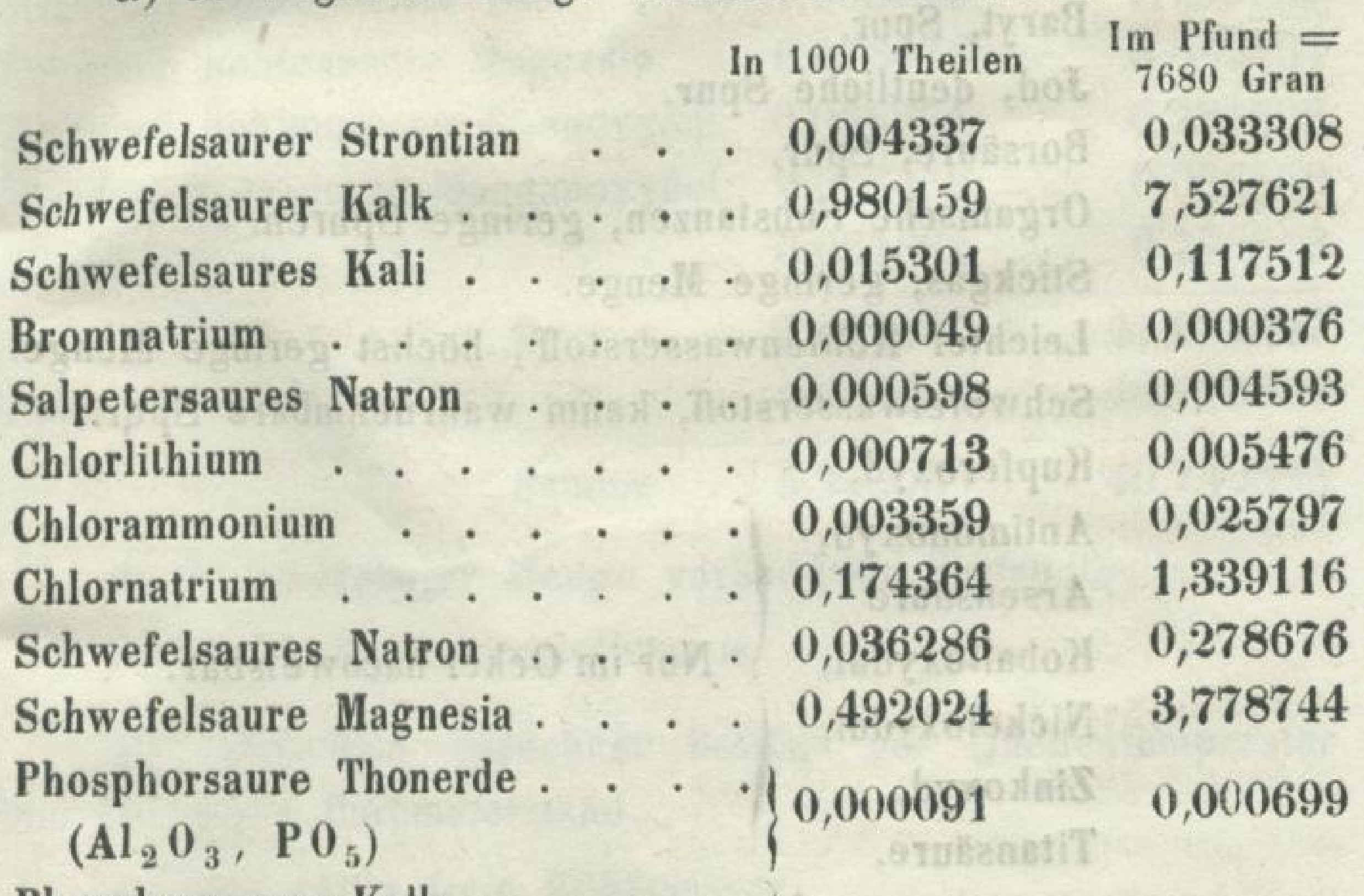

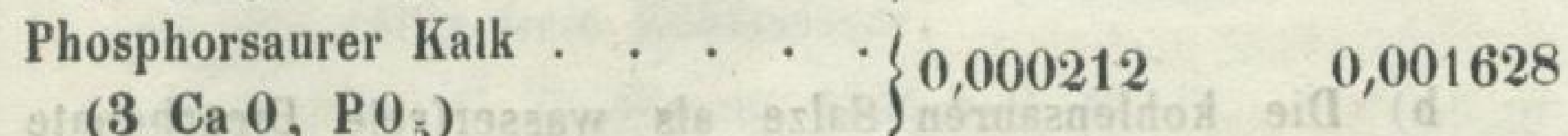

Kohlensaurer Kalk . . . . . $0,697043 \quad 5,353290$

Transport $\quad 2,404536 \quad 18,466836$ 


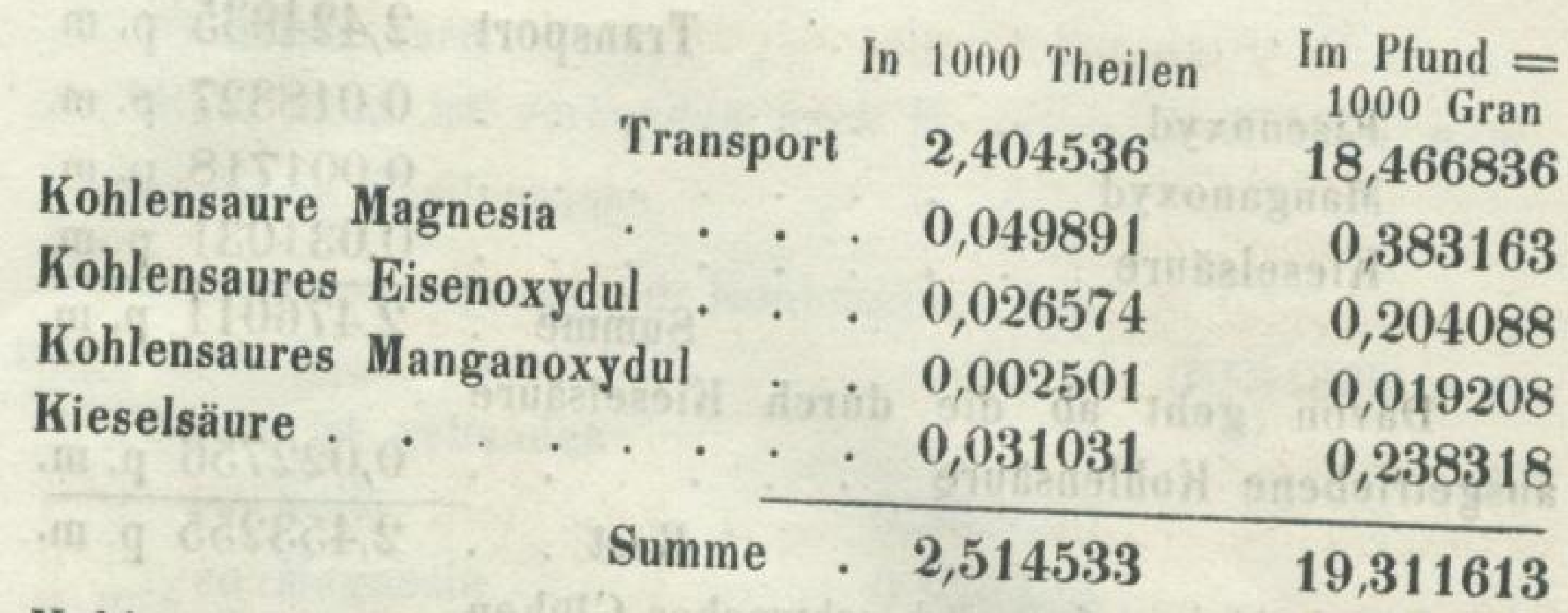

Kohlensäure mit einfachen Carbo-

naten zu Bicarbonaten verbunden 0,343869

2,640914

Summe $\quad 2,858402 \quad 21,952527$

Kohlensäure, völlig freie $\quad 2,446661 \quad 18,790356$

Summe aller Bestandtheile . $5,305063 \quad 40,742883$

$\beta$. In unwägbarer Menge vorhandene Bestandtheile:

Baryt, Spur.

Jod, deutliche Spur.

Borsäure, Spur.

Organische Substanzen, geringe Spuren.

Stickgas, geringe Menge.

Leichter Kohlenwasserstoff, höchst geringe Menge.

Schwefelwasserstoff, kaum wahrnehmbare Spur.

Kupferoxyd,

Antimonoxyd,

Arsensäure

Kobaltoxydul,

Nur im Ocker nachweisbar.

Nickeloxydul,

Zinkoxyd,

Titansäure,

b) Die kohlensauren Salze als wasserfreie Bicarbonate berechnet: 
a) In wägbarer Menge vorhandene Bestandtheile :

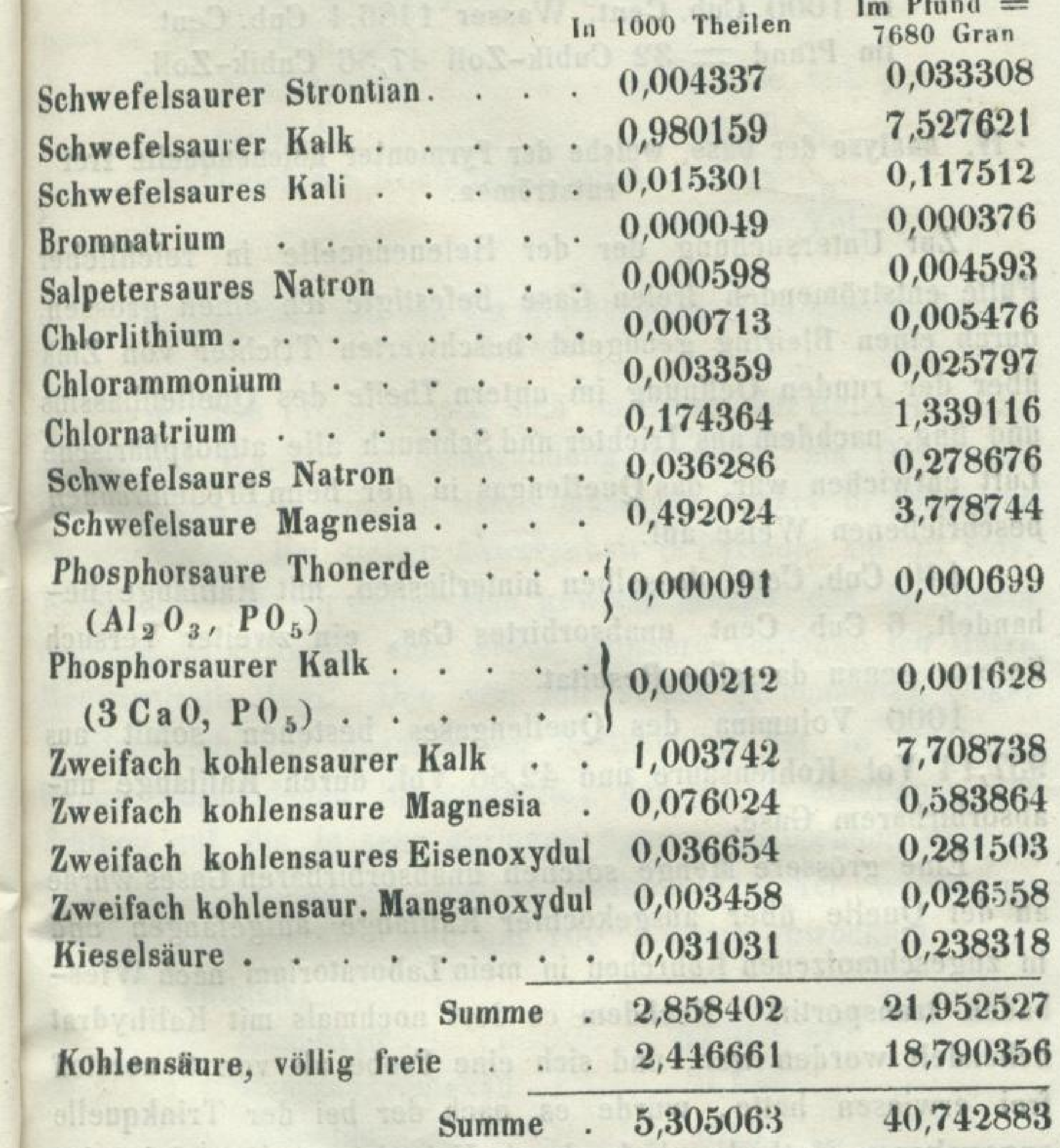

$\beta$ ) In unwägbarer Menge vorhandene Bestandtheile:

Siehe die Zusammenstellung a.

Auf Volumina berechnet beträgt bei Quellentemperatur und normalem Barometerstand:

a) Die völlig freie Kohlensäure:

In 1000 C. C Wasser 1305.5 C. C.

Im Pfund $=32$ Cubik Zoll 41,71 Cubik-Zoll. 
b): Die freie und halbgebundene Kohlensäure:

In 1000 Cub. Cent. Wasser 1486,4 Cub. Cent. Im Pfund $=32$ Cubik-Zoll 47,56 Cubik-Zoll.

IV. Analyse der Gase, welche der Pyrmonter Helenenquelle frei entströmen.

Zur Untersuchung der der Helenenquelle in reichlicher Fülle entströmenden freien Gase befestigte ich einen grossen, durch einen Bleiring genügend beschwerten Trichter von Zink über der runden Oeffnung im untern Theile des Quellenbassins und fing, nachdem aus Trichter und Schlauch alle atmosphärische Luft entwichen war, das Quellengas in der beim Brodelbrunnen beschriebenen Weise auf.

140 Cub. Cent desselben hinterliessen, mit Kalilauge behandelt, $6 \mathrm{Cub}$. Cent. unabsorbirtes Gas, ein zweiter Versuch lieferte genau dasselbe Resultat.

1000 Volumina des Quellengases bestehen somit aus 957,14 Vol. Kohlensäure und 42,86 Vol. durch Kalilauge unabsorbirbarem Gase.

Eine grössere Menge solchen unabsorbirbaren Gases wurde an der Quelle über ausgekochter Kalilauge aufgefangen und in zugeschmolzenen Röhrchen in mein Laboratorium nach Wiesbaden transportirt Nachdem es dort nochmals mit Kalihydrat behandelt worden war, und sich eine Probe als von Sauerstoff frei erwiesen hatte, wurde es nach der bei der Trinkquelle angegebenen Methode, d. h. durch Ueberleiten über glühendes Kupferoxyd und Auffangen der erzeugten Kohlensäure, analysirt.

37,7 Cub. Cent. Gas von $14,5^{\circ}$ Cels. und $760 \mathrm{~mm}$ gaben 0,0009 Grm. Kohlensäure, $-42,86$ Cub. Cent. würden somit geliefert haben $0,001023 \mathrm{Grm} .-27,5$ C. C. Gas von $14,5^{\circ} \mathrm{C}$. und $760 \mathrm{~mm}$ gaben $0,0007 \mathrm{Grm}$. Kohlensäure, $-42,86 \mathrm{C}$. C. würden somit geliefert haben $0,001091 \mathrm{Grm}$. oder im Mittel beider Versuche 0,001057 Grm. Kohlensäure, entsprechend $0,000384 \mathrm{Grm}$. leichtem Kohlenwasserstoff oder 0,561 C C. bei 14,5 ${ }^{\circ}$ Cels. und $760 \mathrm{~mm}$ Druck. 
Das aus der Helenenquelle frei ausströmende Gas besteht somit in 1000 Vol, aus:

$$
\begin{aligned}
& \text { Kohlensäure . . . . 957,14 Vol. } \\
& \text { Stickgas . . . . 4 } 42,30 \text { \% } \\
& \text { Leichtem Kohlenwasserstoff } \frac{0,56}{1000,00 \text { Vol. }}
\end{aligned}
$$

V. Untersuchung des aus der Helenenquelle sich absetzenden

$$
\text { 0ckers. }
$$

Wie oben erwähnt setzt sich im Bassin der Helenenquelle, da wo das Wasser die Steinwandung bespült, ein Ockerrand an, wie sich denn auch in dem Abflusscanal Ocker in grösserer Menge findet. Bei meiner Anwesenheit in Pyrmont am 22. Nov. 1864 sammelte ich selbst eine gewisse Menge des im Bassin abgesetzten Ockers, eine etwas grössere verdanke ich Herrn Medicinalrath Hugi. Den von mir selbst gesammelten Ocker benutzte ich zur quantitativen Bestimmung der in wägbarer Menge vorhandenen Bestandtheile, den später erhaltenen zur Prüfung auf die in sehr geringen Spuren anwesenden Körper. Der zur quantitativen Analyse bestimmte Ocker wurde mit Wasser ausgewaschen und bei $100^{\circ}$ Celsius getrocknet.

Er enthielt :

$$
\begin{aligned}
& \text { Eisenoxyd . . . . } 57,301 \text { pCt. } \\
& \text { Manganoxyduloxyd . . 0,146” } \\
& \text { Thonerde . . . . . 0,167 , } \\
& \text { Kupferoxyd . . . . 0,017 " } \\
& \text { Arsensäure . . . . . 0,330 \% } \\
& \begin{array}{lllll}
\text { Kobaltoxydul . } & . & . & . & . \\
\text { Nickeloxydul .. } & . & . & . & .
\end{array} 0,048 \%
\end{aligned}
$$

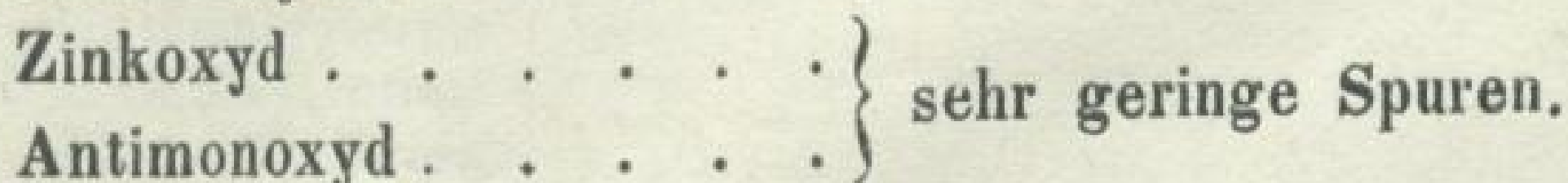

$$
\begin{aligned}
& \text { Kalk . . . . . . 7,384 pCt. } \\
& \left.\begin{array}{lllllll}
\text { Baryt } & \cdot & \cdot & . & \cdot & \cdot & \cdot \\
\text { Strontian } & . & . & . & . & . & .
\end{array}\right\} \text { Spuren. } \\
& \text { Transport } 65,393 \mathrm{pCt} \text {. }
\end{aligned}
$$




\section{$-62-$}

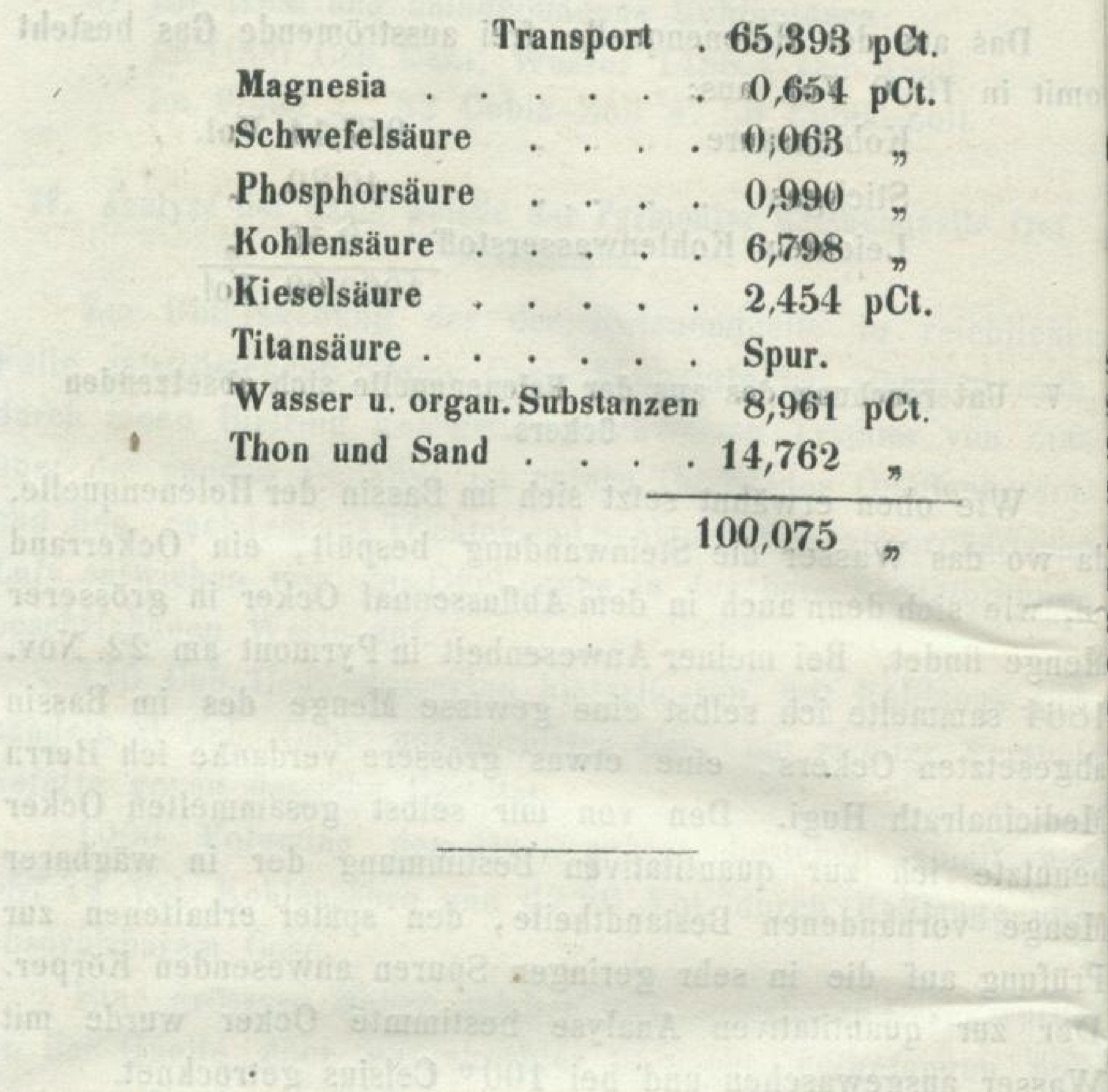




\section{$-63$ \\ IV. \\ Vergleichende Uebersicht}

der 3 untersuchten Pyrmonter Mineralquellen, in Betreff der in Wasser selbst nachweisbaren Bestandtheile. (In Bezug auf die nur im 0cker nachweisbaren Bestandtheile vergleiche die einzelnen Analysen). Gehalt an Granen im Pfund $=7680$ Gran.

Trinkquelle. Brodelbrunnen. Helenenquelle.

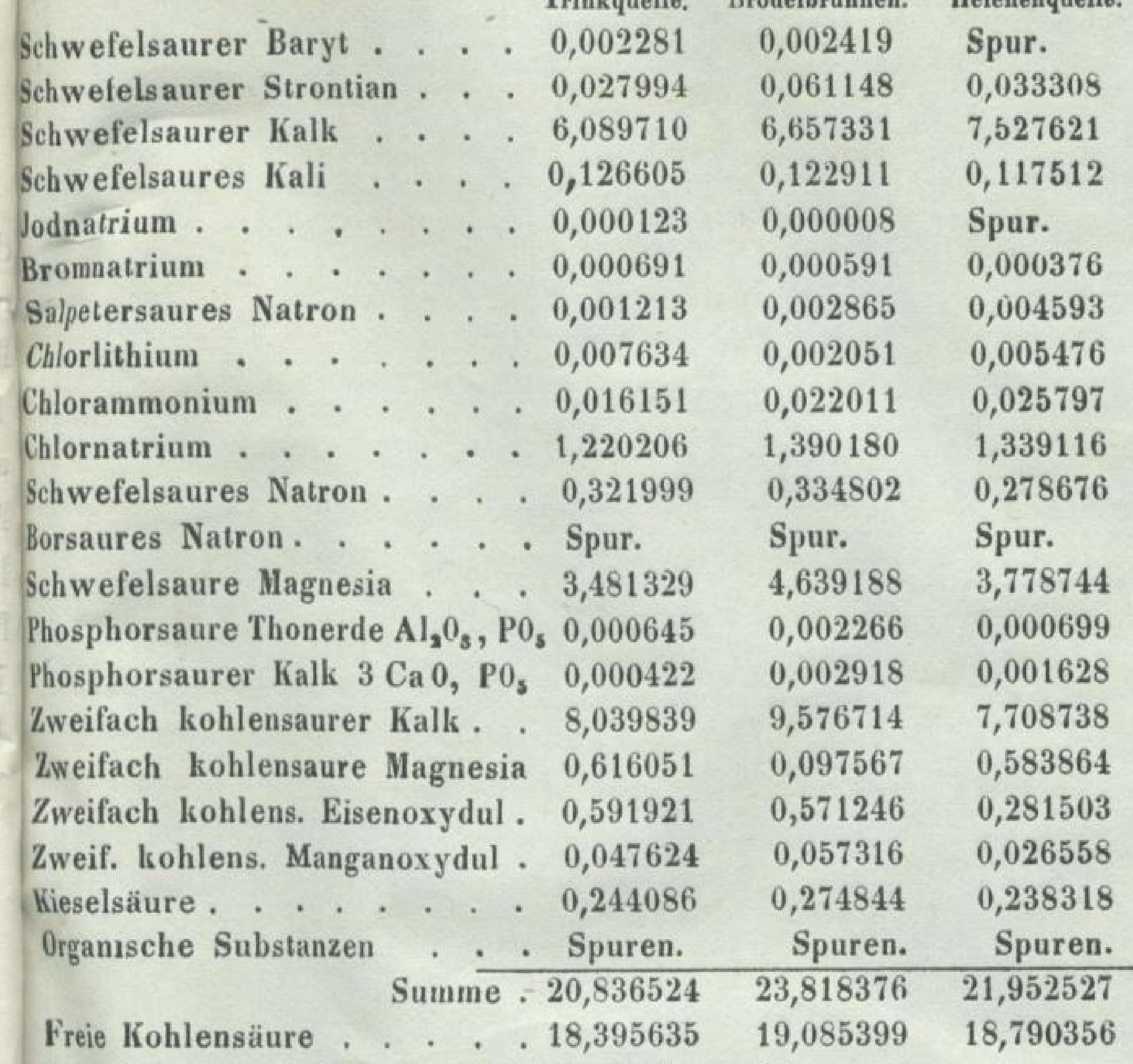

Schwefelwasserstoff . . . . . starke Sp. Spur. kaum wahrnelmb. s. Stickgas . . . . . . . . ger. Menge geringe M. geringe M.

Leichter Kohlenwasserstoff . . Spur. Spur. Spur. Summe aller Bestandtheile . 39,232159 $42,903775 \quad 40,742883$ Bei den Quellentemperaturen kommen auf 1000 Cubik Centim. dieser Wasser von der freien Kohlensäure als Gas . . 1271,1 C.C. 1323,7 C.C. 1303,5 C.C. Von der freien und halbgebundenen Kohlensäure . . . . 1467,6 C.C. 1541,0 C.C. 1486,4 C.C. Wi esbaden, 18. Iärz 1865 . 


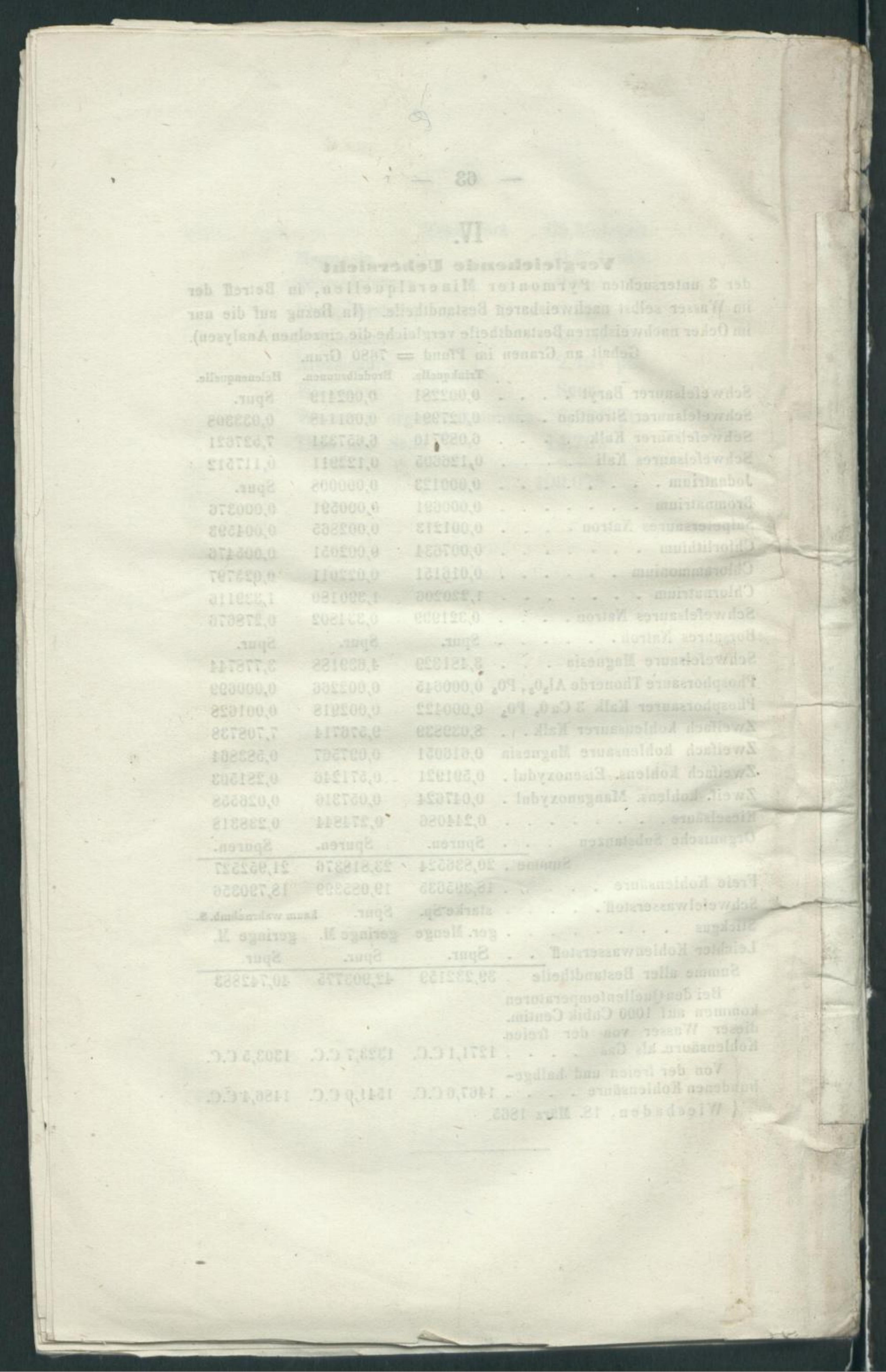

\begin{tabular}{l||l}
\hline SLE Sächsische Landesbibliothek - & hitp://digital slub-dresden delid369830482/74 \\
UB. Staats- und Universitätsbibliothek Dresden
\end{tabular} 



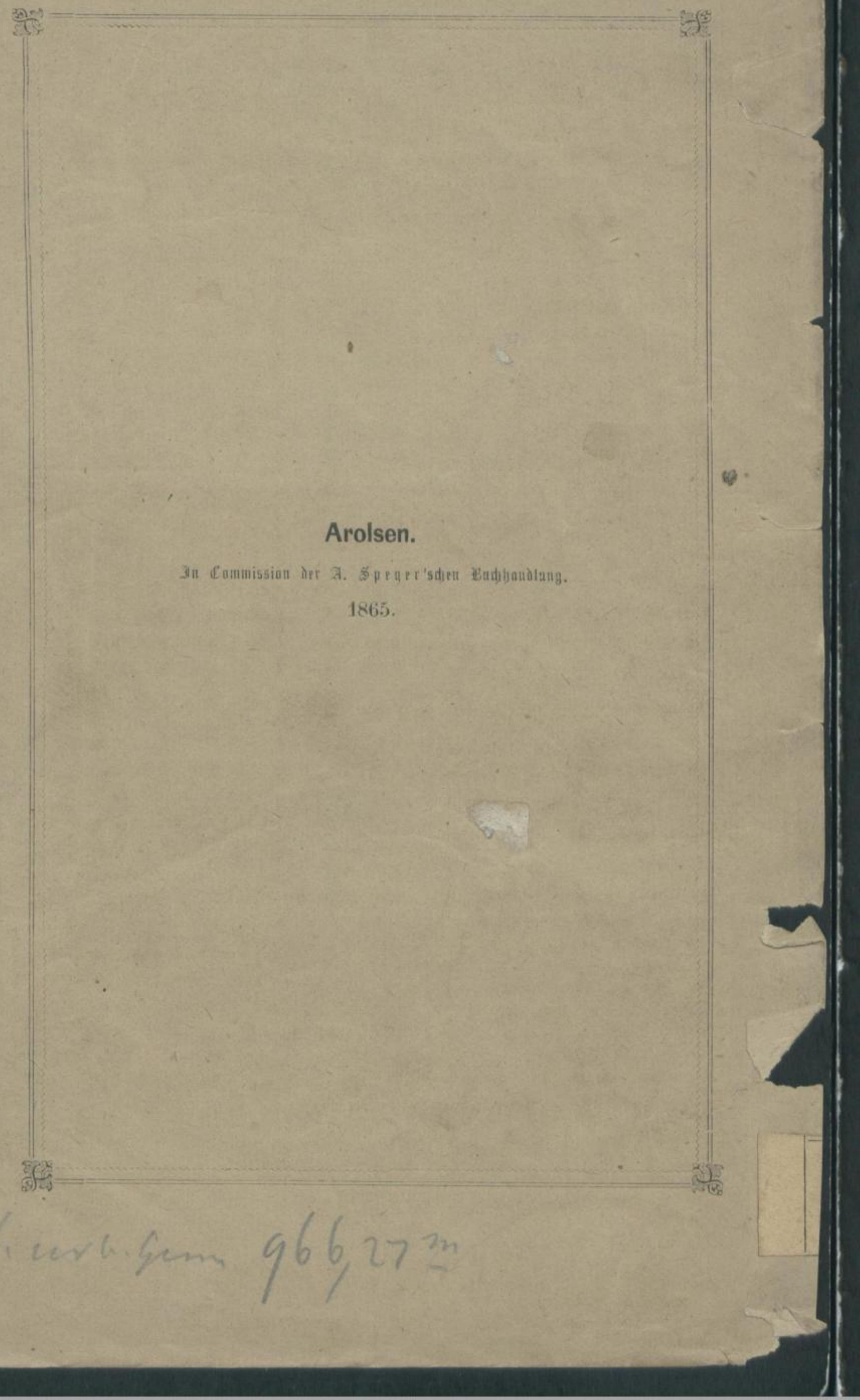

\begin{tabular}{l||l}
\hline S. Sächsische Landesbibliothek - & hitp://igital.slub-dresden.delid369830482/76 \\
UBB & Staats- und Universitätsbibliothek Dresden
\end{tabular} 